\title{
Modernising Secondary School Buildings in Portugal
}

Alastair Blyth, Rodolfo Almeida, David Forrester, Ann Gorey, Gaby Hostens
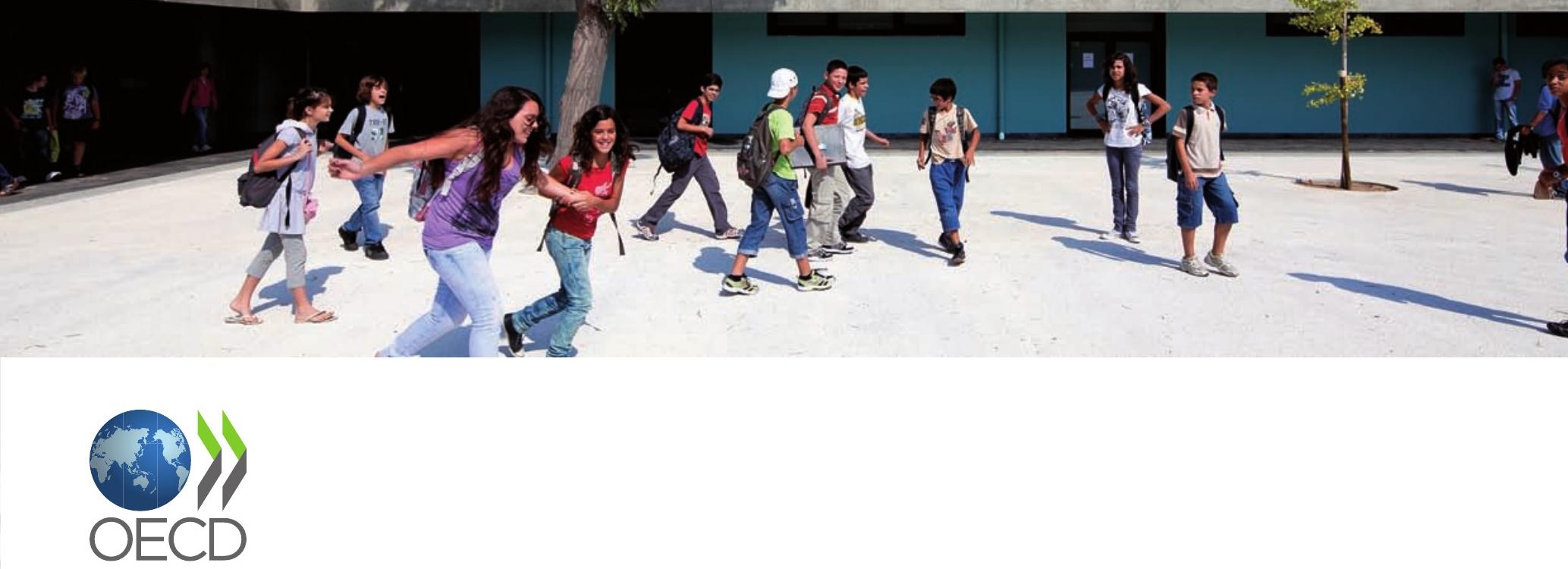

Modernising Secondary School Buildings in Portugal

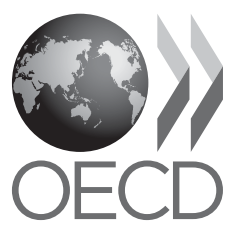


This work is published on the responsibility of the Secretary-General of the OECD. The opinions expressed and arguments employed herein do not necessarily reflect the official views of the Organisation or of the governments of its member countries.

This document and any map included herein are without prejudice to the status of or sovereignty over any territory, to the delimitation of international frontiers and boundaries and to the name of any territory, city or area.

ISBN 978-92-64-12877-4 (PDF)

Photo credit: Salvaterra de Magos Secondary School, Salvaterra de Magos @ Joâo Morgado.

Corrigenda to OECD publications may be found on line at: www.oecd.org/publishing/corrigenda.

(c) OECD 2012

You can copy, download or print OECD content for your own use, and you can include excerpts from OECD publications, databases and multimedia products in your own documents, presentations, blogs, websites and teaching materials, provided that suitable acknowledgement of OECD as source and copyright owner is given. All requests for public or commercial use and translation rights should be submitted to rights@oecd.org. Requests for permission to photocopy portions of this material for public or commercial use shall be addressed directly to the Copyright Clearance Center (CCC) at info@copyright.com or the Centre français d'exploitation du droit de copie (CFC) at contact@cfcopies.com. 


\section{Foreword}

The quality of school buildings is critically important in the drive for improving education. Good quality facilities provide teachers and students with supportive environments which are responsive to their changing needs and can make a real difference to learning and teaching.

This report is the outcome of the first national review by the OECD Centre for Effective Learning Environments (CELE). It draws on the experience of international experts and the work of CELE.

Many countries face challenges with their school building stock which are similar to those which Portugal is addressing in its secondary school building modernisation programme (SMP). As well as suggesting refinements that could be made in the SMP, the review reflects experience that other countries can draw upon.

Not only is Portugal investing in renovating and reconfiguring these schools, but it is investing in their long-term maintenance, and that is crucial for the sustainability of the system in the years to come.

Education is one of the key investments for society in the twenty-first century. I hope that this report will help make best use of that investment.

\section{Richard Yelland}

Head of the OECD Centre for Effective Learning Environments

August 201 I
Front entrance, Rainha Dona Leonor Secondary School, Lisbon

\section{(C) João Morgado}

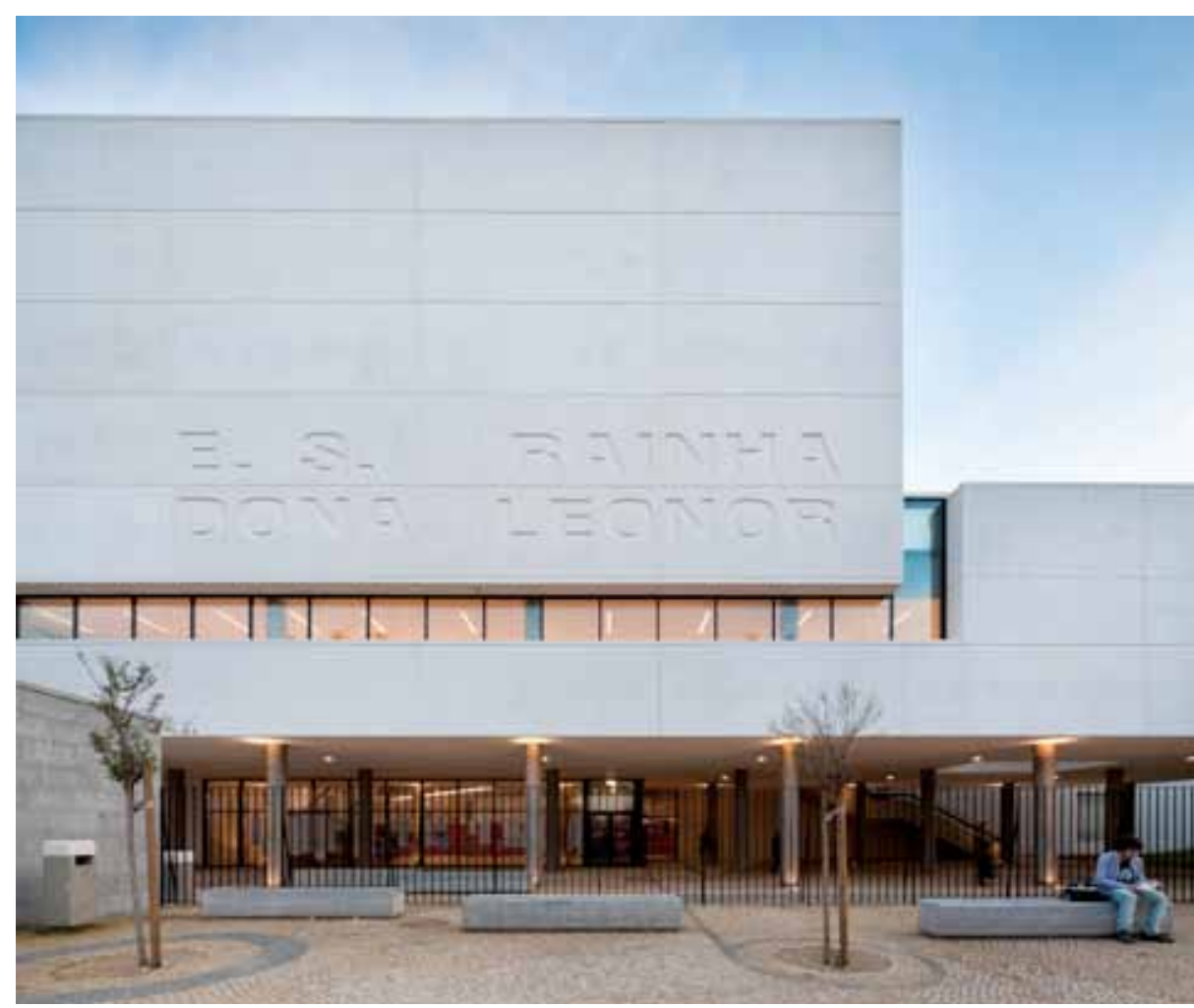




\section{Acknowledgements}

Portugal's participation in the review from February 2009 was co-ordinated by Teresa Valsassina Heitor, Deputy Director of Parque Escolar since February 2007. The background information prepared by José Freire da Silva with Rafaela Pinto and Joana Azevado formed a valuable contribution to the review and much support was provided by João Sintra Nunes, Director general of Parque Escolar and the Office for Education Statistics and Planning (GEPE, Gabinete de Estatística e Planeamento da Educação) in the Ministry of Education, with co-ordination by Isabel Almeida, Deputy-Director, GEPE, and Delegate of Portugal to OECD's Education Policy Committee.

The Review Team (photo, right) would also like to acknowledge the contribution of the large number of people who gave valuable time from their busy schedules to assist in this work. The team would like to thank João Sintra Nunes, Teresa Heitor and her team, in particular Rafaela Pinto and José Freire da Silva, for their invaluable help in facilitating the review, organising meetings, responding to questions from the Review Team and facilitating the team's travel to the various meetings throughout Portugal.

The Report is issued under the responsibility of the Review Team. The findings, analyses and conclusions - which are based on information provided as well as observations - are also those of the Review Team. Whilst the Review Team benefitted greatly from discussions and input from a wide range of people, any errors or misinterpretations in this Report are its responsibility. It was assembled by Hannah von Ahlefeld, with editorial support from Carola Miras.
OECD Review Team, with staff at Parque Escolar

\section{(C) Rodolfo Almeida}

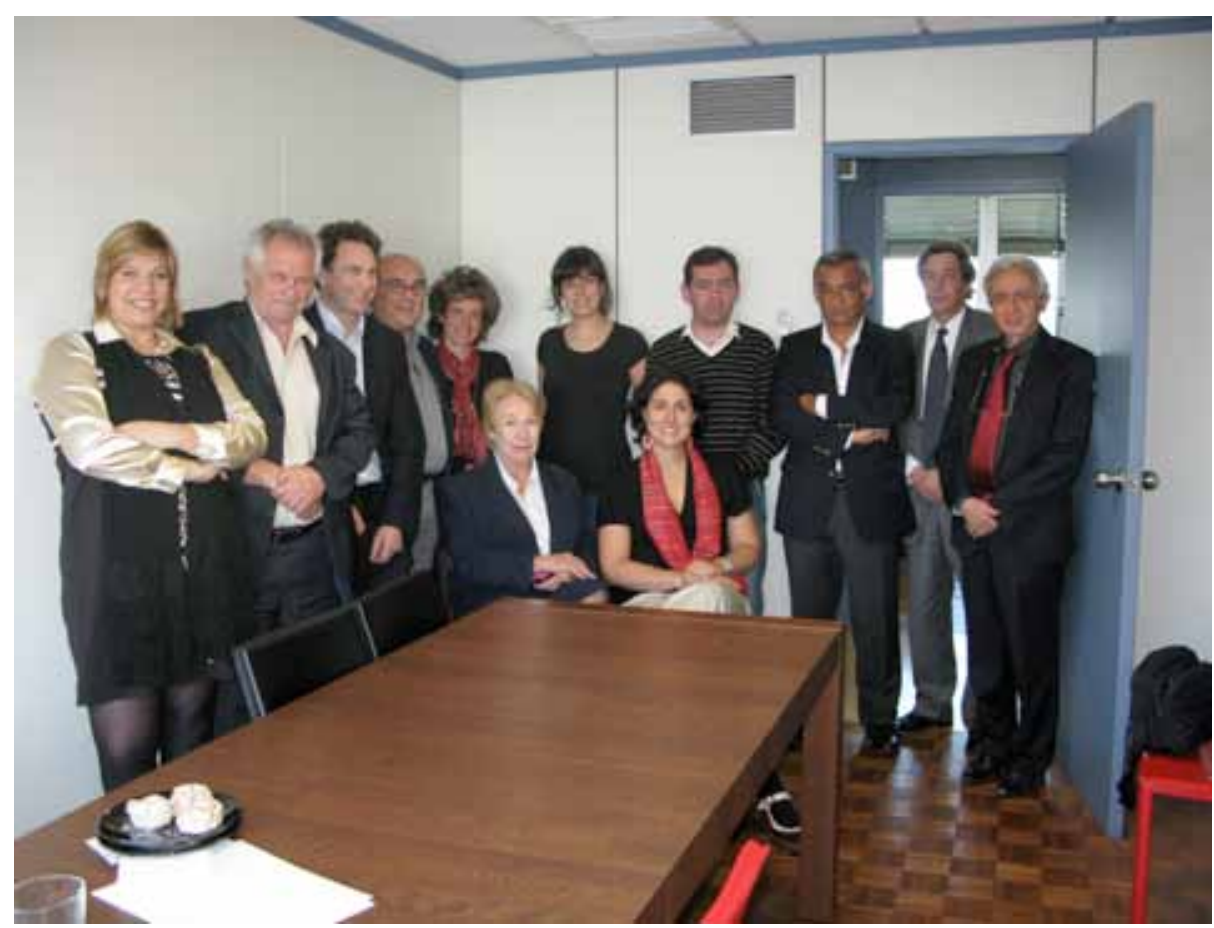


TABLE OF CONTENTS

0. Executive summary.

Background.

The physical quality and suitability of school buildings.

Meeting Portugal's strategic objectives for secondary education

Governance and relationships

Funding.

Funding mechanisms

Delivery

Options for rationalising the School Building Modernisation Programme

I. Introduction

I.I The Secondary School Building Modernisation Programme

1.2 Objectives of the review

1.3 Structure of the report.

1.4 The review visit

2. Context and features of the SMP

2.I Secondary education in Portugal

2.I.I The secondary school system

2.1.2 Demographic and enrolment trends.

2.1.3 Quality and standards

2.1.4 The wider education policy context.

2.2 The SMP.

2.2.I Aims and objectives of the SMP

2.3 Administration and delivery

2.3.I Remit of Parque Escolar.

2.3.2 Management structure of Parque Escolar.

2.4 Funding the SMP

2.4.I Cost...

2.4.2 Allocating and prioritising funds

2.4.3 Funding for the continued maintenance of schools. 


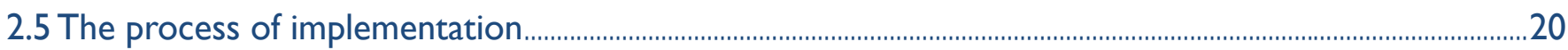

2.5. I Timeframe and phasing of the programme............................................................................................................2

2.5.2 Selecting the schools for modernisation...................................................................................................................2

2.5.3 The process for modernising each school ........................................................................................................

2.5.4 Tender and appointment procedures ............................................................................................................2

2.5.5 Post-completion management model ..............................................................................................................................2

3. Strengths and challenges of the SMP $\ldots$

3.I Meeting the strategic objectives for education in Portugal .............................................................................2

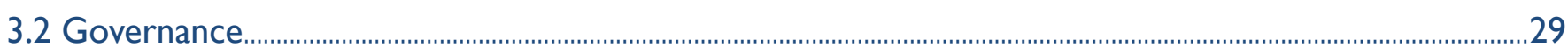

3.2.1 Importance of a strong independent body to manage the SMP .............................................................2

3.2.2 Specific concerns about the governance of the SMP .......................................................................................2

3.2.3 Communication and information flow between Parque Escolar and stakeholders ..................................30

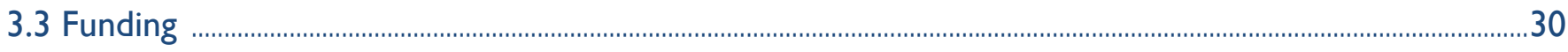

3.3.I Funding levels and cost control ......................................................................................................................

3.3.2 Funding sources and mechanisms ......................................................................................................................

3.3.3 Developing a sustainable funding process....................................................................................................................

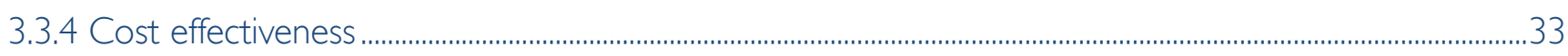

3.4 Quality, suitability and sufficiency of the modernised schools ..............................................................3

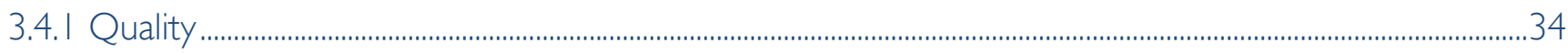

3.4.2 Organisation of the design, monitoring and evaluation unit at Parque Escolar ..........................................35

3.4.3 Developing the functional programme................................................................................................................. 35

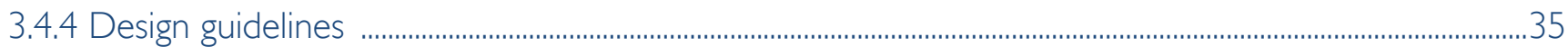

3.4.5 Supporting the school once the building is completed and handed over ....................................................37

3.4.6 Reviewing the buildings after hand-over.................................................................................................................

3.4.7 Learning from innovation ........................................................................................................................................ 38

3.4.8 Regulation of construction in Portugal ............................................................................................................ 38

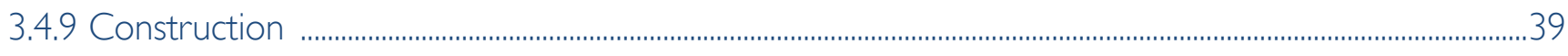

3.4. I0 Overall conclusions on organisation and design ............................................................................................... 40

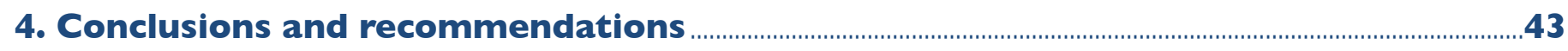

4.I The impact of the SMP on the quality and suitability of school buildings ......................................................44

4.2 Meeting Portugal's strategic objectives for secondary education ........................................................................45

4.3 Options for rationalising the SMP ....................................................................................................................................46

4.4 Governance and relationships ................................................................................................................................. 47 
4.5 Funding

4.5. I The level of funding available ……......................................................................................................................... 47

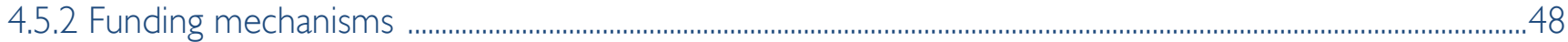

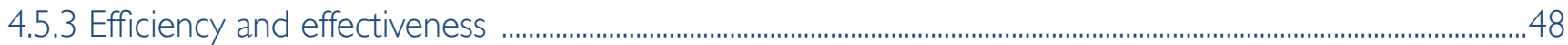

References

Annex A. Technical guidance for Parque Escolar …….....................................................................5

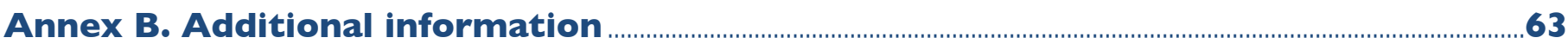

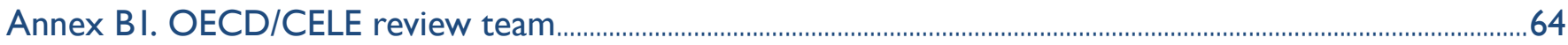

Annex B2. Programme of the review visit and people interviewed ........................................................................65

Annex B3. Parque Escolar: Obligations, organisation and employees ………………………………….....................66

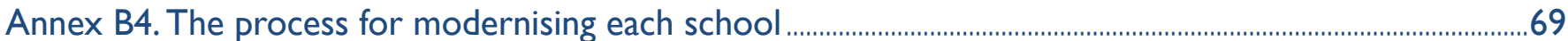





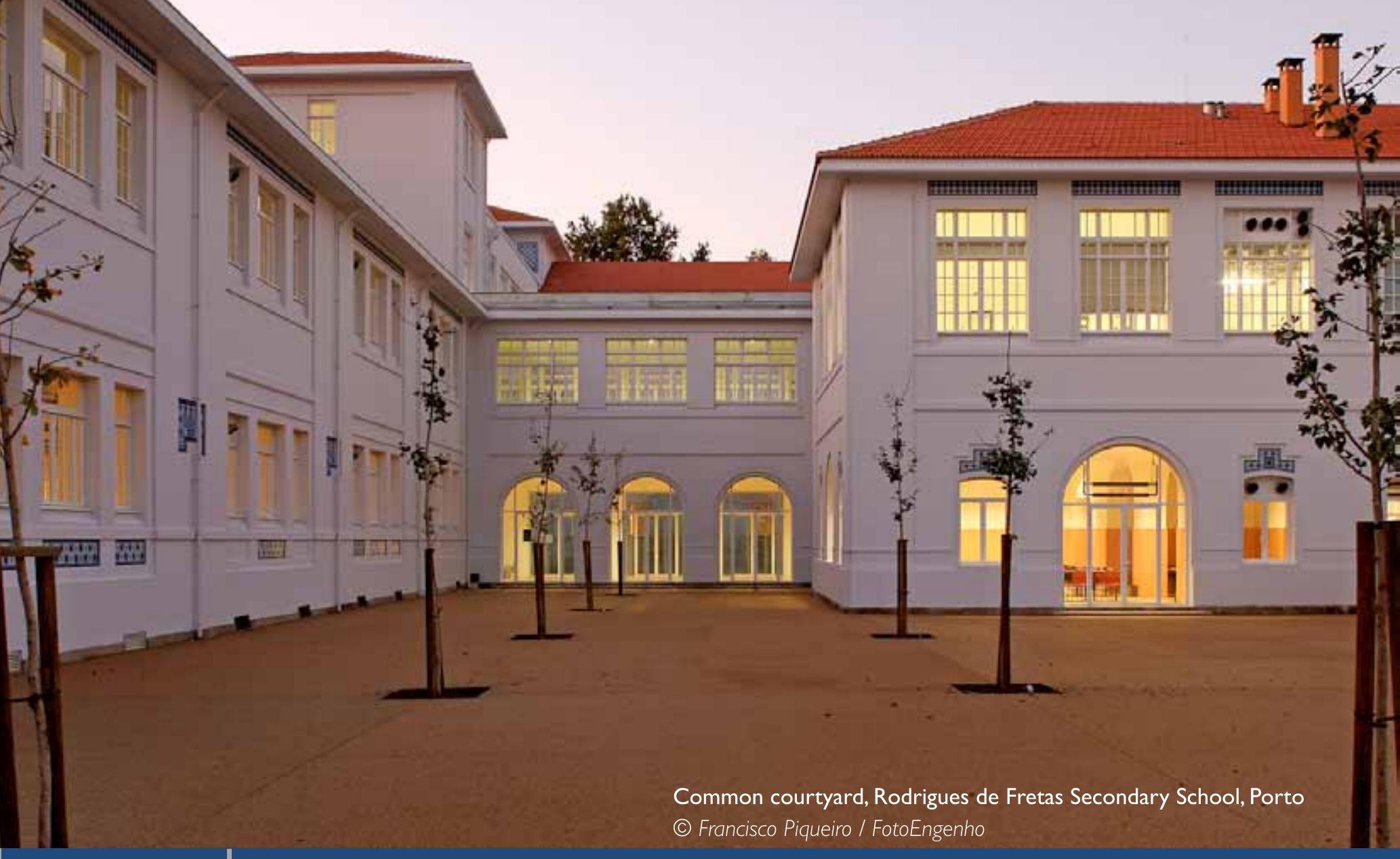

EXECUTIVE SUMMARY 


\section{Background}

This is the report of a review undertaken by the OECD Centre for Effective Learning Environments (CELE) for the Portuguese Government of the Secondary School Building Modernisation Programme (SMP) a major programme to rehabilitate the secondary schools in Portugal. The programme is an ambitious one, entailing the rebuilding, extension, adaptation and re-equipment by 2015 of 332 of the 477 schools that provide upper secondary education in Portugal, with a total investment for the first 205 schools of EUR 2.45 billion. The Portuguese Government has established a state-owned company, Parque Escolar, which has a high degree of independence, to oversee and manage all aspects of the SMP.

The OECD Review Team was asked to focus on five key issues:

- How effectively the SMP addresses the physical quality of school buildings, the suitability of the facilities for current and future needs, whether there are sufficient spaces to meet these needs, and how stakeholders are engaged in the process;

- How the SMP can better meet Portugal's strategic objectives for secondary education;

- Whether and how the overall programme should be rationalised;

- The governance structure of the SMP and the relationship between Parque Escolar, national educational authorities, school institutions and other stakeholders; and

- The funding mechanisms, levels of funding available, and the efficiency with which resources are used.

\section{The physical quality and suitability} of school buildings

Parque Escolar has driven the SMP strongly and effectively, drawing on international benchmarks and best practice. The SMP is set to secure a transformation in the physical quality of the majority of secondary schools in Portugal, and ensure their suitability for a more practical, scientific and vocational curriculum and for changing educational needs. This is a challenging task. It is made more difficult by the speed of implementation of the SMP, which has been determined for a mixture of reasons related to the availability of finance, the state of the global economy and other factors exogenous to the needs of the education service.
Meeting Portugal's strategic objectives for secondary education

The SMP is intent on meeting the government's key objectives for secondary education, and:

- Forecasts of demand used to determine the design size of each school in the SMP, combined with space standards that have some headroom or flexibility by international standards, so as to ensure that the stock of schools is sufficient for the foreseeable future;

- The implications for the size and character of secondary schools in Portugal of the rise in the compulsory school participation age to 18 ;

- Curricular developments towards much greater use of ICT and more personalised and laboratory-based teaching methods;

- Restoring a vocational curriculum option to all secondary schools.

There are issues, however, as regards the capacity of the remodelled secondary schools to meet all the specialist education and training needs of young people that elsewhere (e.g. in Australia or the United Kingdom) would be met in larger scale and more employer-focused specialist facilities, or to motivate the kind of young people who would previously have chosen to leave school but, in future, will be obliged to stay on.

Figure 0.I. Dining area, Rocha Peixoto Secondary School, Póvoa de Varzim (C) Francisco Piqueiro / FotoEngenho

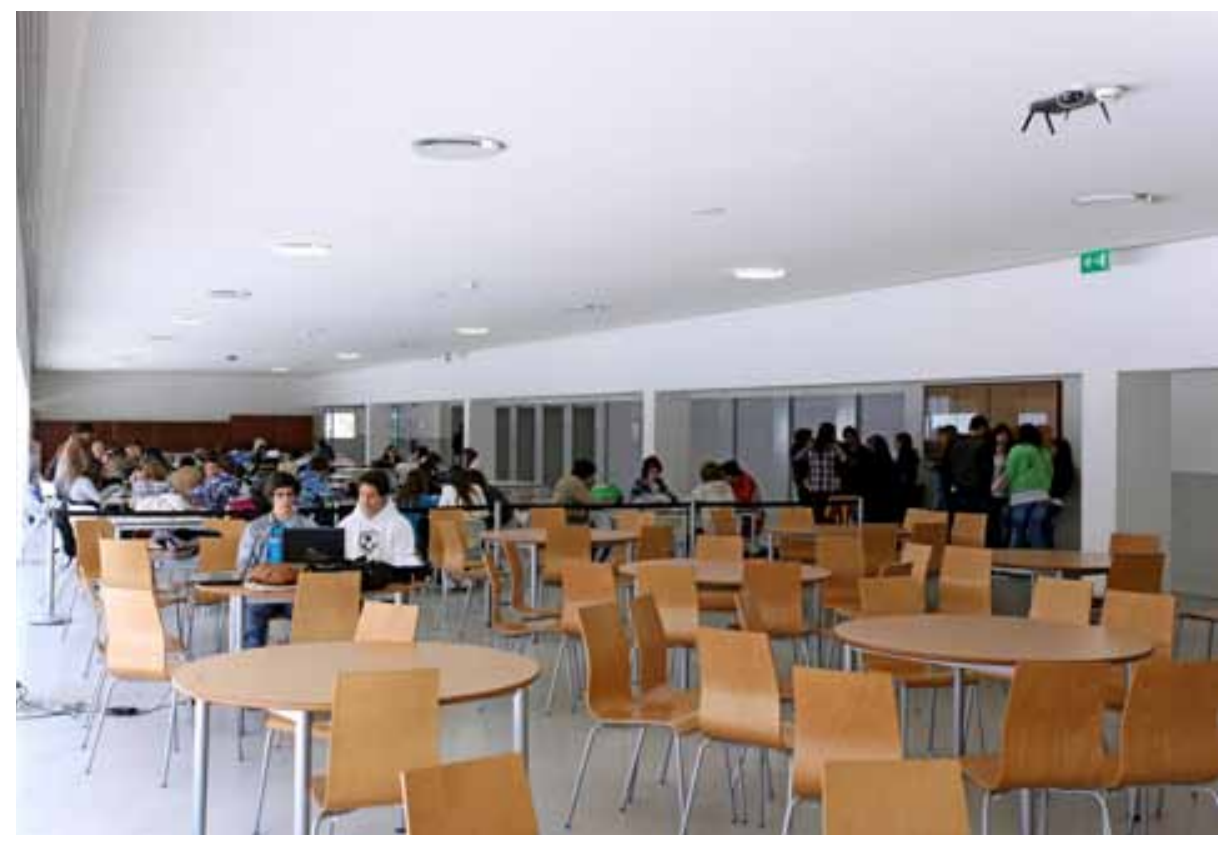

To address these issues, the government, along with Parque Escolar, should monitor the impact on demand and outcomes of the new vocational provision for 15-18 year olds in secondary schools. If there is evidence of gaps or failures to meet demand, it will consider options for the development of more specialist vocational provision serving a local area or cluster of schools.

\section{Governance and relationships}

The creation of Parque Escolar as a special-purpose state owned company with specific responsibility for planning and delivery of the SMP has been a very significant, if not the crucial, factor in its success to date. The model developed has drawn on international practice in other countries where economic stimulus programmes and public-private-partnership (PPP) programmes are being run; but it has also drawn on Portugal's own traditions and its analysis of what combination of public and private sector best practice is most likely to work. The resulting body is well organised, and ably managed by people with appropriate expertise in architecture, engineering, finance and project management. It has succeeded impressively to date. It may serve as a model for international application.

The development of the design for each school and its execution have entailed 
good relationships and close consultation with the schools themselves and others most directly affected locally; but at national level there has been relatively little consultation with the key national stakeholders. This may mean that valuable opportunities for developing ideas and for integrating the SMP with developing education, economic and social policies are being lost. The Government should appoint a national consultative body to provide advice and feedback to Parque Escolar.

To complement this, Parque Escolar should introduce a number of refinements to its procedures, including: undertaking post-completion reviews of each school under the SMP; independent research to establish how the spaces in a structured sample of the schools are being used; development of a web-based design manual, management guidelines for schools and short-term training and workshops, each embodying the best practice identified by the above processes; and creation of a specialised but widely accessible Technical Documentation Centre relating to the SMP.

\section{Funding}

With substantial support from the European Union (EU), and taking advantage of a political and economic climate in favour of such public investment, between 2007 and $20 \mathrm{II}$, the Portuguese Government is investing EUR 2.45 billion in modernising the first 205 schools under a building programme that is intended to transform 332 of the country's secondary schools by 2015 . In doing so, it aims to make up for a generation of under-funding that has resulted in the physical deterioration of the buildings, obsolete equipment, and spaces for learning which do not reflect 2 lst century needs. The indications are that the sums allocated are sufficient for the intended principal purpose.

There remain questions as to the provision of funding for the similar updating of at least some of the 145 secondary schools which are not included, and which within the next few years may show similar deficiencies to some of those now being remodelled. Primary and other schools delivering basic education will also need to be renovated.

The provision within the overall SMP funding to provide for the repair and maintenance of the 332 schools is an admirable - and possibly unique - feature of the SMP. It is a potential model for international application. It is not clear, however, that the sums set aside ( $7 \%$ of the total programme) will be sufficient for the purpose, i.e. whether they are to include provision for updating and re-equipping the schools between now and 2037 in line with the requirements for the changing curriculum, pedagogy and learning styles.

Figure 0.2. Social space, Soares dos Reis Secondary School, Porto (C) Francisco Piqueiro / FotoEngenho

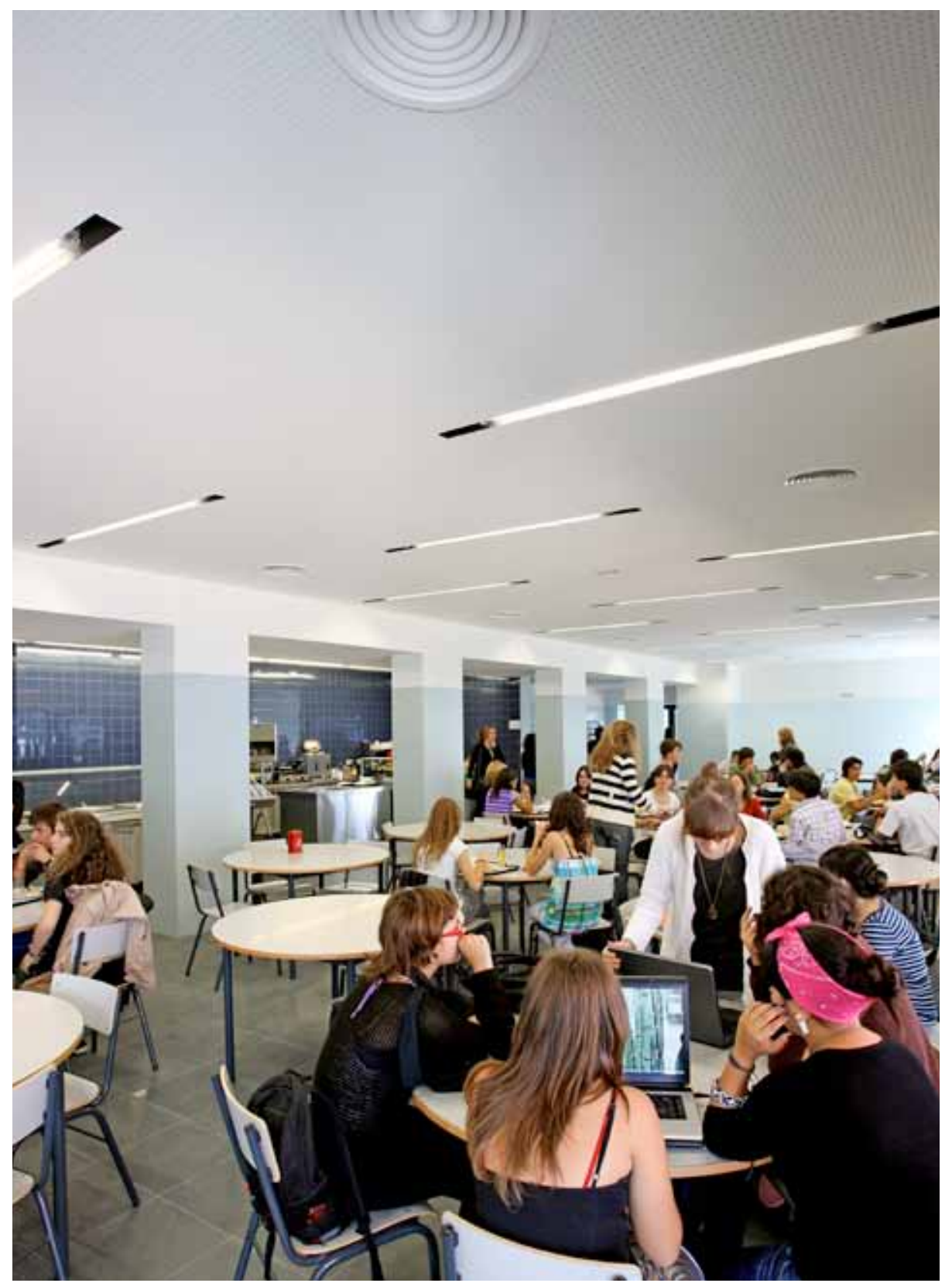


enjoying political priority at a time when the circumstances of Portugal within the $\mathrm{EU}$, and the world recession, have given the Portuguese Government a dual incentive to press forward with an Intervention Programme with all due speed. Those concerned are to be congratulated on having secured so large an injection of funding into the secondary school system.

Innovation has been shown in the development of the regime for the continuing maintenance of schools after their remodelling. There are, however, questions as to the robustness of these arrangements for the longer term. The contractual maintenance arrangements, and levels of finance set aside under them for continuing repairs and improvement, should be kept under review over the years ahead and be adapted if it makes sense to align responsibilities with new models of service delivery.

\section{Delivery}

Responsibility for the whole process involved in the SMP rests with Parque Escolar. So far, the indications are that it is on course to achieve the planned rate of delivery. That in itself would be an impressive achievement. Where there have been delays to individual projects, they have been no more than a few weeks. In relation to some concerns expressed as to the consultation process, the design and the flexibility of the resulting buildings, the arrangements seem well suited for their purpose. They reflect or exceed international best practice and are likely to secure the efficient achievement of its completion.

The speed of the build up of the SMP, however, is such that there is limited scope for learning and applying lessons along the way as regards either education and design issues or finance and the budget.A lot therefore depends on having established a "right first time" allocation and control process. The process is clearly efficient. In the Review Team's view, it is too early to be quite so confident about the cost-effectiveness of the SMP:

- The quality of finish of the buildings observed is commendable, but the design may not always prove as flexible and representative of best 2 I st century innovative practice as might have been expected of the learning environments of today and the foreseeable future.
- The modernised schools need to include appropriate spaces for the vocational education and training (VET) curriculum envisaged in each case locally, but the specialist spaces may not always prove to be fit for purpose in a few years' time as demand for different specialisations fluctuates.

- The space standards being applied provide generous spaces and give flexibility of delivery, but within finite resources may be at the cost of other objectives: schools that are unnecessarily large will impose additional longterm energy, cleaning and maintenance costs. It may be possible to make better use of the space and associated financial resources.

- At a system level, the use of the resources available for schools that have attracted priority allocations means that the remaining secondary schools may struggle to attract funding for their modernisation, as may schools for younger pupils and alternative forms of delivery of VET, which may be needed for a proportion of young adults.

Figure 0.3. New laboratories, Rainha Santa Isabel Secondary School, Estremoz (C) José Manuel

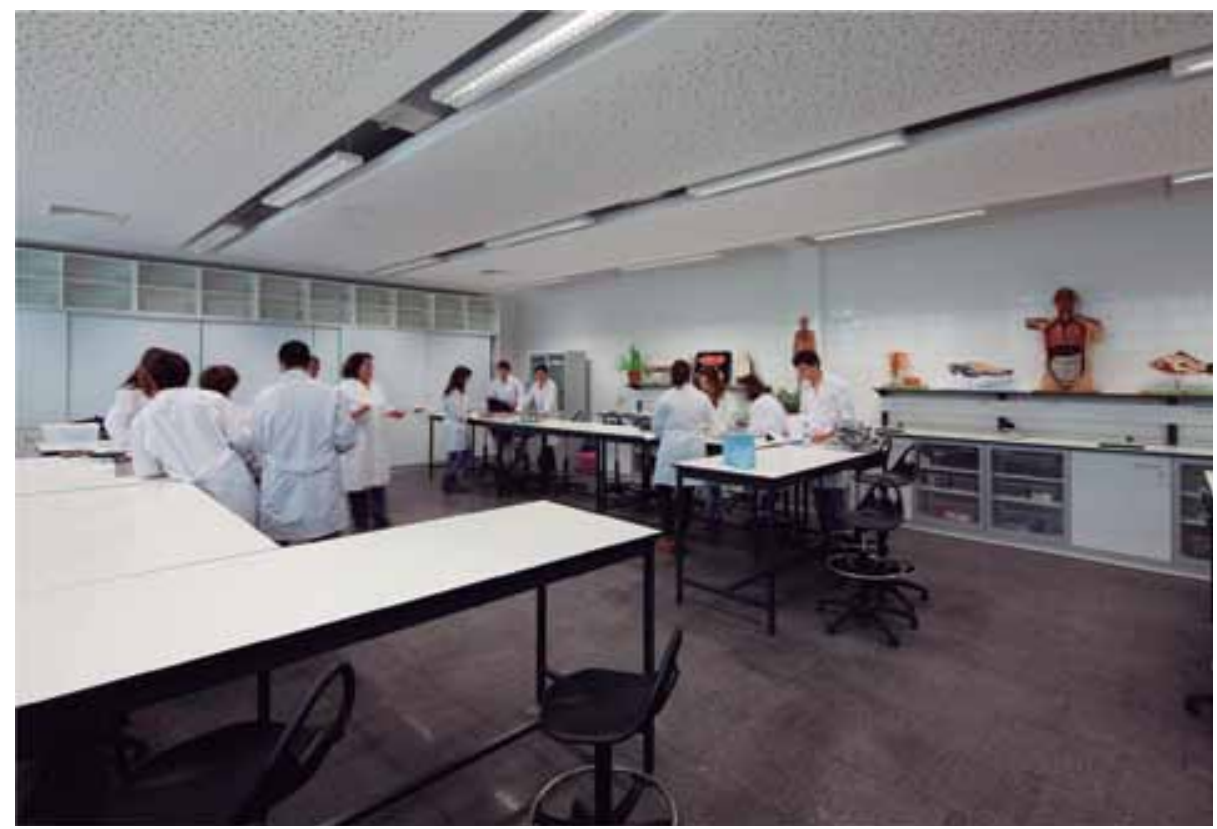

The various processes advocated above should be used to ameliorate the effects of concentrating so large an investment programme into so short a space of time, and to consider holding back a reserve to provide for implementing desired modifications thus identified.

\section{Options for rationalising the Secondary School Building Modernisation Programme}

Benefitting from its independent status and highly focussed remit, Parque Escolar has made a major impact and achieved a considerable amount in a short time. However, the very strengths of such independence are also a potential weakness. Questions arise as regards links with other policies and programmes and engagement with other bodies and stakeholders. The Review Team has recommended measures to address these. Nevertheless, the SMP is of a scale and importance to justify and support the separate infrastructure created to manage it so long as the active period of construction is underway. Thereafter, it will be necessary to consider how to manage the transition to the next stage. 


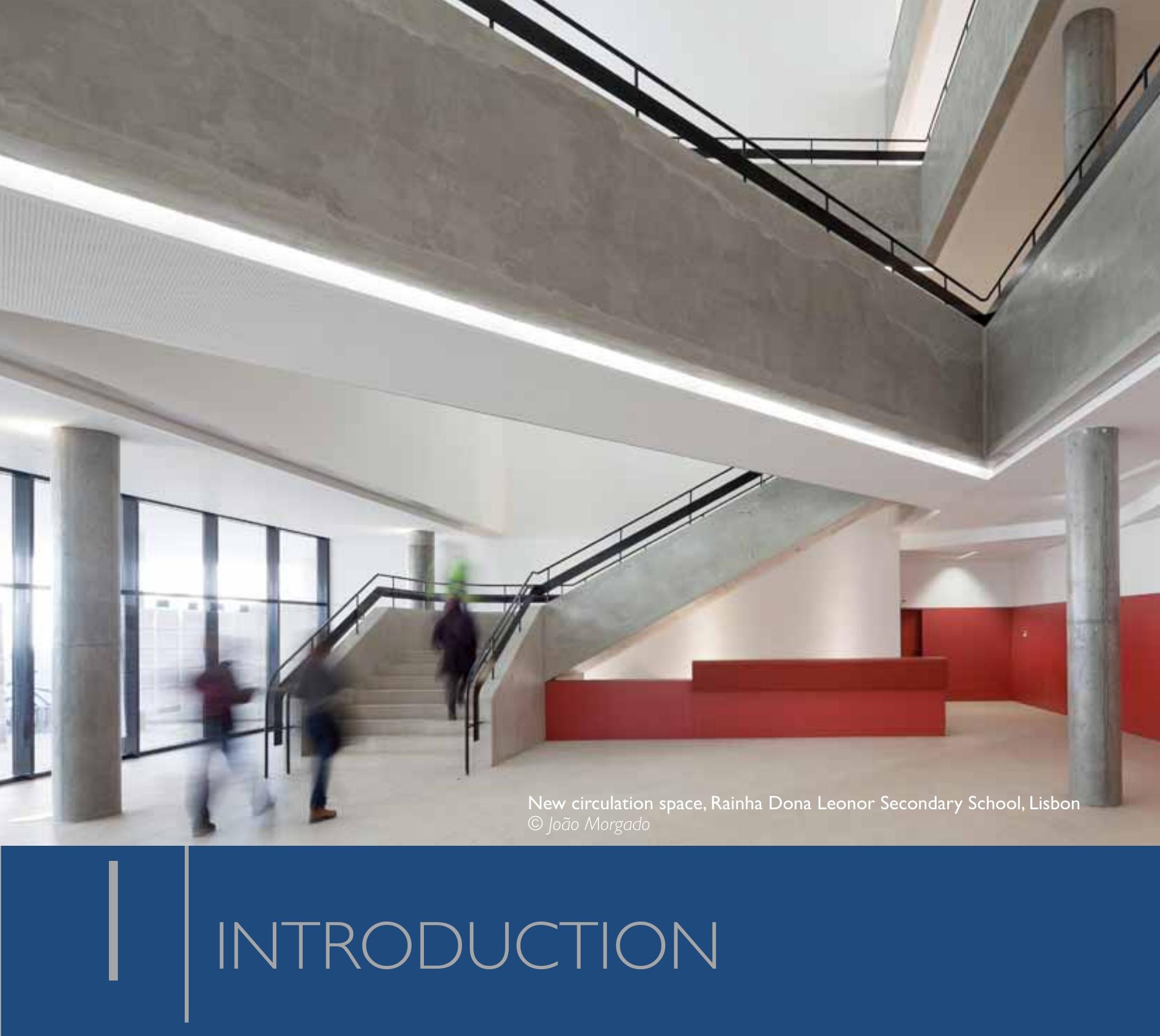

This chapter briefly introduces the School Building Modernisation Programme (SMP) in Portugal and how it was reviewed by the OECD. 


\section{I.I The Secondary School Building Modernisation Programme}

In January 2007, the Portuguese government launched a policy to rehabilitate 332 secondary schools by 2015 , with a total investment for the first 205 schools of EUR 2.45 billion (Figure I.I). In doing so, the Government had three principal concerns in relation to the school building stock:

- Its physical deterioration.

- Poor environmental standards in terms of energy performance, environmental comfort and sanitary standards.

- Its functional inadequacy for teaching and learning.

The objectives of the SMP are fourfold:

- To modernise the physical infrastructure of secondary schools in Portugal, addressing the three concerns above.

- To open schools up to the wider community; and to extend opportunities for learning to the whole community.

- To provide for the future maintenance and conservation of the buildings thus modernised.

- To reduce their environmental impact. To manage this programme the Government created a special-purpose state owned company, Parque Escolar, with a high degree of administrative and financial autonomy, and its own assets.

\section{I.2 Objectives of the review}

The Portuguese Ministry of Education asked the OECD Centre for Effective
Learning Environments (CELE) to carry out a review of the SMP with a view to producing an objective assessment and evaluation of the effectiveness of the SMP.

The Review Team was invited to focus on five key issues:

- The performance of the SMP in terms of emerging challenges in Europe, and in particular how it addresses the physical quality of school buildings, the suitability of the facilities for current and future needs and whether there are sufficient spaces to meet the needs, and how stakeholders are engaged in the process.

- How the SMP can better meet Portugal's strategic objectives for secondary education.

- Whether and how the overall programme should be rationalised.

- The governance structure of the SMP and the relationship between Parque Escolar, national educational authorities, school institutions and other stakeholders.

- The funding mechanisms, levels of funding available, and the efficiency with which resources are used.

The composition of the Review Team is in Annex BI.

\section{I.3 Structure of the report}

The remainder of the report is organised into three main sections. Section 3 provides the national context with a description of the main characteristics of the Portuguese education system, and a sum- mary with key features of the SMP. This Section also aims to inform international readers by identifying what is distinctive about the SMP and the context in which it is being undertaken. Section 4 then provides analysis of the strengths of the programme together with the challenges and problems it faces. Section 5 draws together conclusions and recommendations from the analysis.

\section{I.4 The review visit}

The review visit took place from I I-I5 May 2009 and covered four of the five education regions: the North, Centre, Lisbon and Tagus Valley, and Alentejo. Algarve was not included as for the moment no schools have been involved in the SMP, although they will be in later phases of the programme. The programme for the review visit is in Annex B2. The Review Team held discussions with a wide range of stakeholders including: Ministry of Education agencies; representatives of educational authorities; school principals, teachers, staff, parents and students; the national parents' organisation; teacher unions; teacher professional organisations; consultants to Parque Escolar; architects and engineers involved in the programme. The Review Team selected seven schools for in-depth visits across the four regions, which enabled interaction with school principals and school boards, teachers, students, staff and parents. From this the team was able to gain a range of perspectives and insights on the SMP.

Figure I.I. Dom Dinis Secondary School, Lisbon, before and after modernisation.

(C) Parque Escolar

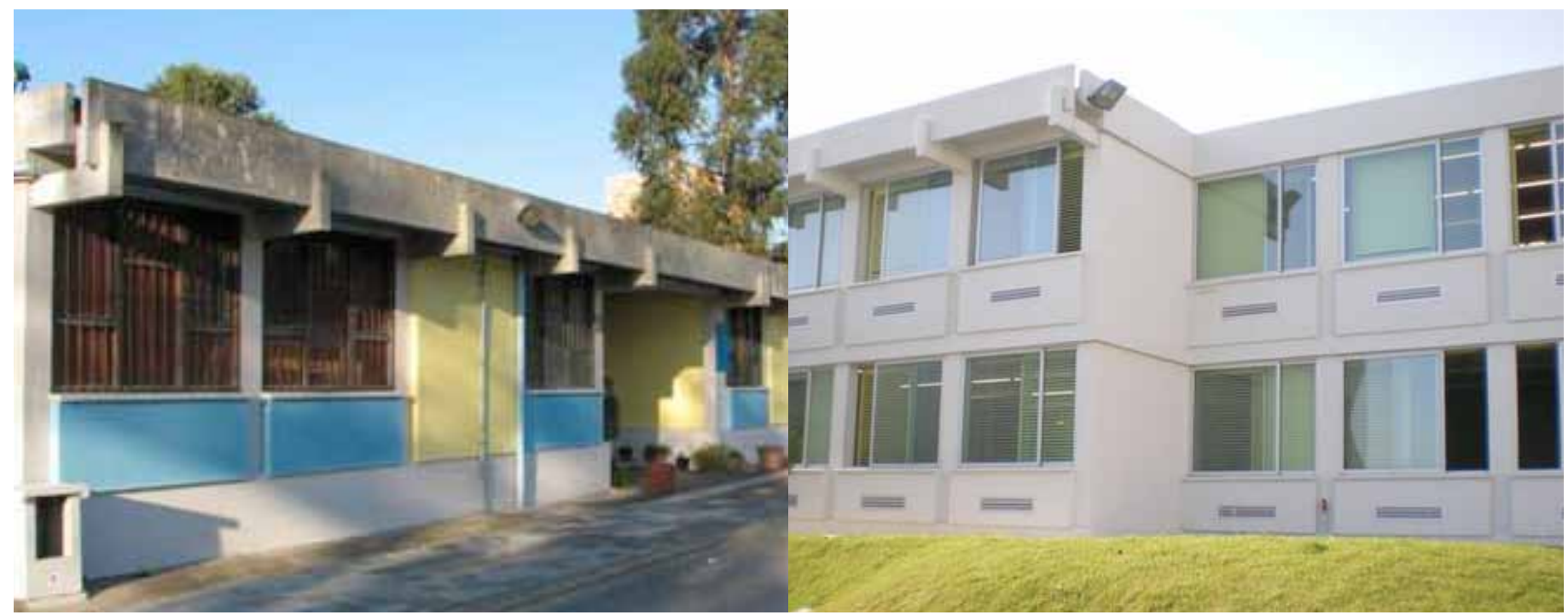




\section{I Secondary education in Portugal}

\subsection{The secondary school system}

Upper secondary education (ensino secundário) in Portugal is separate structurally and pedagogically from basic education (ensino básico). Basic education, which makes up the nine years of what was previously compulsory education, covers three consecutive cycles (two primary cycles at ISCED level I and one secondary cycle at ISCED level 2) and lasts for 9 years, from age 6 until age 15. Compulsory education was then followed by 3 years of non-compulsory upper secondary education at ISCED level 3 (Figure 2.I). The compulsory participation age was raised to 18 in 2009.

Despite the structural and pedagogical differences between them, basic education and upper secondary education can both be found in the same schools. Indeed almost all of the schools included in the SMP include: upper secondary education with 3 rd cycle (i.e. $12-17$ years inclusive) or with 3 rd and 2nd cycles (i.e. 10- 17 years).

Upper secondary education is organised in several strands, with courses that are geared mainly either to working life or to the continuation of studies at higher education level. It currently includes: general science-humanities courses, technologi$\mathrm{cal}$ and specialised artistic courses. There are also professional courses geared towards an initial qualification, giving priority to students entering the labour market, but allowing them to study further
Figure 2.I. Structure of the Portuguese education system

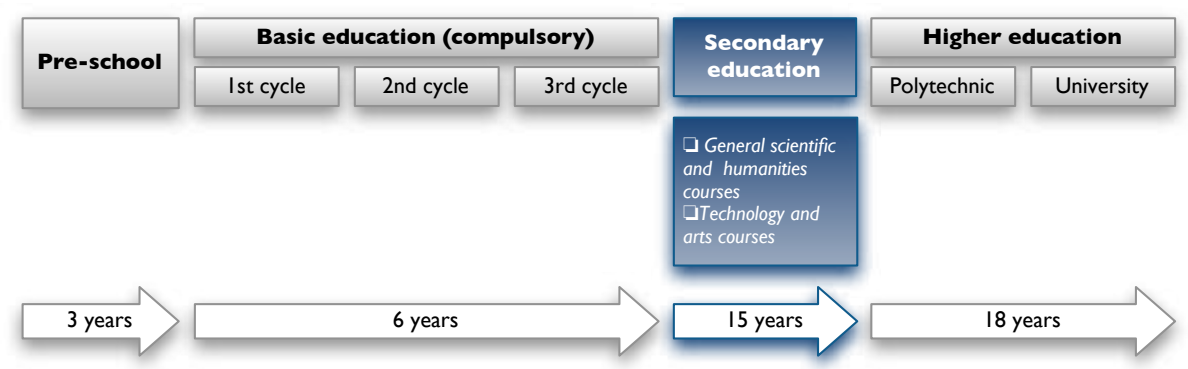

Source: Based on the graph of Portuguese Educational Organisation chart printed in the bulletin "Estatísticas de Educação 2006-2007" published by GEPE in the statistical department of the Ministry of Education.

as well. Upon successful completion of general scientific and humanities courses students can enrol in higher education (polytechnic or university).

After the revolution in 1974 participation in technological courses collapsed in favour of enrolment in general courses, which have been seen as a more attractive option mainly because they tended to lead to higher education. Now, however, the government is reinvesting in these courses in order to provide a balanced range of education and training opportunities.

As a general rule, students enrol in a school within their catchment area. They can only enrol in schools outside their catchment area if places are available, or if the course that they want to take is not available at their local school.

Although the Ministry of Education defines the national curriculum and publishes teaching guidelines and recommendations which need to be adhered

Figure 2.2. Student enrolment in secondary education in Portugal from 1990-2007

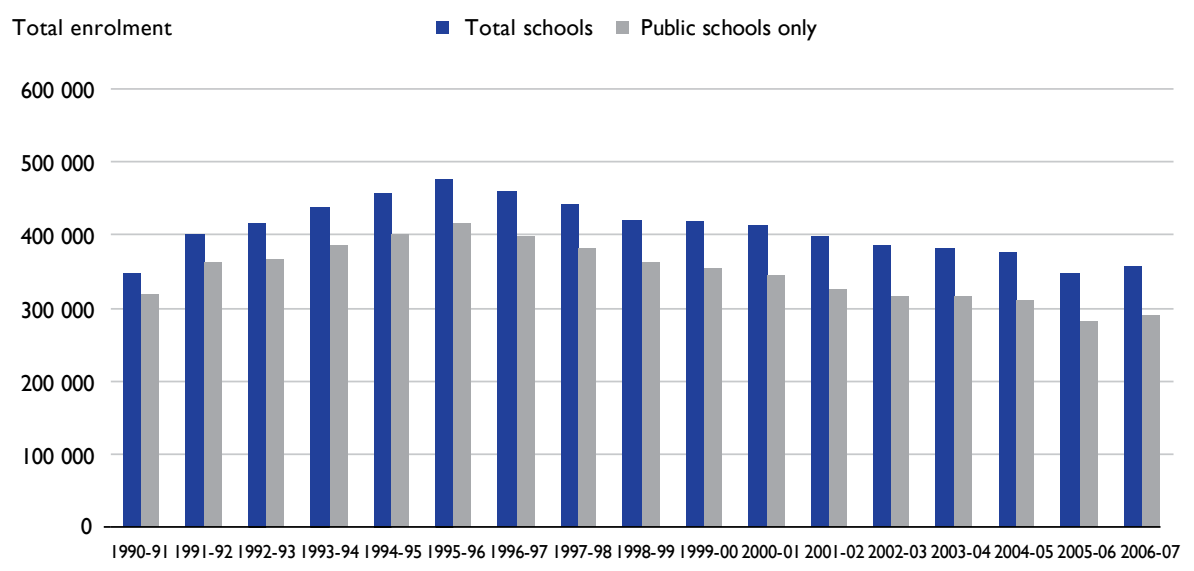

Source: Data from 1990-9I until 2004-05 from INE in “Portugal Statistical Yearbook 2006”, 2007 edition; and from 2005-07 data from "Education Statistics" published by GEPE statistical department of the Ministry of Education. to in secondary schools, school teams or individual teachers have some options to adapt the curriculum to local pedagogical or societal needs. Also, professional and vocational courses have some leeway to tailor the VET curriculum to respond to skills needs in regional socio-economic labour markets.

\subsubsection{Demographic and enrolment trends}

The total population of Portugal is a little over 10 million. This has been fairly stable overall in recent years: 10.4 million in 2002 , increasing slowly to 10.6 million in 2006. Within these totals, however, there have been significant changes in the composition of the population. As elsewhere in Western Europe, the birth rate has fallen (by some 10\% since 2002) and, with rising life expectancy (to 77 years of age for both sexes in 2004-05), the average age of the population has increased significantly, and the young dependency index has fallen (to $23 \%$ in 2004-05). These trends are particularly marked inland.

The 0 tol 4-year-old population has fallen only marginally, however: from 1.65 million in 2002 to 1.64 million in 2006 (Eurydice, 2009). The 15-24 population has declined in the same period by rather more: from I.4 million to 1.27 million (Eurydice, 2009).

Between 1990 and 2005, the pre-school to secondary school population in Portugal fell from around 2 million to I.7 million pupils (a loss of $15 \%$ or 300000 enrolled students). Within these totals, the number of pupils in public schools declined from some 1.8 million to some 1.6 million. Since 2005, however, preliminary figures indicate a reversal of this previous trend, attributable to a combination of factors: the expansion of 
Table 2.I. Total student enrolments in Portugal, by level of education, 2006-07

\begin{tabular}{l|c|c} 
Age range of students & Enrolments (in '000s) & As \% of total \\
\hline $0-5$ (Pre-school) & 263.0 & 14.8 \\
\hline $6-9\left(\right.$ I $^{\text {st }}$ cycle) & 499.0 & 28.2 \\
\hline I0-II $\left(2^{\text {nd }}\right.$ cycle) & 255.2 & 14.4 \\
\hline I2-I4 (3rd cycle) & 398.4 & 22.5 \\
\hline I5-I7+ (Secondary) & 336.9 & 20.2 \\
\hline Total & 1752.6 & 100.0
\end{tabular}

Source: Bulletin "Estatísticas de Educação 2006-2007" published by GEPE in the statistical department of the Ministry of Education.

the pre-compulsory school network, and measures to motivate and retain early leavers from secondary school, which have increased the proportions in school of those under and over the ages of compulsory education (Table 2.I).

The number of students in secondary education (i.e. aged over 15-17 and therefore past the age of basic or compulsory education) grew from some 340000 in 1990-9| to a peak of 480000 in 1995-96 (an increase of around 40\%), and then fell to a low point of 326000 in 2005-06. Since then, there has been a modest increase ( 10000 in 2006-07) and a further increase in 2007-08, on the basis of preliminary figures (Figure 2.2). This is attributed to recent measures to diversify the secondary school curriculum and the fact that more young people have been encouraged to stay on in full-time education.

\subsubsection{Quality and standards}

Within the last generation Portugal has seen significant increases in the numbers and proportions of its population completing secondary education and gaining qualifications. But these improvements have been from a relatively low base, and international comparisons give continuing concern in Portugal about school standards and quality. The Portuguese results in three PISA surveys (2000, 2003 and 2006, see Table 2.2) have each been well below the OECD average of 500 for the three domains of reading, mathematical and scientific literacy (OECD, 200 I; OECD, 2007).

As noted above, post compulsory school participation rates remain low by international standards. Portuguese schools also struggle more than most elsewhere to moderate the impact of socio-economic background on performances and to achieve equitable learning outcomes for all. This is attested by the application of a PISA index of economic, social and cultural status based on students' home background factors: parental occupational status, parental education, and the number of books at home.This then measures the impact of the socio-economic background of the students on their performance. In Portugal, the impact of socioeconomic background on performance is above the OECD average for PISA 2003 and 2006.

\section{I.4 The wider education policy context}

As in other OECD countries, the Portuguese government has sought to improve the standards and performance of education and training. It has introduced a range of education policies to take account of developments in education thinking within Portugal and internationally, and to promote the desired improvements. Each of these policies has implications for how, what and where teaching and learning takes place. They include:

- The development of a more practical, experimental, personalised and differentiated 2Ist Century School curriculum, particularly in the Third Cycle (I2-14) and in secondary education, to reengage those not motivated by the existing academic curriculum.

- Much greater and more effective use of ICT and e-learning, supported by significant investment in up-to-date ICT infrastructure. The Government is building local area networks, estab-
Source: OECD PISA Database. lishing broadband connections, providing all schools with computers and electronic whiteboards and organising an ambitious in-service-training programme to make teachers proficient in the use of ICT. Portals are being developed and teachers are encouraged to produce content and share it with their colleagues. ${ }^{2}$

- The restoration of a major technical and vocational education (TVE) route in upper secondary education, which was abandoned with the democratic ('carnation') revolution in 1974 and has led to major deskilling of young people since then. This has been promoted by a New Opportunities Programme, which has also sought to give adults (only a third of whom have graduated from secondary school) a second chance of gaining basic skills and other qualifications to equip them for work in the 2 I st Century. The restoration of the TVE route has major implications for schools, which need the specialist space and equipment as well as ethos to provide the new courses, and will need to develop close links with employers e.g. for work experience and internships. Considerable progress had been made on both fronts since 2006. 90000 students, a third of Year 10 (the first year of Portugal's secondary phase) are now on TVE courses: the target is to increase school enrolment via the diversification of the education streams and have $50 \%$ of $15-17$ year olds enrolled on vocational courses by 2010 . This looks achievable. Second, 900000 adults (aged 16 to 65 years) out of the 3.5 million nationally that did not complete 12th grade of education have enrolled on courses since 2006. The target of I million by 2010 is again seen as readily within reach (Capucha, 2009).

- The linked policy to open up schools to the community in evenings and at other times for adult and community education and other community-related purposes, and by doing so provide opportunities to raise the levels of

Table 2.2. PISA results for Portugal for each literacy cycle

\begin{tabular}{l|c|c|c} 
PISA literacy domain & 2000 & 2003 & 2006 \\
\hline Reading literacy & 470 & 478 & 472 \\
\hline Mathematical literacy & 454 & 466 & 466 \\
\hline Scientific literacy & 459 & 468 & 474
\end{tabular}


education while making full use of the buildings and equipment provided.

- The existence of a parallel system of Ministry of Employment funded Training Centres, which has meant that some of the more practical training for young people can be left to institutions better equipped to offer it.

- The decision, embodied in law in August 2009, to raise the school leaving age to 18: this will significantly increase the number of 15 to 17-year olds from the current voluntary staying on rates: $90 \%$ at age 16 and $80 \%$ at age I7. It will also impact importantly on the character of school buildings required across the country.

- Steps towards devolution to self-governing schools, with more powerful appointed principals accountable to their local communities through new School Councils, supported by rigorous inspection and increased information, and with a shared responsibility with Parque Escolar for the maintenance of secondary school buildings.

None of these policies fall within the remit of Parque Escolar; but all have to be taken into account and form an important part of the context for the SMP.

Similarly, while not directly impacting on the SMP, it has also been important politically that parallel programmes have been launched to refurbish primary (Ist cycle) and middle/lower secondary schools (2nd cycle). This has been linked to a national programme to rationalise small primary schools, combined with investment under the municipal authorities that are responsible for their maintenance. Between 2005 and 2009 a total of 194 school centres (combining Ist cycle with pre-schooling) were built. A further 437 school centres are approved to start up to 2015 , corresponding to EUR 69I 779915 of public investment (Ministry of Education, 2009).

\subsection{The SMP}

\subsection{Aims and objectives of the SMP}

The Portuguese government has recognised that school buildings play an important role in improving standards of education (Council of Ministers, 2007). It believes that providing the school community with well-equipped and maintained facilities is key to stimulating both the younger generations and society as a whole to develop and broaden their knowledge and skills. Its perception has been that the quality of school buildings in Portugal has deteriorated to the extent that they no longer provide environments conducive to contemporary education. This has been supported by several surveys of facilities carried out in the last decade. ${ }^{3}$

The SMP aims to address this by renovating and upgrading the schools. Its ultimate goal is to provide the Portuguese educational system not just with state-ofthe-art new school buildings but with a new approach to the way the community sees schools and relates with raising the levels of educational achievement across the community, the provision of academic and vocational education options, and the concept of lifelong learning.

The strategy for meeting the objectives of the SMP falls broadly into three areas:

- Modernisation of the physical infrastructure, including repairing existing structures, providing buildings that meet contemporary standards for habitability and environmental comfort, and creating spaces suitable for contemporary educational needs and which are flexible enough to meet emerging demands.

- Opening up schools to the local community.

- Maintenance and management of the buildings after modernisation.

The aim is to provide:

- Attractive spaces that promote well-being, allow good teaching practice, provide access to information and support teachers' work outside the classroom.

- Flexible spaces that can adapt quickly and inexpensively to changes in the curriculum, to evolving pedagogical theory and practice, to the demands of the school community, and to fast developments in ICT.

- Multifunctional spaces for diverse and widespread use by school communities.

- Safe, accessible and inclusive spaces that provide users with a healthy environment and support people with restricted mobility and special educational needs.

- Durable and environmentally efficient solutions to reduce energy consumption, as well as management and maintenance costs.

\subsection{Administration and delivery}

\subsection{Remit of Parque Escolar}

To deliver the SMP, the Portuguese Government set up an independent stateowned company, Parque Escolar, in January 2007. ${ }^{4}$ Parque Escolar is responsible for planning, managing, developing and carrying out the SMP. In many ways, it appears to function like a typical private sector company: it has administrative and financial autonomy and is free to take a commercial approach to managing the procurement and maintenance of the schools. It is expected to be self-funding from the fee that it is paid by the state for managing the SMP, and from the rent paid to it by the state once the work has been completed. Nevertheless, it is closely supervised by the Ministries of Education and Finance, which are directly involved in all key management decisions such as appointing the board of directors.

The relationship between Parque Escolar and the Portuguese Government has been regulated by two instruments: a public service agreement that sets out both the obligations for implementing the SMP and the fee for managing the SMP; and an infrastructure availability and operations agreement which sets out the rent to be paid to Parque Escolar and the obligation for maintenance. The first public service agreement ended on 3I December 2009 and is automatically renewed for a subsequent three year period unless the government officially notifies Parque Escolar otherwise.

To deliver the SMP, Parque Escolar is required to work in partnership with both the Regional Education Authorities and the executive boards of the local schools to define, among other things, the scope of the projects, a timetable for the work and the maintenance services.

\subsubsection{Management structure of Parque Escolar}

Parque Escolar is led by a five-member board of directors appointed by the Government with a three year mandate. There is an independent auditor who monitors Parque Escolar's accounts and certifies its annual financial reports. All departments within Parque Escolar report directly to the board of directors. See Annex B3 for a comprehensive departmental breakdown. 
In the two years following its inception, Parque Escolar grew to 101 employees and estimates that it will reach a peak of 160 to 180 during the investment phase of the SMP. Once the investment phase is completed, it expects the number of permanent employees to decrease to about 75.

The staff are based partly in Lisbon and partly in regional offices across Portugal, to enable them to offer local support to the SMP. Given that the focus of the SMP is to deliver a construction programme and then manage the property, it is not surprising that most of the employees come from a construction sector background. However, there are also education and other specialists within Parque Escolar. Broadly the breakdown by background type is as follows (see Annex B3 for details):

- 42 engineers (32 civil engineers); ( 10 other engineering specialisms)

- 23 architects

- 10 secondary education specialists

- 6 behavioural scientists and organisational psychologists

- 5 legal advisors

- 9 management/financial specialists

- 6 other specialists

\subsection{Funding the SMP}

\subsection{Cost}

Responsibility for capital expenditure on schools of the second and third cycles of basic education and on secondary schools in Portugal rests with the Ministry of Education. ${ }^{5}$ With the support and active engagement of the Portuguese Government, the Ministry allocated EUR 2086

Table 2.3. Planned expenditure* on the SMP from 2007-20II

\begin{tabular}{l|c|c} 
Year & $\begin{array}{c}\text { Planned } \\
\text { expenditure }\end{array}$ & $\begin{array}{c}\text { Cumulative \% } \\
\text { of programme } \\
\text { spent }\end{array}$ \\
\hline 2007 & 8 & 0.03 \\
\hline 2008 & 84 & 3.7 \\
\hline 2009 & 805 & 36.6 \\
\hline 2010 & 1360 & 92.1 \\
\hline 2011 & 193 & 100.0 \\
\hline Total & 2450 & 100.0
\end{tabular}

* All figures expressed in EUR million at 2008 current prices.

Source: Parque Escolar (2009)

Table 2.4. Planned disbursement of funds* for the SMP

\begin{tabular}{c|c|c|cc} 
Year & ElB loan & CEB loan & $\begin{array}{c}\text { Commercial } \\
\text { medium or long } \\
\text { term debt }\end{array}$ & Total \\
\hline 2009 & 300 & 36 & & 336 \\
\hline 2010 & 597 & 139 & 16 & 736 \\
\hline 2011 & 186 & & 388 & 574 \\
\hline 2012 & & & 76 & 76
\end{tabular}

*All figures expressed in EUR million at 2008 current prices.

Source: Parque Escolar (2009)

million at 2008 prices, since increased to EUR 2494 million, over the period 2007-II to the SMP. The Budget for the SMP provided for over $90 \%$ of this to be spent by the end of the 2010 calendar year (Table 2.3).

The funding for the SMP came from three sources of debt finance and two grants:

\section{Debt financing}

- A long-term loan of EUR I 085 million (44\% of the total funding) from the European Investment Bank (EIB).

- A long-term Council of Europe Development Bank (CEB) loan of EUR I75 -250 million for the 205 schools.

- Long-term commercial bank loans estimated at EUR 480 million (some $20 \%$ of the total).

\section{Grants}

- EUR 353 million grant from the Portuguese Exchequer; 300 million supported by the "Investment and Employment Initiative" (Law 10/2009 of 10 March) and EUR 53 million from the PIDDAC - Programme of Investments and Expenditure of Develop-

Table 2.5. Allocation of funds*, by phase

\begin{tabular}{|c|c|c|c|c|c|c|}
\hline Year & $\begin{array}{l}\text { No. of } \\
\text { schools }\end{array}$ & $\begin{array}{l}\text { Planned } \\
\text { date for } \\
\text { completion }\end{array}$ & $\begin{array}{l}\text { Construction/ } \\
\text { rehabilitation } \\
\text { costs ind. } \\
\text { interest }\end{array}$ & $\begin{array}{l}\text { Equipment } \\
\text { costs }\end{array}$ & $\begin{array}{l}\text { Total } \\
\text { costs }\end{array}$ & $\begin{array}{c}\text { Average } \\
\text { cost per } \\
\text { school }\end{array}$ \\
\hline Pilot phase & 4 & 2008 & 58.5 & 3.5 & 62 & 15.5 \\
\hline Phase I & 26 & 2009 & 306.3 & 20.7 & 327 & 12.6 \\
\hline Phase 2 & 75 & 2010 & 797.3 & 59.7 & 857 & 11.4 \\
\hline Phase 3 & 100 & 2011 & $n / a$ & $n / a$ & 1206 & 12.1 \\
\hline Total & 205 & 2011 & & & 2450 & I 1.8 \\
\hline Final planned & 332 & 2015 & & & & \\
\hline
\end{tabular}

* All figures expressed in EUR million at 2008 current prices.

Source: Parque Escolar (2009) ment of the Central Administration from 2007 to 2009.

- EUR 354 million (14\%) in grants to Portugal from the EU Structural Fund (ERDF) or Cohesion Fund, in relation to Portugal's National Strategic Reference Framework.

The funding for the SMP is being disbursed as in Table 2.4.

The allocation of these funds by phase, number of schools, category of expenditure and average cost per school is shown in Table 2.5.

\subsubsection{Allocating and prioritising funds}

The age of the existing stock of school buildings in Portugal varies, with the oldest dating back to the 19th century. The school buildings fall into three broad groups related to the building types used successively in the design and construction of school facilities throughout the 20th century. Of 477 secondary schools, $77 \%$ date from 1970 or later, reflecting the major expansion in the school network and extension of compulsory schooling since then. The distribution of the stock of public secondary schools by age of construction is shown in Table 2.6. 
Table 2.6. Distribution of schools, by age of construction

\begin{tabular}{l|r|r|}
\multirow{2}{*}{ Group } & $\begin{array}{c}\text { Date of } \\
\text { construction }\end{array}$ & Percentage \\
\hline $\mathrm{I}$ & Up to 1935 & 2 \\
\hline 2 & $1935-49$ & 5 \\
\cline { 2 - 3 } & $1950-59$ & 6 \\
\cline { 2 - 3 } & $1960-69$ & 10 \\
\hline \multirow{4}{*}{3} & $1970-79$ & 16 \\
\cline { 2 - 3 } & $1980-89$ & 42 \\
\cline { 2 - 3 } & $1990-99$ & 12 \\
\cline { 2 - 3 } & $2000-07$ & 7
\end{tabular}

Source: Parque Escolar (2009)

In January 2007 the government launched the SMP to renovate and modernise 332 of the 477 schools by 2015 , with the first 166 to be modernised by 201 I. The selection of schools to be included in the SMP has been based on a comprehensive survey of the age, characteristics and condition of the stock. This has included detailed technical analysis of school building types that are best suited to remodelling in various ways; schools that with such remodelling might have a considerably extended life; and those schools (often newer buildings constructed with materials of lesser quality) that may be less suitable for refurbishment and may need replacement.

\subsubsection{Funding for the continued maintenance of schools}

An important component of the SMP strategy is that it includes maintaining the schools once they have been renovated. Therefore, part of the ini-

Figure 2.3. Timetable for the first phases of the SMP

\begin{tabular}{|c|c|c|c|c|c|}
\hline \multicolumn{6}{|c|}{ Construction phase } \\
\hline & 2007 & 2008 & 2009 & 2010 & 2011 \\
\hline Pilot phase & \multicolumn{2}{|c|}{4 schools } & & & \\
\hline Phase I & & \multicolumn{2}{|c|}{26 schools } & & \\
\hline Phase 2 & & & \multicolumn{2}{|c|}{75 schools } & \\
\hline Phase 3 & & & & \multicolumn{2}{|c|}{$\bar{\equiv} 100(6 I+39)$ schools } \\
\hline
\end{tabular}

- Pilot Phase: 4 schools completed by the first quarter (QI) of 2009.

- Phase I: 26 schools completed by Q3 2009.

- Phase 2: the construction of 75 schools to start in Q2 2009 and be completed by Q3 2010.

- Phase 3: the construction of $61+39$ schools to start in Q4 2009 and be completed by Q3 201 I.

The four schools in the pilot phase have been completed; and construction of the schools in Phase I is under way. Ten schools were scheduled for completion by September 2009, a further 12 during November and December and the final four of this phase by February 2010.The construction contracts for the schools in Phase 2 have been signed, and the schools in Phase 3 have started preparing their strategic plans.

\subsubsection{Selecting the schools for modernisation}

Schools are being selected for each of the main phases of the SMP, not only on the basis of their condition (as described above), but also on the basis of projected enrolments and the views of the regional education authorities, which are consulted and asked to select schools with a view to their regional plans, the structure of the schools network and cluster organisations. The regional directorates of Parque Escolar make a preliminary selection and draw up a shortlist from which the final selection is drawn. A fair regional distribution is an additional criterion. Parque Escolar wanted some flexibility to achieve regional balance across the country and meet political priorities. The remaining schools will be selected after the renewal of the Public Service Agreement in December 2009.

However, for the pilot phase, selection was carried out on a different basis. This phase was intended as a learning process and so it was important to have a sample of schools that could provide models for all schools in Portugal: built in different periods according to different architectural designs and standards. Some are historic buildings and belong to the architectural heritage of the country, some show great architectural uniformity because of standardisation techniques, other are pavilion style structures based on a limited set of standard architectural designs. 
Each of the pilot schools, two schools in Lisbon and two in Porto, has some unique features: one school includes a music school (Rodrigues de Freitas in Porto, Figures 2.2, 4.2, 4.3 and B2); another is an arts school (Soares dos Reis in Porto, Figures $0.2,2.4,3.1,3.7,3.1 \mathrm{I}, 4.4$ and p. 53); a third school (Dom Dinis in Lisbon, Figures I.I, 3.4, 3.5, 3.I0 and BI) combines middle and upper secondary school (from grade 7 up to grade 12) and the fourth combines regular and professional education with a training centre for adults (D. João de Castro in Lisbon). These schools were seen as mirroring the current poor state of secondary education learning environments in the country. They also exemplified the complexity of the education and training system and the different architectural designs and styles.

\subsubsection{The process for modernising each school}

The process is broken down into three principal phases: the pre-design, design and construction phases. Parque Esco- lar has developed a process map for this (see Figure 2.6).

During the pre-design phase the school develops a strategic plan which brings together the school's vision, pedagogical approach and main educational goals, and by looking at the weaknesses and opportunities of the school's existing infrastructure, it identifies the physical resources required to meet its educational needs. The school submits the strategic plan online. The information from the strategic plan is used to develop a functional programme and schedule of accommodation which are then given to the architects for them to start their design work.

An in-depth technical survey of the condition of the structure and fabric of the school, including a seismic analysis, is carried out. This is done through contracts with faculties of engineering in the different regions where schools are located. The survey reports are used to inform decisions on what should be remodelled, pulled down and/or replaced; the opti- mum design; and the detailed construction work.

The design phase consists of five stages through which the design is gradually developed: the functional programme; concept design; schematic design; building phase design; licensing project (preparing the project so that the local authority can give a license to build). The stages reflect practice in other countries and allow for progressive decision-making with the "milestones" acting as gateways. Thus, in one case reported to the team, a decision to remodel and extend upwards an existing building was overturned at a late stage in favour of demolition following detailed inspection of the pillars and beams.

During the construction phase the building contractor carries out the work supervised by a separate company. This supervisor makes sure that the contractor follows the contract and oversees on-site safety procedures. It also oversees any input from the design team that is needed during construction. Another important function that the supervisor performs is

Figure 2.4. Arts space, Soares dos Reis Secondary School, Porto

(c) Francisco Piqueiro / FotoEngenho

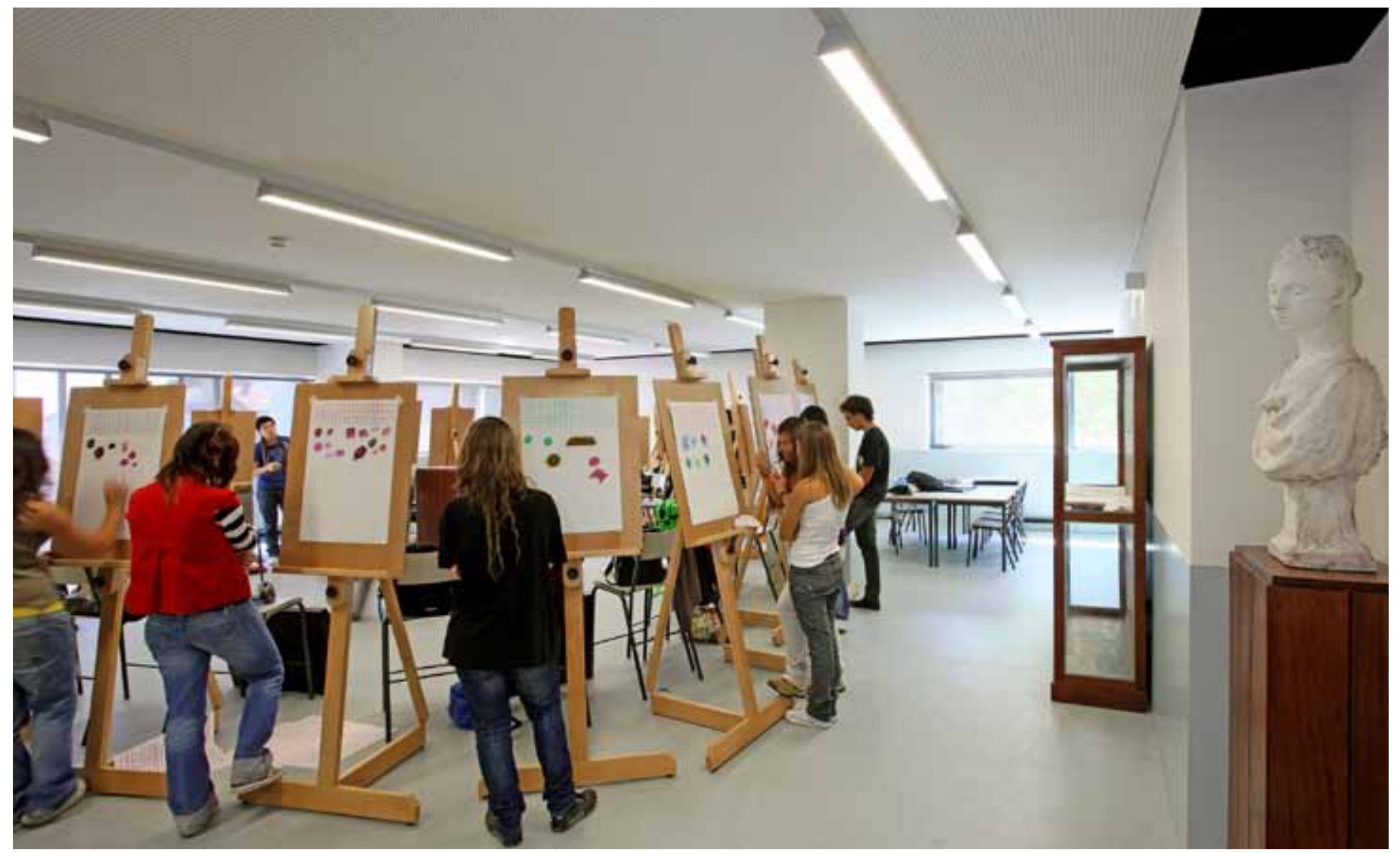


to co-ordinate with the school in particular over the phasing of the construction so that the school is able to vacate some areas and occupy others in sequence with the contractor. This allows both the school to continue to function safely and the contractor to carry out its work without major disruptions.

\subsubsection{Tender and appointment procedures}

\section{Procedure for selecting and appointing the architects, other design specialists and supervisors}

The architects are contracted to work on individual school projects. Their appointment is negotiated and Parque Escolar has developed an evaluation method to select potential architects; it has a database with details of some 200 architects. The criteria for evaluating potential architects are based on the experience of the architects generally and with education projects and capacity to carry out the work. The supervisors are similarly appointed. The design specialists such as engineers are contracted to Parque Escolar although they work under the supervision of the architect.

\section{Procedures for tendering and appointing construction and maintenance contractors}

The implementation of the SMP is being carried out through international public tender for the majority of the contracts.

The four pilot projects were contracted through direct negotiations following prior consultation with five construction companies. This was done for two reasons: to speed up the process because it was important to start the main phases of the SMP in 2007-08 to meet the schedule; and to test the process, in particular the impact of construction on the normal activities of the school, with experienced contractors.

The construction/rehabilitation and maintenance contracts are awarded through international restricted public tenders. An advertisement was placed in the Official Journal of the European Union and in a national bulletin. This is in line with the European procurement directives which have been incorporated into Portuguese national legislation.

Rather than put each individual school project out to tender, schools are grouped. For Phase I these groups included six to eight schools. Phase I was organised with four different bids with 26 schools divided into four groups. The bid for the fourth group was cancelled, so the construction planning phase for this group of schools was carried out under direct procurement with prior consultation of several firms. For the remainder of the construction work phases there were six public bids.

For Phase 2A the schools were grouped into 28 smaller units of mainly two or three schools with one exception of eight. Some of the work is being carried

\section{Figure 2.5. Reading room, Alves Martins Secondary School,Viseu}

(C) Arte Fotográfica / André Oliveira and Joâo Pinto

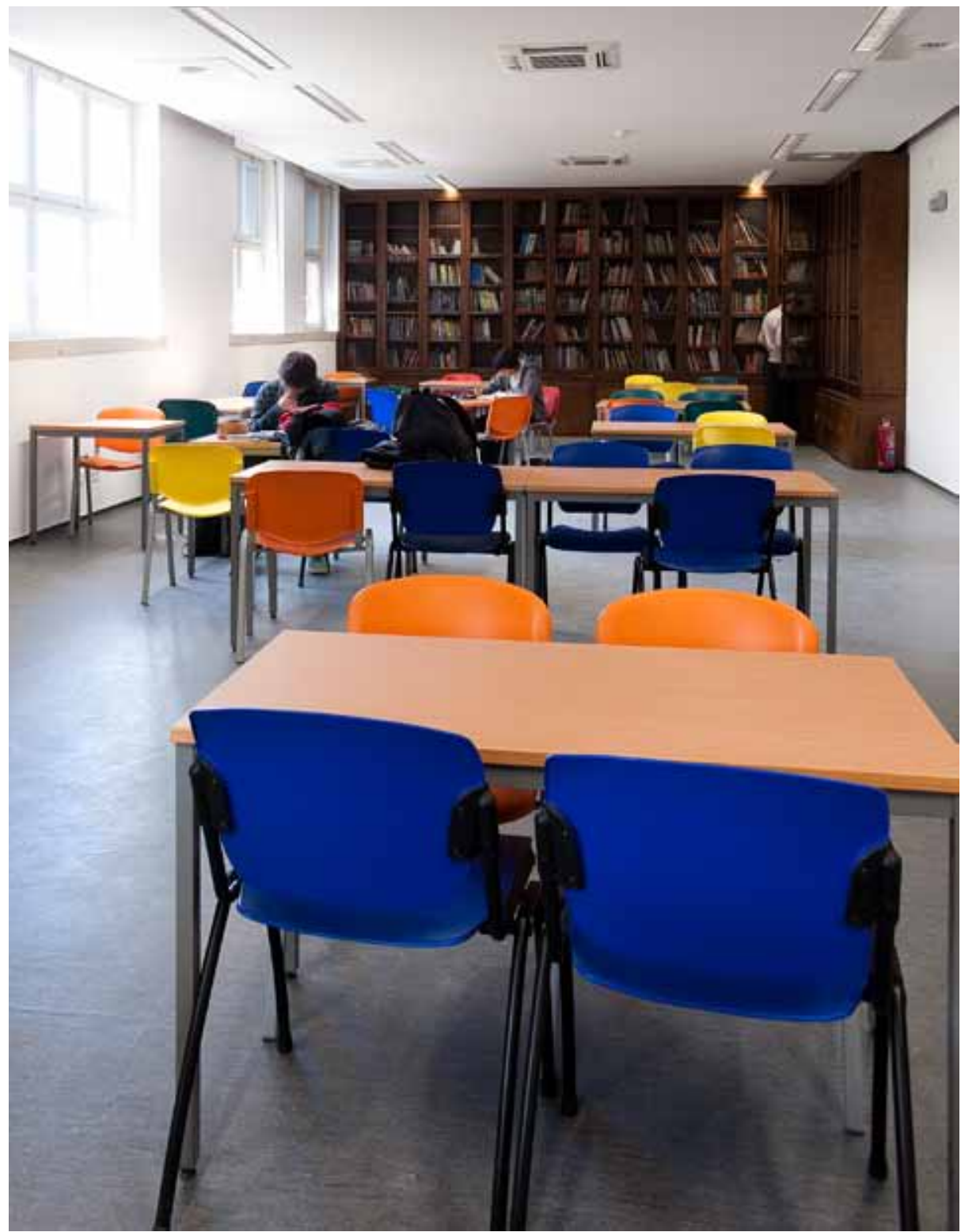
consortia of various sizes.

The pre-qualification phase is used to select companies against a range of criteria, for example, capital, workforce and experience. For Phase I the number of pre-qualified organisations was limited to 15 although in later phases this was increased. During the main tender phase, bidders present a fixed price for construction and a fee for maintenance, which is based on a forecast of the likely maintenance regime.

In the Portuguese construction industry out by individual companies, the rest by 
Figure 2.6. Process map developed by Parque Escolar for the SMP

\begin{tabular}{|c|c|c|c|c|c|c|c|c|}
\hline \multirow[b]{2}{*}{ Tasks } & \multicolumn{8}{|c|}{ Stakeholders } \\
\hline & REAs & PE & Schools & Designers & Consultants & Inspectors & Contractors & Time frame \\
\hline \multicolumn{9}{|c|}{$\begin{array}{l}\text { Schools selected according to condition, sufficiency, } \\
\text { enrolment and attractiveness criteria }\end{array}$} \\
\hline $\begin{array}{l}\text { National general overview } \\
\text { schools involved }\end{array}$ & & & & & & & & Milestone \\
\hline \multicolumn{9}{|c|}{$\begin{array}{l}\text { Regional general overview meeting with schools, } \\
\text { presenting on-line strategic plan questionnaire and } \\
\text { instructions for completion }\end{array}$} \\
\hline \multicolumn{9}{|l|}{ Selection of designers } \\
\hline \multicolumn{9}{|c|}{ Submission of strategic plan information } \\
\hline School visit & & & & & & & & Milestone \\
\hline \multicolumn{9}{|c|}{ Physical condition and anomalies survey } \\
\hline \multicolumn{9}{|l|}{ Seismic analysis } \\
\hline \multicolumn{9}{|c|}{$\begin{array}{l}\text { Project information delivery: Design guidelines } \\
\text { and photographic and building surveys }\end{array}$} \\
\hline \multicolumn{9}{|l|}{ Building survey (when needed) } \\
\hline Brief development and del & & & & & & & & Milestone \\
\hline \multicolumn{9}{|c|}{ Concept design: Draft presentation to PE } \\
\hline \multicolumn{9}{|c|}{$\begin{array}{l}\text { Concept design: Draft presentation to the school's } \\
\text { Board of Management }\end{array}$} \\
\hline Concept design validation & & & & & & & & Milestone \\
\hline \multicolumn{9}{|c|}{$\begin{array}{l}\text { Schematic design validation: Draft presentation to } \\
\mathrm{PE}\end{array}$} \\
\hline \multicolumn{9}{|c|}{$\begin{array}{l}\text { Schematic design validation: Draft presentation to } \\
\text { the school's Board of Management }\end{array}$} \\
\hline \multicolumn{9}{|c|}{ Schematic design: Formal presentation to the school } \\
\hline Schematic design validatio & & & & & & & & Milestone \\
\hline \multicolumn{9}{|l|}{ Building phases preparation } \\
\hline \multicolumn{9}{|c|}{$\begin{array}{l}\text { Detailed design development and delivery of } \\
\text { construction documents }\end{array}$} \\
\hline \multicolumn{9}{|l|}{ Project revision } \\
\hline \multicolumn{9}{|l|}{ Tender bids management } \\
\hline Construction phase & & & & & & & & Milestone \\
\hline
\end{tabular}


most building contractors are relatively small so there is some reliance on contractors operating as consortia and forming joint ventures. Approximately onethird of those that tendered during the second phase are individual companies, one-third are joint ventures between two companies and one-third are joint ventures between three companies.

Figure 2.7. New elevator, Alves Martins Secondary School,Viseu

(c) Arte Fotográfica / André Oliveira and Joâo Pinto

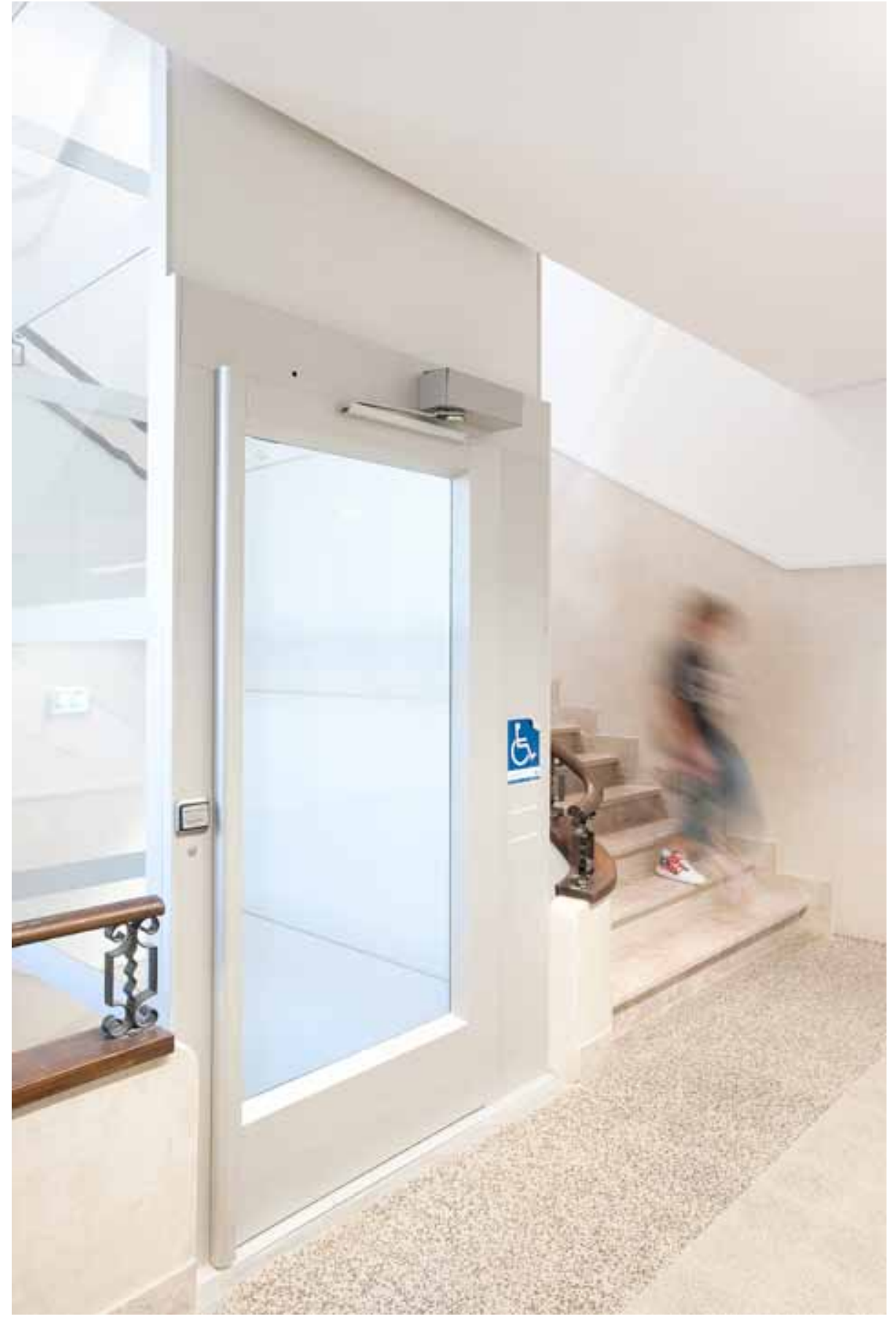

contract covers post-completion maintenance work.

A firm of supervisors is employed by Parque Escolar to administer the construction contract on its behalf, monitor the costs, co-ordinate the project with the school and liaise with the architect over problems that may arise and need architectural input. They may also be required to make design-related decisions, in particular those that relate to parts of the building or site which are inaccessible until uncovered during construction.

\subsubsection{Post-completion management model}

The Portuguese state, through the Regional Educational Authorities, is responsible for maintaining and insuring the buildings until the rehabilitation work is completed, even if the property asset has already been transferred to Parque Escolar. Once work is completed, Parque Escolar becomes responsible for the maintenance and insurance. Since Parque Escolar is a state-owned company (functioning as a commercial entity) it must purchase building insurance rather than rely on the government's self-insurance arrangements (Box 2.I). Consequently it is important to have a clear understanding of the sites it is managing and the condition of the assets on those sites.

Parque Escolar is required to carry out the maintenance of the school facilities and equipment as well as renewal of equipment in such a way as to ensure that the school continues to be fully functional. This includes renewing all school and technical equipment at the end of its useful life, which is calculated on a depreciation model commonly used in asset management.

Contracts for conservation and maintenance are established with a duration of 10 years. They include four components: prevention, corrective, functional and high maintenance.

The "functional" component seeks to respond to any changes to meet new demands. It has a fixed budget (limit) for each period of five years. When the intervention results from a school's own requirement, Parque Escolar must approve it. Major changes in the school building, resulting from specific programmes established by the Ministry of Education should receive special financing. 


\section{Box 2.I. Key roles of those involved in the SMP}

\section{Regional Education Authorities (REA)}

Responsible, along with Parque Escolar, for selecting the schools for modernisation.

\section{Parque Escolar}

Manages the project, defines the brief for buildings and provides support and guidance. Parque Escolar has regional infrastructure departments which manage the projects in their geographical area, broadly defined by regions (North, Centre, Lisbon and South). There are two co-ordinators for each project: an architect and an engineer. The technical engineers are also cost managers and review the cost budgets during project development.

\section{School}

Sets out the strategic plan, and comments and reviews designs at concept, schematic and construction phases.

\section{Consultants to Parque Escolar}

Provide specific expertise to Parque Escolar on the condition of buildings, seismic surveys, library design, workshops, museum and science laboratory design. Advice is also provided on the requirements for information and communication technology (ICT).

\section{Architects}

Responsible for developing the design of the building and leading the design team. Their involvement begins when Parque Escolar discusses the functional plan with the school. Once that is agreed, it is handed to the architect along with the design guidelines and survey information. During construction, the architect provides design advice and attends weekly site meetings. The architect also prepares the health and safety plan in line with health and safety legislation.

\section{Specialist designers}

Include engineers, lighting consultants and other specialists as appropriate. They generally work under the supervision of the architect, although they can be directly contracted to Parque Escolar. Generally get involved at the schematic design phase, although could be earlier if there are particular issues that need addressing during concept development such as seismic safety.

\section{Supervisor}

Carries out a technical audit on the design on behalf of Parque Escolar; administers the construction contract; and makes sure that the contractor is constructing the building in accordance with the technical information. Validates the health and safety plan prepared by the architect and passes it on to the contractor, who updates the plan to take account of construction, which is validated by the supervisor. Responsible for co-ordination between the contractor and the school and arranging construction phasing to align with the needs of the school and construction.

\section{Contractor}

Responsible for carrying out the construction according to the specifications and construction drawings and completing the construction work within the cost and timeframes set out in the construction contract. Responsible for updating the health and safety plan, and for phasing the construction operations in line with the phasing plan agreed with the school and supervisor.

Once the construction work has finished, ownership of the school facilities is transferred from the state to Parque Escolar, which is then responsible for carrying out the maintenance and renewal of the school facilities and equipment. In return Parque Escolar receives an "Availability rent" of EUR $1.65 \mathrm{per} \mathrm{m}^{2} / \mathrm{month}$ of gross floor area (2008 prices), and a fixed in- come which is calculated every year and agrred with the Portuguese state. This fixed income is estimated on the basis of full cost recovery, which should also ensure the economic and financial balance of Parque Escolar's activity. For areas of a school that are not available, Parque Escolar will be subject to a non-availability penalty. The contracts between Parque
Escolar and the contractors responsible for carrying out the maintenance will include clauses that transfer this risk to them. Parque Escolar signs an Infrastructure availability and operations agreement with the Ministries of Education and Finance which is expected to last 30 years. 


\section{Notes}

I. Figure 4.10 in Learning for Tomorrow's World. First results from PISA 2003 (OECD, 2004) and Figure 4.10 in Science Competencies for Tomorrow's World. First results from PISA 2006 (OECD, 2007).

2. Portuguese Technological Plan Annex I: Education. http://www.planotecnologico.pt/InnerPage.aspx?idCat=47\&idMasterCat=30\& idLang $=2$

3. The surveys revealed the extent of deterioration in the buildings caused through natural obsolescence and the lack of continuous maintenance. The reports also showed that the buildings were, by and large, functionally obsolete and not suitable for modern educational needs in terms of environmental comfort, security, accessibility, classrooms, libraries, laboratories, image and information technology education. The poor condition of the schools came about because over the past 40 years more attention was focused on expanding the school network with less attention being paid to systematic maintenance or upgrading of schools to meet changing needs (Parque Escolar, 2009b).

4. Parque Escolar is an Entidade Publica Empresarial (a state-owned company) of which there are 55 in different sectors in Portugal: 42 in the health care sector; 5 in the transportation and infrastructures sector; 3 in the culture sector; 2 in the economic sector; 2 in the financing sector and $I$ in the education sector (Parque Escolar). Source: Ministry of Finance and Public Administration, General Directorate for the Treasury and Finance.

5. As a result of decentralisation (Decree Law 159/1999 I4th September), the local authorities have been granted some competencies for funding and spending on education which include the construction, maintenance, equipment and running of pre-schools and first cycle school assets. In 2008 these measures were reinforced (Decree Law 144/2008, 28th July) and some local authorities also became responsible for the construction, furnishing, equipment and maintenance of second and third cycle school assets in order to promote the creation of new schools or modernisation or conversion of the existing ones. The transfer of powers to local authorities was made by agreement with the central government. Not all local authorities accepted.

6. Decree-Law No 34/2009 “...defines the exceptional public contracting measures applicable to restricted calls for tender with prior qualification and direct award procedures for contracts including the modernisation of the school infrastructure network."

7. 39 schools were added to the 61 proposed for this. 


\section{I. Meeting the strategic objectives for education}

The government's school policy in Portugal is, as elsewhere, focused on two fundamental objectives: first, to provide school places for the eligible population; and second, to support continuing improvements in the quality of learning and outcomes from secondary education. However it also has a third policy objective, not unique to Portugal but more evident here than elsewhere: the restoration - in an updated 2 Ist century form - of a vocational route that motivates and equips for a fulfilling working life those young people that have felt excluded by the limited general academic curriculum available to them in the recent past.

It is clear that the SMP is strongly directed towards meeting all three of these objectives. Taking them in turn:

- Providing sufficient school places: Parque Escolar draws on informed forecasts of demand to determine the design size of each school in the SMP. There are issues (discussed below under Cost Effectiveness) as regards the relatively generous space standards being applied. But all in all, the SMP seems well designed to meet this objective.

- Ensuring quality of learning and outcomes: there is some international evidence as to both the practical and the motivational impact on outcomes of appropriately designed new or remodelled educational buildings. The impacts seem particularly great in terms of attracting and supporting the least motivated and the more vulnerable students. There are issues as regards detailed design to which the Review Team return below. But, in general, the SMP - which should transform the greater part of the secondary school stock in Portugal - seems well focused on this fundamental objective.

- Restoring a vocational route: a key purpose of the SMP is to secure a major expansion and improvement of practical laboratory and workshop facilities in Portugal's secondary schools (Figures 0.3, 3.I, 3.5 and 4.I). This is commendable, but may not be enough. International experience indicates that, in relatively small institutions with a comprehensive remit, it is difficult to offer students vocational education and provide them with a genuine choice of relevant courses. Schools with a small number of students in a given specialism cannot justify investment in expensive facilities and infrastructure or support the necessary critical mass of specialist staff. Within the context of the Portuguese educational system, there could be advantages in considering arrangements, whereby specific secondary schools in each region are designated as specialist vocational centres for particular subjects or industrial sectors, with strong links with relevant enterprises in the region.

Related to the second and third of these principal objectives are a number of developments in pedagogy, and it is a key part of the SMP's mission to support them. They are reflected in the third and fourth objectives of the SMP identified in the Council Resolution (Council of Ministers, 2007):

3. Adaptation of the spatial and functional conditions to the demands resulting from secondary education organisation and curricula, namely:

a. Greater flexibility in the organisation

of the curricula;

b. Diversity of pedagogic practices;

c. Continuous access to diverse informa- tion sources (resource centres);

d. Improvement of experiment-based teaching for sciences and technology

(laboratories and workshops);

e. Intensive use of information and com-

munication technologies (ICT);

f. Inclusion of pupils with special education needs;

g. Continuous presence of teachers and

pupils in the school throughout the day; and

\section{Opening the school to the community.}

The concept of quality lies at the core of the SMP, its mission and the strategic objectives described above. The CELE Organising Framework on Evaluating Quality in Educational Spaces seeks to define quality within the context of policy issues, and according to a series of principles and criteria of quality.' Many of the quality principles in the OECD Framework are encapsulated in this Council Resolution.

The Review Team discuss aspects of the design of buildings and their impact in greater detail below. From conversations with teachers and students as part of the Review Team's fieldwork, it is clear that the new upgraded infrastructure is seen as having a strong positive impact
Figure 3.I. Workshop, Soares dos Reis Arts School, Porto

(c) Parque Escolar

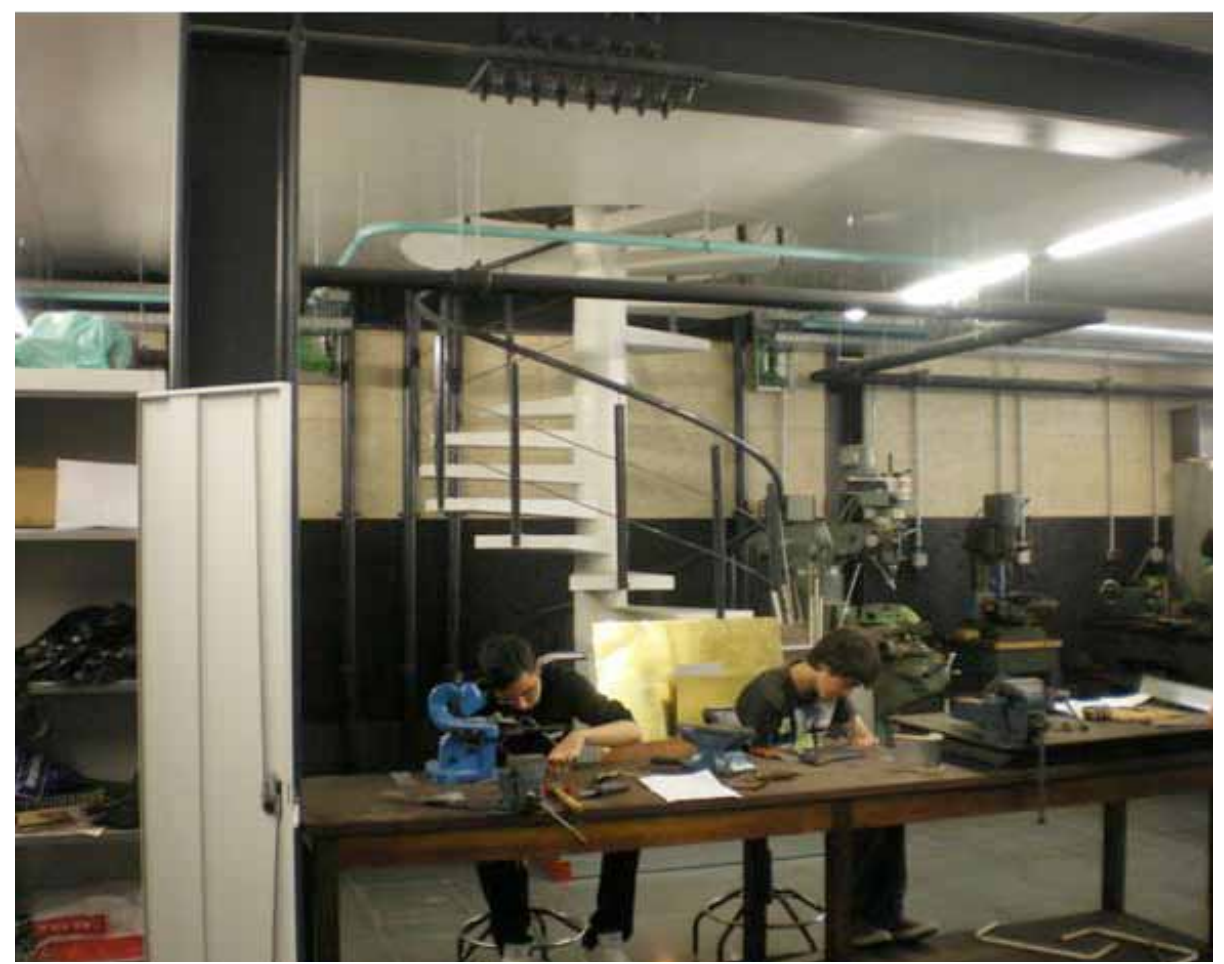


on teaching and learning: more attractive, flexible and multifunctional spaces were seen as enabling teachers to diversify their teaching, e.g. providing for more personalised approaches and hands-on experiments and supporting the development and application of ICT. The new buildings were seen as likely to increase the ambitions of students, including those who are highly motivated and those who previously have not enjoyed their schooling. They also meet the professional needs and expectations of teachers and administrative staff as well as the local and business community.

Teachers and students consistently told us that they have great respect for the new buildings and school equipment. Damage to school furniture, teaching equipment and educational resources was a major nuisance in schools across the country, and was reported as having all but disappeared in the upgraded facilities.

The Review Team observed in schools it visited a range of spaces that are used by local communities including auditoria, sports facilities and some social spaces. Classrooms were also being used for adult education evening classes.

\subsection{Governance}

\subsection{Importance of a strong independent body to manage the SMP}

The governance of the Portuguese education system is shared between different tiers of government - national, regional and local, including executive school boards traditionally elected by teachers. While much of the power is centralised with, for example, central control of the curriculum and textbooks and all teachers appointed nationally and allocated to schools, in practice successive governments have struggled to achieve the changes they wish to introduce, or at the speed they wish. It is clear to us that the establishment of a strong independent body, Parque Escolar, with a clear mission, and the resources and authority to pursue that mission, has been critical to the success of the SMP to date, and augurs well for its full realisation.

PE's particular profile - a $100 \%$ state owned company with a Board appointed by the Cabinet - ensures that it has the necessary political authority and links. It is separate from the Ministries of Finance and Education to which it answers. It ap-

Figure 3.2. External circulation space, Dom Pedro Secondary School, Lisbon

(c) Nuno Pires / Luís Calixto

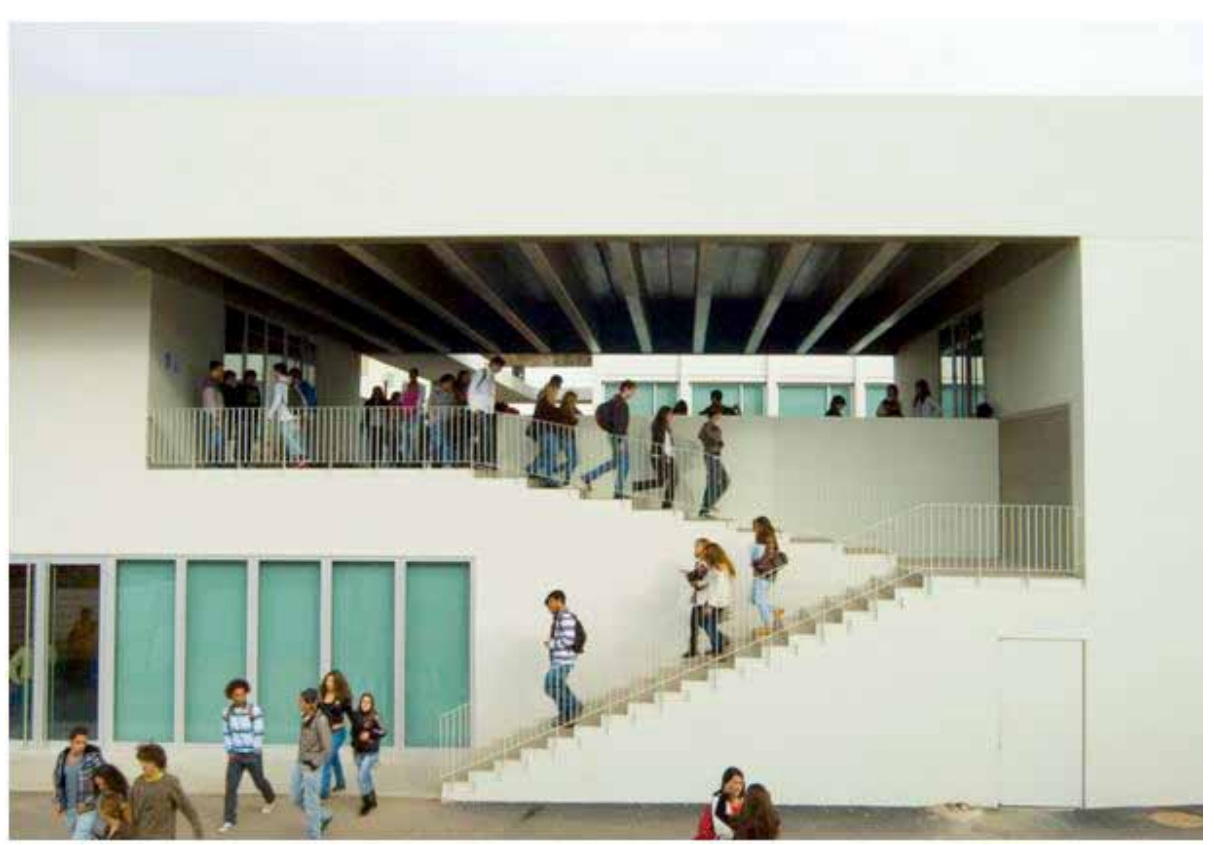

points staff with private sector expertise and understanding, and it adopts efficient working practices from the private sector. This, combined with what appear to be good international tendering procedures, has given Portugal an effective instrument both to lead the consultation process which underpins change in the self-consciously democratic society that Portugal has become and, in the light of such consultation, to secure delivery of the SMP to time and budget and the effective future maintenance of the remodelled buildings.

\subsubsection{Specific concerns about the governance of the SMP}

The Review Team's questions in relation to governance relate to two key aspects of the SMP. First, the speed and drive with which it is being implemented put huge pressure on those at the centre to "get it right first time". This diminishes opportunities for local actors to influence, or feel they influence, the shaping of a project for which they need to feel ownership. In addition, it does not allow opportunities for second thoughts in the light of changing curricular requirements or other circumstances. Second, there are necessarily doubts about the governance capacity at the local level over the long term, i.e. whether schools will be able to make the best use of the new facilities.

As regards the first of these points, there is a clear recognition of the challenges facing the SMP both at the national level, and within Parque Escolar in particular. This explains why an evaluation of the SMP was sought by the OECD/CELE at a very early stage and also accounts for the feedback arrangements put in place within the SMP.

As regards the second point, the change that took place on I June 2009 augurs well. Since then, School Councils are to compose not only elected teaching and non-teaching staff (who may comprise no more than $50 \%$ of the Council) but also pupils, parents, local authority and other community representatives and economic and social forces. The new Councils appoint new principals or directors for each school for an initial period of four years. The new Directors (who will have to pass a course in administration and have had leadership experience within education) will select and appoint their own deputy directors to form the senior school management team. Initially at least, these ap- 
pointments will need to be made from among the existing staff of the school.

The success of this policy to increase delegated authority at institutional level will depend on how the new arrangements develop in detail over time. But the changes are undoubtedly in a direction that has proved to support effective governance and improved standards in schools and other education institutions elsewhere.

However, Parque Escolar could play a useful role by supporting the school principals and acting as a facilitator, providing support and guidance to directors on how to manage their school premises and infrastructure.

\subsubsection{Communication and information flow between Parque Escolar and stakeholders}

The SMP has engaged a diverse range of stakeholders at national, regional and local levels. This has been, and will remain, important both to ensure that diverse needs are taken into account both nationally and locally, but also to manage the different expectations of those affected by the SMP. A significant challenge is to make sure that all the stakeholders feel their voices are heard and that the SMP is

Figure 3.3. Dining area, Aurélia de Sousa Secondary School, Porto (C) Francisco Piqueiro / FotoEngenho

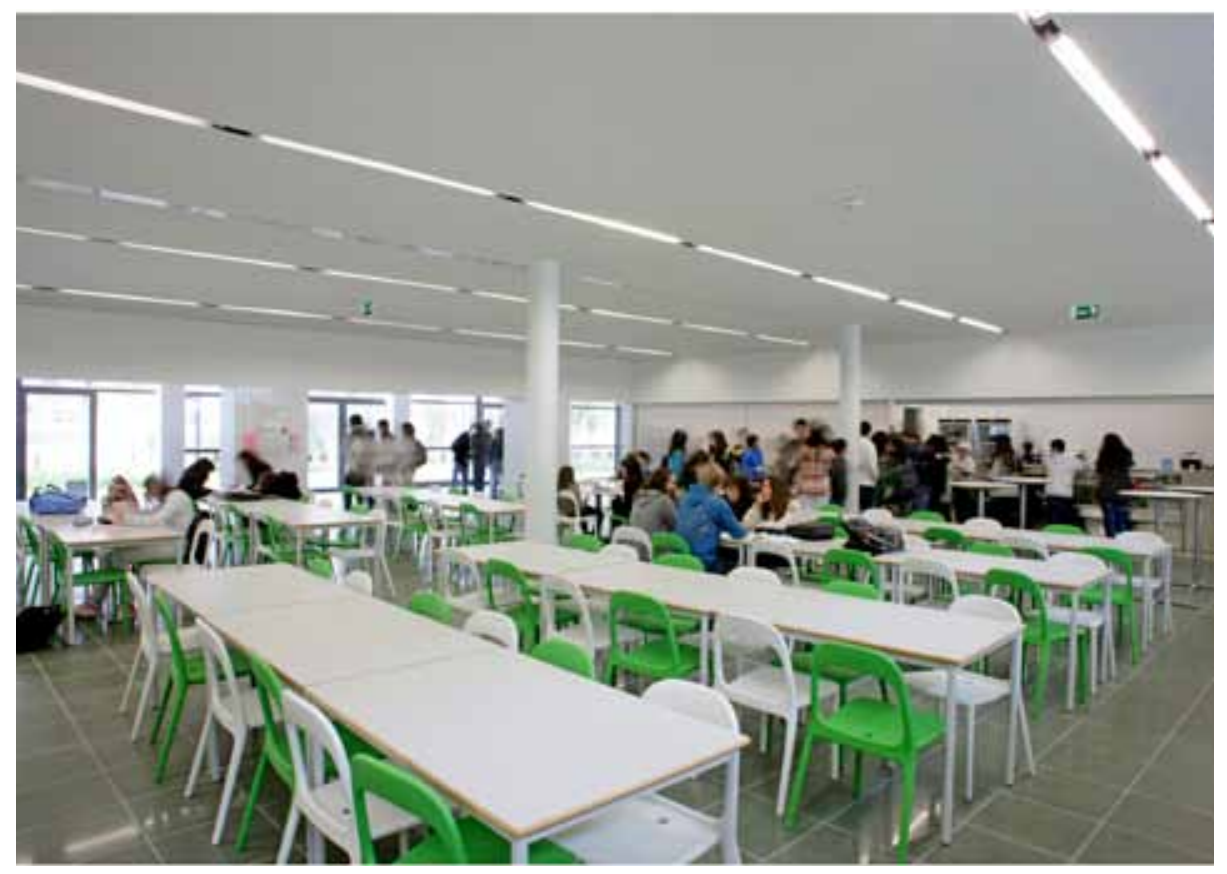

further consultation will benefit the SMP.

At the national level, communication and exchange of information between Parque Escolar and educational stakeholders were seen as either non-existent or, at best, limited. FENPROF (Federaçao $\mathrm{Na}$ cional dos Sindicatos de Professores), the main teachers' union, said that it learned about the SMP through the media. Input by some parts of the Ministry of Education (General Directorate for Innovation and Curriculum Development, DGDCl; National Qualifications Agency; the General Inspectorate of Education, IGE) was limited. The national parents' organisation and the National Education Board were not consulted but fully support the SMP as they see it as a tool to improve the quality of teaching and learning. All the stakeholders are aware of the importance and the scale of the SMP and they understand the sense of urgency in the government for its efficient execution.

Nevertheless, greater involvement of the ministry and the inspectorate is crucial for at least two reasons. First, policy makers need to be commited to the SMP.Second, use can be made of their expertise and competencies in curriculum development, innovation strategies, initial teacher training, especially in an education and training system as centralised as the Portuguese system. Their ideas on teaching and learning in the 2 Ist century may well provide a substantive input into the SMP. Educational facilities should be intimately linked to educational policies, not only in Portugal but also in other countries. Creating effective learning environments requires a combination of quality buildings, curriculum and pedagogy in conjunction with leadership through effective management, administration and governance at all levels.

\subsection{Funding}

\subsection{Funding levels and cost control}

The decision to embark on a major secondary school building modernisation programme in Portugal and the scale and nature of financing allocated to it - some EUR 2.45 billion over five years - have to be seen against the background of a school system that in recent years had very little capital expenditure devoted to it: "EUR 50-100 million per year", to quote the Secretary of State. These sums were insufficient for even basic repairs 
and maintenance. This has contributed to a major deterioration of the stock, and the SMP is determined not to let it happen again.

The sums sought for the SMP have been based on a needs analysis under six headings:

- Studies, design and project development.

- Construction and rehabilitation costs, including supervision and inspection costs.

- School equipment (furniture, kitchen equipment, sport and laboratory equipment, etc.).

- Project planning costs.

- Other fixed asset investments required for Parque Escolar to perform its functions (e.g. furniture and administrative equipment).

- Parque Escolar's start-up and running costs (intangible assets).

The projected costs of future repairs and maintenance up to 2037 have been added to these sums. This provision is a distinctive - and admirable - feature of the SMP.

The process by which construction cost estimates have been developed seems appropriate, in principle. It has been based on an assessment of the cost of remodelling the various categories of facilities that make up the school building stock, and refined in the light of experience with the pilot phase of the SMP.

Figure 3.4. Social space, Dom Dinis Secondary School, Lisbon

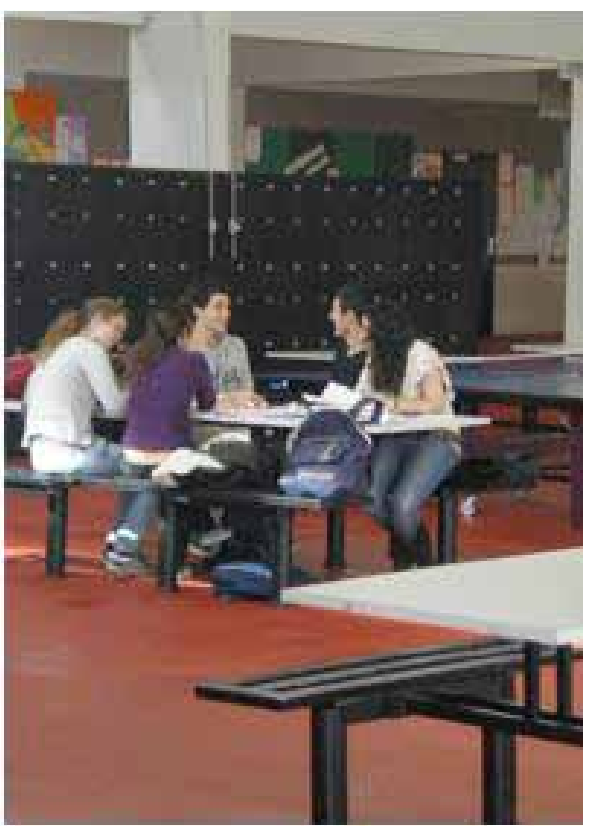

That said, as noted in 4.2.2, the speed of the planned build up of the SMP is such that there is limited scope for learning and applying lessons along the way either as regards education and design issues or as regards finance and the budget. A lot therefore depends on having established a "right first time" allocation and control process.A good start in this direction was the establishment of a single purposedesigned body, Parque Escolar, within the public sector but with many private sector characteristics: focus, drive, and speed of delivery.

While local actors are consulted, responsibility for the whole process - from overall planning, through initial design, contracting and ongoing maintenance rests with Parque Escolar. It has adopted a standard international good practice prequalification procedure - also driven, it should be said, by EU procurement directives (OJEU, 2004) - which aims to identify 25-30 companies which are capable of doing a job and include them on an approved list. Then these are invited to tender. Parque Escolar has set an indicative budget for each contract to counter the risk of a group of contractors colluding to set an inflated price. Previous public sector procurement rules allowed contracts to be awarded up to $25 \%$ above indicative prices. Now Parque Escolar's procedures include ceilings. Selection is based on price, but also takes into account previous experience and performance. Moreover, checks are carried out to ensure that a contractor is not over-stretched, i.e. that key staff are not required to be in more than one place at a time. In this respect, Parque Escolar has clearly benefitted from having a centralised computerbased information system.

So far, it seems that the SMP is on course to achieve the planned impressive rate of delivery. Delays to individual projects to date have been no more than a few weeks. In many cases, contractors have deployed large numbers of employees (the Review Team witnessed 100 on site more than once) and sub-contractors. They have had recourse to extend site shift work as necessary so as to complete contracts on time. Contractors have had incentives to do so. They work under fixed price contracts, and Parque Escolar takes a firm line on the responsibility of the contractor for meeting any cost overruns or for correcting any defects identified during the contract or its post completion period.
Another feature of the SMP that augurs well for it achieving value for money is the spotlight of publicity under which it is being conducted. It is subject to full external audit. Parque Escolar has engaged PriceWaterhouseCoopers (PWC) as internal auditors. Key stakeholders whom the Review Team met saw the administration of the SMP as a very clear process, and as a model for organising the allocation, distribution and monitoring of public funds. One indicator of success in this regard communicated to the Review Team was that despite the intense political interest in the SMP and its high profile, there have been no questions raised in Parliament.

\subsubsection{Funding sources and mechanisms}

The level of investment made in the SMP has required political leadership and commitment at the highest level. Formal negotiations on the total sums to be made available and their phasing have, as one would expect, been between the Ministry of Finance and Ministry of Education, and investment decisions have required their Ministers' dual signatures. Nevertheless, both the exceptional level of investment and the speed of implementation agreed for the SMP have reflected collective political commitment by the government. That said, Portugal's circumstances within the EU and in relation to the world economic recession have given the government a dual incentive to press forward with the SMP:

- In order to maximise access to available funds from the EU up to 2013-14 when Portugal's preferred funding status for ERDF, ESF and other EU funding will lapse.

- To offer an immediate response to the G20 and other international Keynesian initiatives to use "New Deal style" publicly funded capital programmes to offset the downturn in privately funded activity.

$70 \%$ of the funding for the SMP is in the form of loans. The Review Team has not sought to examine the precise terms on which those loans have been negotiated. The Review Team cannot therefore comment meaningfully on this aspect of the value for money of the SMP, but it is expected that much of the financing is on soft terms, and that the timing of these loans has been an important factor in determining the exceptionally tight timetable for the SMP. 


\subsubsection{Developing a sustainable funding process}

The SMP has rested on a conjunction of events: political will (Council of Ministers, 2007), the availability of funding from the $\mathrm{EU}$, and a climate encouraging investment in public works to offset the impact of the world recession. This conjunction is unlikely to be repeated for a generation, if ever. In that regard, the SMP is not sustainable. Furthermore, it is being led and implemented in a way that embodies a sense of purpose and energy - like a war economy - that again is unlikely to be sustainable in the long term. What is sustainable is the prospect of more consistent maintenance that should at least enable the stock of schools to be kept in a reasonable state for the next generation. Indeed, the buildings must be maintained and refurbished to meet ongoing educational needs and this must be sustained if the SMP is to meet the needs of $2 \mathrm{I}$ st century education.

The challenge to make the stock fit for purpose for a changing future will require rather more than this. It will require funding on a reasonable scale to permit accommodation and appropriate equipment to be remodelled to meet needs that cannot be envisaged now, but can almost certainly be expected to affect schools over the next 20 years or so. This is especially true of

Figure 3.5. Double-height space and staircase in renovated science laboratory, Passos Manuel Secondary School, Lisbon

(C) Nuno Pires / Luís Calixto

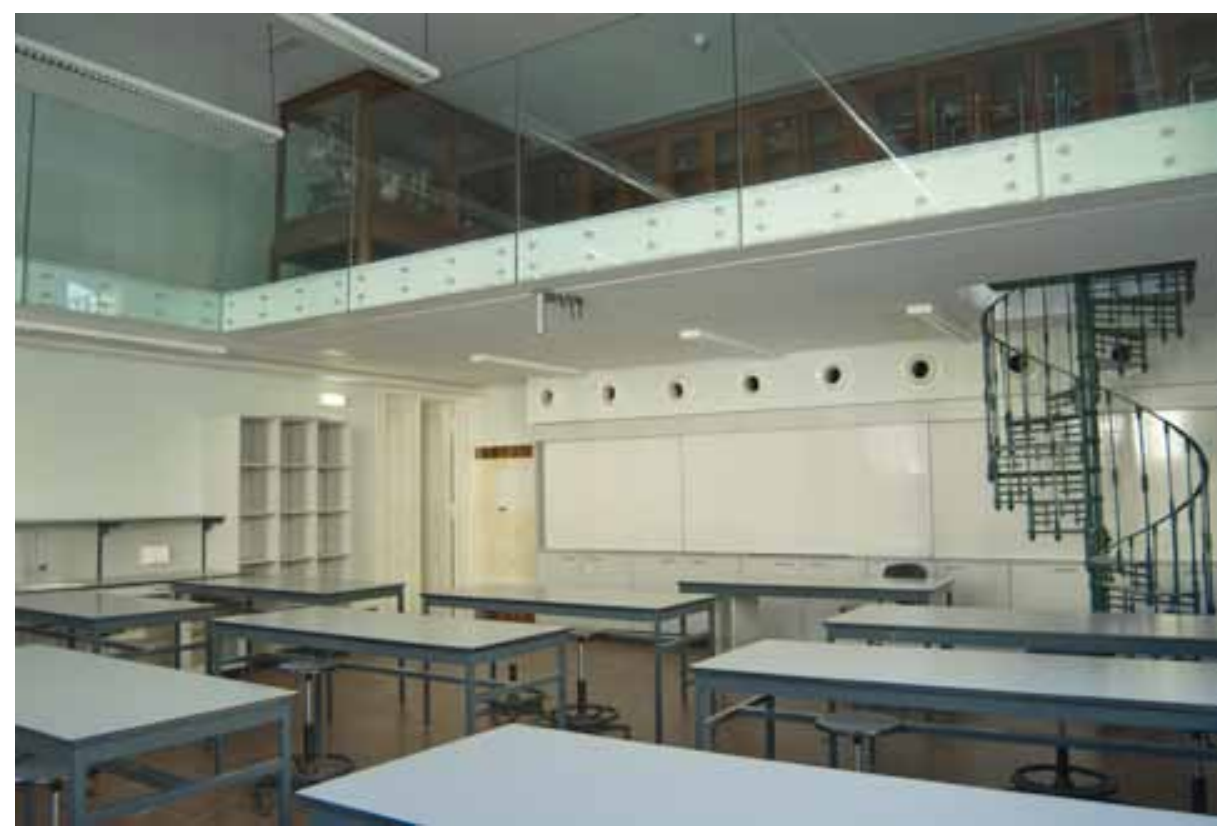

range of $3 \mathrm{~km}$ of the school. schools in Portugal as society accords them a prominent and comprehensive role as regards young people and adults alike. However, a striking, innovative and welcome element of the SMP is that it includes funding for future maintenance costs. This is reflected in an agreement between Parque Escolar and each modernised school. Under each agreement, Parque Escolar will be entitled to receive and retain an "availability rent" to be established on the basis of full cost recovery, which should also ensure the economic and financial stability of Parque Escolar's activity. A further interesting feature of these arrangements is the provision for what the Portuguese call "non-availability penalties". These are defined and regulated under the terms set out in the model agreement. Penalties will be applied to Parque Escolar whenever there is space (for example, classroom, laboratory, gym) in any school, as a consequence of causes attributable to Parque Escolar, that cannot be:

- Used for its intended purpose during the availability period defined in the agreement (considering an availability period of 17 hours/day, from 7:00 to midnight).

- Temporarily replaced, for the same purpose, by any other available area on the same school or in any other equivalent infrastructure within a maximum
At the end of each school term each school will report to Parque Escolar on any spaces that have been unavailable and this will be used to calculate an abatement to the rent to be charged: this clearly gives Parque Escolar and its contractors an incentive to minimise the time that any space is unavailable.

This approach, which is based on a business plan and agreement, builds in boundaries for both parties and a long-term planning horizon in contrast to normal annual budget-setting, which is seen in Portugal (and elsewhere) as all too often leading to maintenance budgets that are inadequate for anything other than the most basic cosmetic measures. Although centralised and benefitting from the inherent advantages of such a regime in terms of expertise and economies of scale, the contact point for each agreement will provide personalised support. The model is in some regards analogous to Public-Private-Partnership (PPP) contracts elsewhere, where the cost of maintenance is built into an initial construction contract and covered ultimately by the state, which pays rent to a contracted company (OECD, 2008; PriceWaterhouse, 2008). The Portuguese authorities looked at a range of models such as the UK PPP as well as special purpose vehicles and state-owned companies set up in Catalonia and Valencia in Spain. Subsequently, they chose to develop their own centre which encompasses innovative practices with practical experience in the planning and delivery of major construction projects.

Those responsible for running schools will have a financial incentive to take care of their schools themselves and make fewer claims on Parque Escolar's services. If costs to Parque Escolar prove lower than expected, some of the savings are to be returned to the school for educational purposes. Schools will also be able to retain the proceeds from income-generating opportunities such as renting out spaces and teaching areas, sales from student shops and bars and merchandising. How valuable these contractual arrangements prove to be will depend on how well the school manages its relationship with its maintenance company and how sensibly it plans its required maintenance, for example, whether it looks to have one lamp replaced every week or several lamps once a month. Schools will also be responsible for rent even if they only 
partially occupy their buildings - like a normal leaseholder. They will be responsible for finding another use for buildings, for example, for the professional development of adults. This is clearly new to Portugal and gives schools a healthy start. Over time, Parque Escolar estimates that $7-10 \%$ of costs of the "investment" in construction/rehabilitation will be borne by alternative users. $50 \%$ of that will go to schools to cover additional caretaking and staff costs, and 50\% to Parque Escolar to cover a share of rental.

The approach to maintenance envisaged here has not yet been materially tested, since the SMP is at an early stage. The arrangements are clearly capable of evolving in the light of experience - though any significant change in the figures employed would clearly be destabilising and impair the inherently desirable disciplines imposed by the regime. The Review Team concluded that the arrangements should give schools better accommodation and a better callout service over the next 10 years. Beyond that, however, it is not clear that the EUR 175 million provision (7\% of the total SMP) built in for maintenance will prove sufficient. It is not a very large proportion of the value of a capital stock: it will not provide for the sort of replacement programme that a private company or individual would think necessary over
30 years. It assumes, in short, that the SMP has secured a once-in-a-generation transformation of the secondary school sector's building stock.

\subsubsection{Cost effectiveness}

The Review Team was clear that a major investment programme (of the kind embodied in the SMP) to transform the stock of secondary schools in Portugal is well justified. It believes that the arrangements for managing and implementing the SMP are appropriate, and indeed a potential model for international application. The efficiency of the process, and cost control of individual projects and the SMP as a whole, so far at least, seem admirable. It is, however, in the Review Team's view too early to be equally confident about the cost-effectiveness of the SMP:

- The quality of finish of the buildings observed is commendable, but the design may not always prove as flexible and encouraging of best 2 I st century innovative learning environments as might be expected today.

- The modernised schools are being planned to include appropriate spaces for the VET curriculum envisaged in each case locally; but that curriculum and the associated spaces and equipment may not cover the full needs for VET across each region, and may not always

Figure 3.6. Modernised classroom, Dom Dinis Secondary School, Lisbon

(C) Fotografia de Arquitectura / Fernando Guerra e Sérgio Guerra

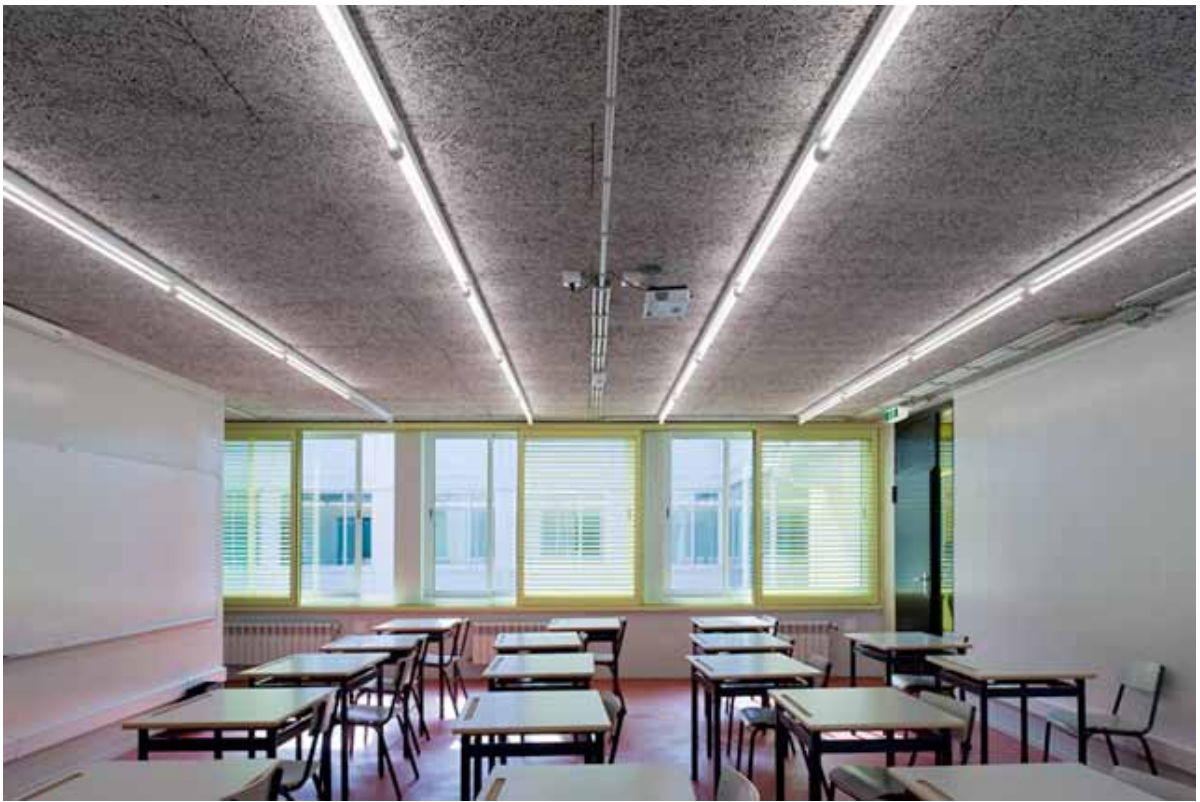

prove to be fit for purpose in a few years' time as demand for different specialism fluctuates.

- The space standards being applied (taking account of the amount of "dead space" inherent in many older building designs, even after modernisation) give flexibility of delivery and will be welcomed by professional staff, but within finite resources may be at the cost of other objectives.

- At a system level, the concentration of so much expenditure in such a short period of time means that opportunities are lost to have a more incremental sustainable approach that enables lessons to be learned from experience and applied to the next phase of schools a few years later: this is a "right first time" programme.

- Similarly the use of the resources available for those schools that have attracted priority allocations means that the remaining secondary schools may struggle to attract funding for their modernisation in a few years' time, as may schools for younger pupils and alternative forms of delivery of VET, which may be required for young adults.

\subsection{Quality, suitability and sufficiency of the modernised schools}

Parque Escolar is managing a very ambitious and complex programme of modernisation within a limited time frame, and with significant constraints, such as, remodelling schools while they are functioning. This creates a complex management problem for Parque Escolar and also the schools and the building contractors who have to work around them.

The SMP is both complex and wide-ranging in that it has to provide an individual solution for each of the selected schools, meet the qualitative aims of the SMP, as well as meet the constraints of both time and budget.

\subsection{Quality}

Judging by the schools visited by the Review Team during its visit, it was evident that Parque Escolar has succeeded in addressing many of these quality issues. It noted in particular the provision of:

- Improved physical comfort features (thermal, acoustic and visual). Each space has excellent acoustic ceilings, provision of audiovisual projectors, 
whiteboards, storage spaces, and adequate furniture.

- ICT throughout the school building: classrooms, laboratories, workshops, circulation spaces, libraries, etc; this will increase the quality of education, not only through the use of ICT, but also by allowing informal learning in every space, be it a circulation or a social space (Figures 3.2, 3.4 and 3.10).

- Flexible science laboratories, with one central preparation room for two laboratories. They allow for teaching different science subjects and enable a variety of different teaching and learning styles including teacher-directed learning, team work, small and individual learning (Figures 0.3, 3.I, 3.5 and 4.I).

- Good quality and functional furniture and equipment (Figures 2.5 and 3.6).

- Quality spaces for teachers, including teacher preparation areas closely linked to the learning areas and a communal staff room; these spaces are arranged with comfortable furniture for rest and study, and will facilitate the team work of teachers (Figure $\mathrm{BI}$ ).

Figure 3.7. Connecting existing teaching blocks, Soares dos Reis Arts School, Porto

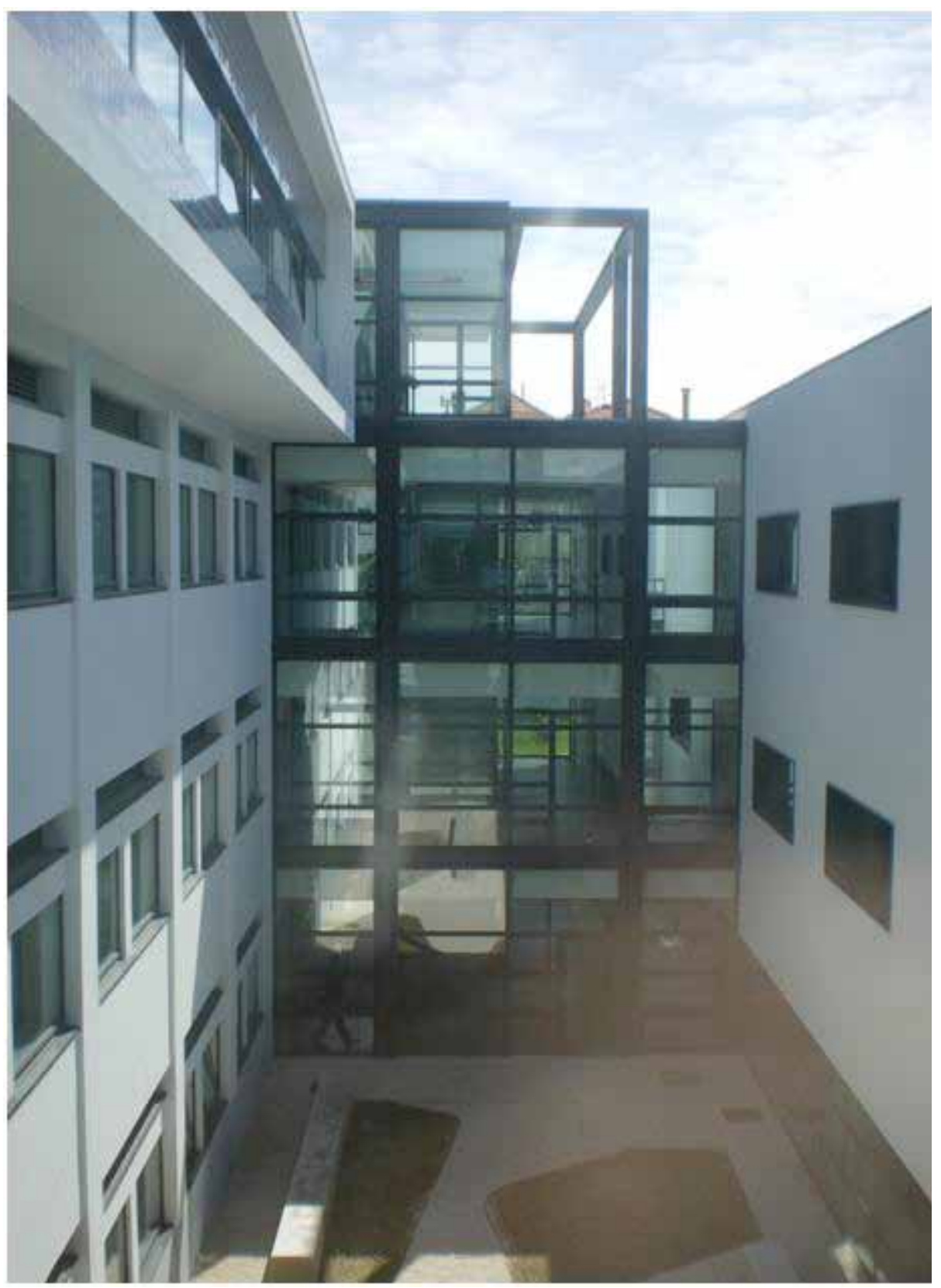

- High quality sanitary facilities, which help ensure appropriate hygiene.

- Attractive social spaces, cafeteria and dining areas for students. These spaces create a feeling of ownership and belonging and their use can be further extended, if located adjacent to the library/multimedia centre to facilitate informal learning by creating a learning street (Figures 0.I , 0.2, 3.3, 3.4, 3.10 and 4.4).

- Flexible and high-quality sport facilities which have been built or refurbished to a high quality with appropriate equipment and floor materials that can be easily replaced or repaired (Figures 4.2 and p. I5).

- Spaces for community use. Spaces - such as auditoria, sports facilities, social spaces and classrooms - are used by local communities. Some were being used for adult education evening classes (Figures 4.2 and 4.3).

- Visual connection between spaces. Classrooms, science laboratories, teachers' rooms have a visual contact with adjoining spaces; this eliminates the concept of the closed space, and it can be further developed for using adjoining circulation spaces for learning (Figures 3.7, 3.14 and 4.4).

- Access for physically handicapped persons, through lifts, ramps or adequately equipped staircases (Figure 2.7).

- Knowledge and memory spaces. These are museum collections in schools, which serve to provide a sense of local and world history (p. 53).

- Environmentally sustainable features such as photovoltaic panels and geothermal heating.

However, other opportunities to improve the quality of the physical learning environment could be explored:

- Well equipped libraries/multimedia centres backed up with good design guidelines, with community access also facilitating a feeling of ownership. However, some of those that the Review Team saw were small by international standards for the number of students using them. They were full of bookshelves and ICT equipment and did not link well with surrounding teaching spaces. This made them less suitable for independent or personalised learning.

- More shaded outdoor learning spaces. On several occasions groups of students were taking part in some form of learning activity, either formally or informally, 
but there were few suitable outdoor learning areas which they could use. Those which have been provided tend to be decorative landscaping rather than places for students to use for small group discussion.

- Greater variety in the size of, and connectivity between, educational spaces. While the architectural designs included in the documentation provided to the Review Team support the national curriculum, some are rather traditional in their concept. That is, they are linear buildings with closed boxes connected by a single or double loaded corridor. There is a lack of variety in the size of educational spaces to meet different teaching and learning situations. In several drawings, there was a lack of connection between multimedia and social spaces; new extensions do not always relate to the whole complex.

- More efficient use of spaces by learners and the community. The Review Team visited the Rodrigues de Freitas Secondary School in Porto, which includes a music conservatory (Figure 4.3). This school has a very complex educational programme and the quality of the new theatre/auditorium constitutes a benchmark for the surrounding community. Yet there are many possibilities for a more contemporary use of the premises, such as using the social

Figure 3.8. Outdoor learnng space, Gabriel Pereira Secondary School, Évora

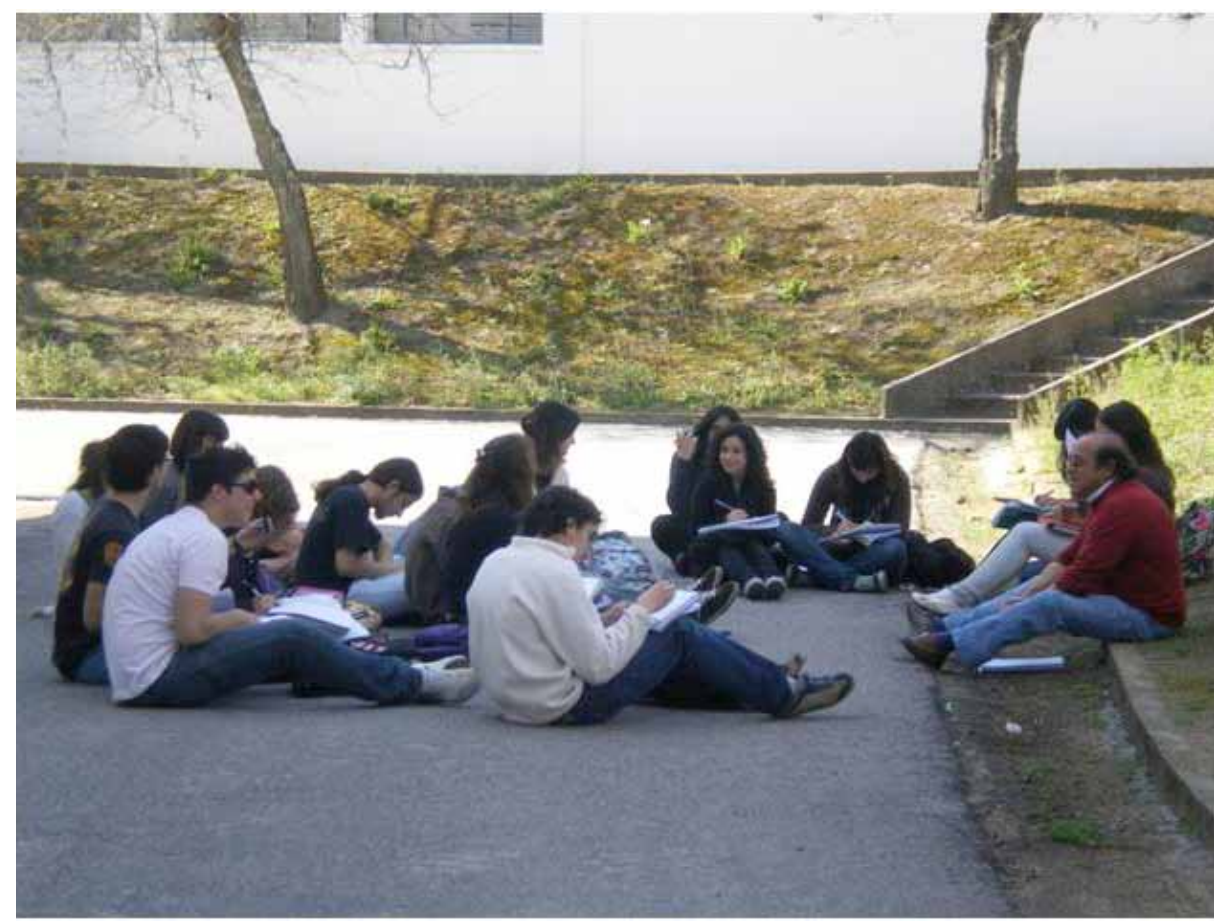

spaces for informal learning, extending the use of the library and making better use of the outdoor areas for learning etc.

\subsubsection{Organisation of the Design, Monitoring and Evaluation Unit at Parque Escolar}

On of Parque Escolar's key roles is to manage the process for developing the brief and programme for the building projects (Figure 3.9). Within Parque Escolar the Design, Monitoring and Evaluation (DME) unit co-ordinates design activities, monitors, evaluates and provides feedback for the following phases of the implementation of the SMP. It liaises with the architects and engineers from the different regional offices of Parque Escolar (North, Centre, Lisbon and South).

The DME process is at the core of the SMP, where education and architecture meet; where educational curricula, teaching methods and innovations need to be clearly translated into a "modernised" school (architecture) and where exemplary preliminary design should begin. After that, the activities for the design, tendering and construction of the refurbished schools can be undertaken with confidence.

The DME unit also works directly with external consultants in the fields of scibuilding to meet future needs as well as cater for present needs. It is at this stage where the "modernisation", in its educational/architectural meaning, really can take place.There is an advantage in bringing together teachers and other stakeholders in the school with the architect to analyse and explore alternative ways of meeting educational needs in different spatial configurations and to explore alternative schedules of accommodation.

In Annex A, the Review Team suggest how a workshop methodology can be used when a strategic plan is converted into a functional programme, to explore alternative schedules of accommodation and to stimulate the dialogue between educators about the pedagogical, social and local needs.

\subsubsection{Design guidelines}

Parque Escolar has assembled a set of design guidelines in a design manual which is given to architects. The manual sets out requirements of the design for the different aspects of a school, ranging from room layouts to technical guidance on 
Figure 3.9 The Design, Monitoring and Evaluation units at Parque Escolar and key responsibilities
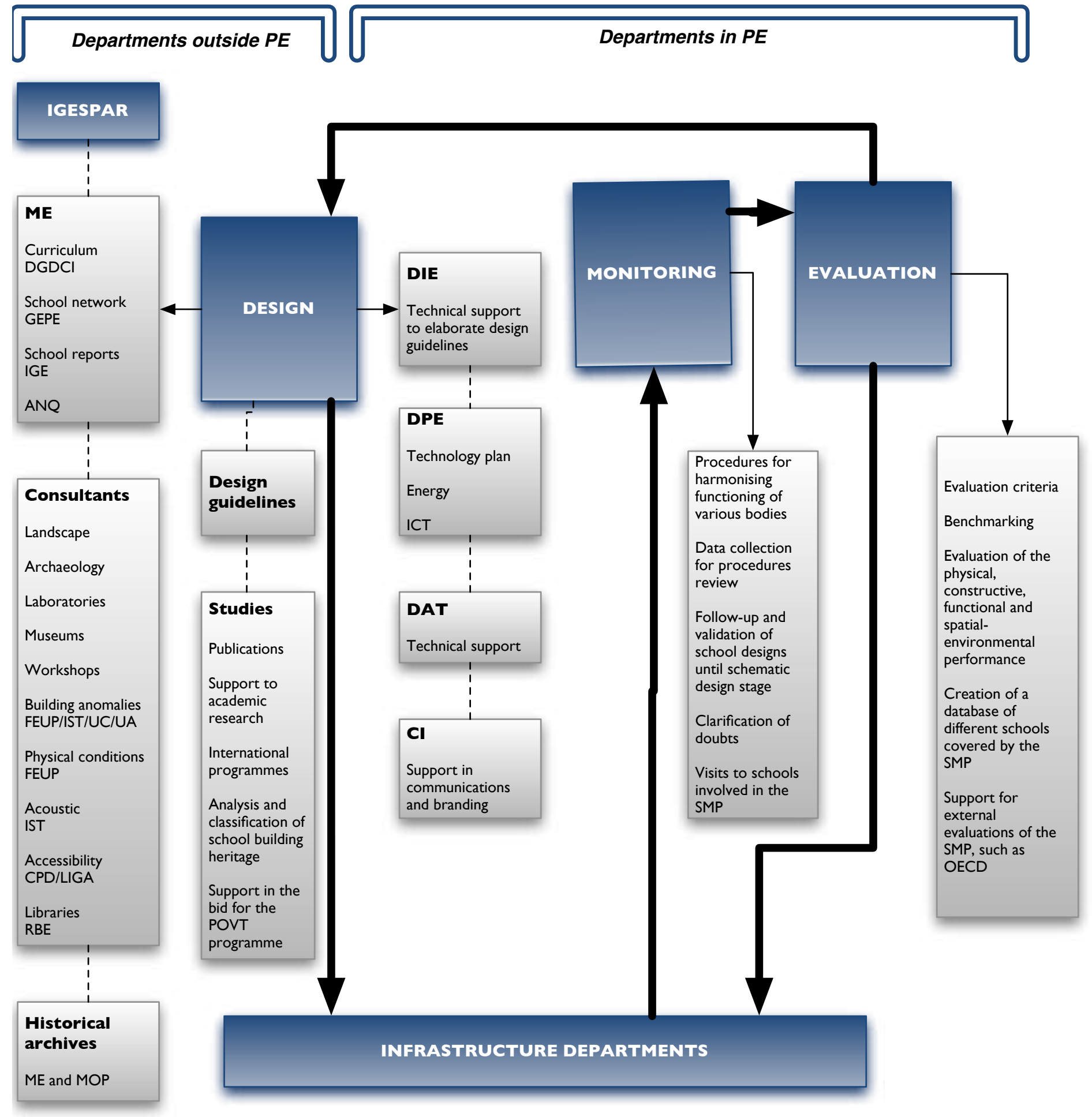

Source: Parque Escolar (2009) 
acoustics and lighting. The manual incorporates the outcomes of meetings with different consultants, such as those with the school libraries network, and the science laboratories consultants from the Faculty of Science and Technology of the Universidade Nova de Lisboa (UNL), as well as with acoustics and lighting experts.

The design manual is updated regularly based on feedback obtained from users, designers and specialist curriculum consultants.

At the time the Review Team saw it, the design manual included rigid diagrams expressed almost like floor plans. These could confuse the architects into thinking that the diagrams are a model that they should adopt, which does not encourage freedom and inspiration to develop innovative designs.

As Parque Escolar has to evaluate and provide feedback for the design of the next round of schools, in Annex A the Review Team have made suggestions as to how the design manual could be developed.

\subsubsection{Supporting the school once the building is completed and handed over}

Gathering together knowledge for developing the design for a building is important but it is also necessary to provide the users of buildings with the knowledge and understanding of how they can get the best out of their buildings. Users of buildings are left on their own to manage what can be complex issues, whether these relate to the technical systems or, more simply, how they might rearrange the furniture to make best use of the flexibility of the spaces. Even without significantly changing the design of the building, the activities of the school (teaching, learning, researching, discussing, etc.) may modify the use of school spaces by diversifying displays, grouping desks and tables, and diversifying or extending the use of other rooms such as laboratories, libraries, dining halls, outdoor spaces, etc.

Therefore, there are advantages in bringing together experience and knowledge to make it easier to use the buildings and, in particular, take advantage of the flexibility of the spaces. A supportive environment would promote the effective use of space and show how the building was designed.

The Review Team heard from the science laboratory specialist about the value of showing teaching staff how they could use laboratory spaces with different arrangements of furniture and how staff were receptive to the new teaching opportunities that this afforded.This type of individual advice is very valuable, and may be applicable to other specialist learning areas. The experience suggests that the SMP could benefit from ongoing training programmes for teachers and their support staff to provide them with opportunities to learn new techniques and benefit from the expertise of specialist consultants (see Recommendations: 4.I).

\subsubsection{Reviewing the buildings after hand-over}

Having invested significant resources and political capital in the SMP, some key questions must be asked. Does the SMP and do the buildings meet the anticipated needs? And how can the buildings continue to meet the needs of education during their lifetime? The answer to both questions suggests that some form of evaluation is needed.

Although Parque Escolar proposes to carry out evaluations of the schools in use, it appears to be geared towards maintenance. A broader systematic postoccupancy evaluation (POE) would be

Figure 3.1 O. Social space, Dom Dinis Secondary School, Lisbon

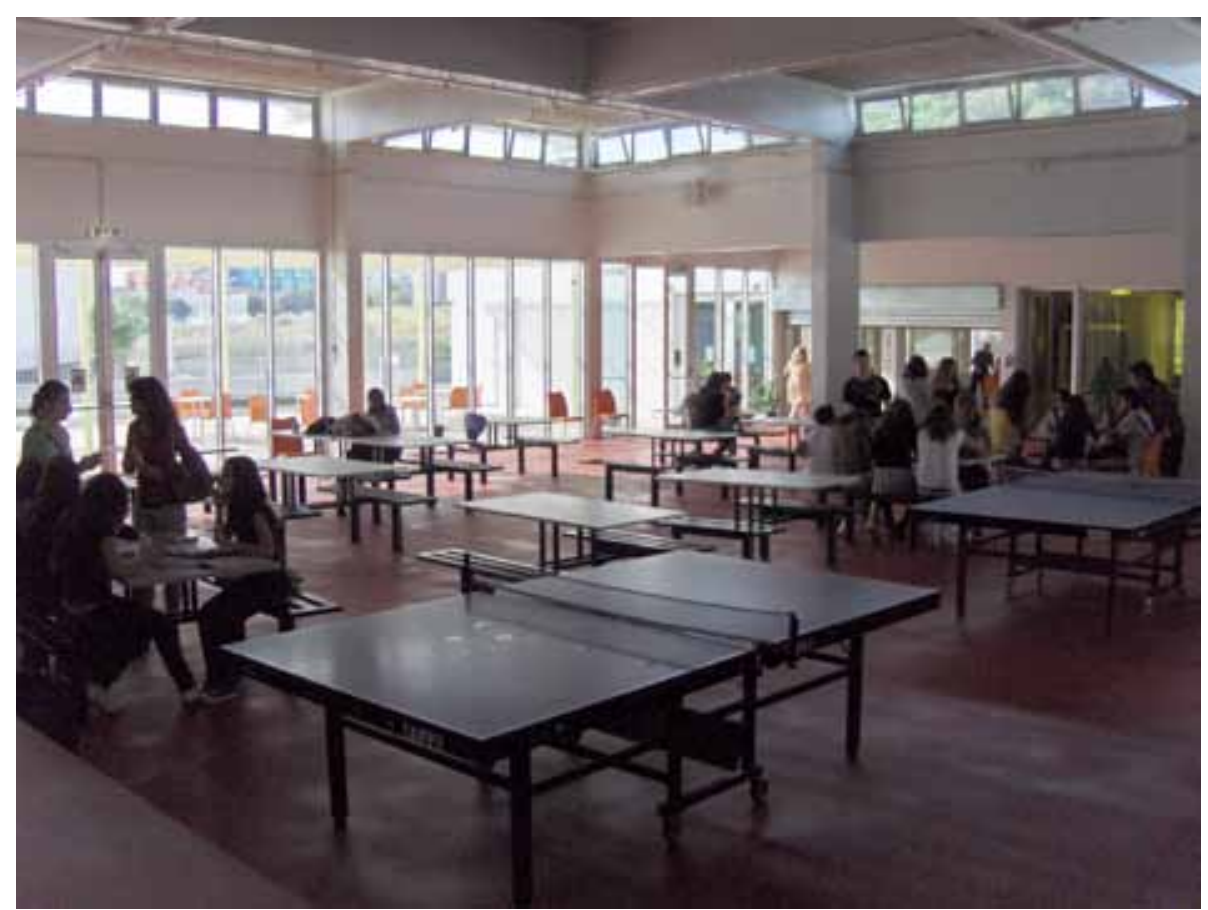


of conducting a review 12 months after completion, this should be done earlier (see Annex B4; Recommendations: 4.I)

\subsubsection{Learning from innovation}

One of the strong points of the SMP is that it incorporates pilot projects, which provide an opportunity to test the process for delivering the project, identifying issues with particular building types which may not be revealed until work starts on them. These include hidden structural defects, site problems arising from hazardous materials (e.g. asbestos), soil contamination from chemicals as well as exploring innovations. This information provides valuable feedback for subsequent projects. The SMP pilot projects have provided valuable insights and lessons learned for projects in the next phases.

Another strategy employed in the SMP is to try innovative approaches such as cooling buildings using geothermal systems, and photovoltaic and solar panels. These are being tested in some of the phase one projects to see how best to apply the techniques in later projects. Other countries are also using demonstration projects to test such innovations. ${ }^{3}$

The Review Team heard that a member of staff from one of the phase one pro-

Figure 3. I I. Facade, Soares dos Reis Arts School, Porto

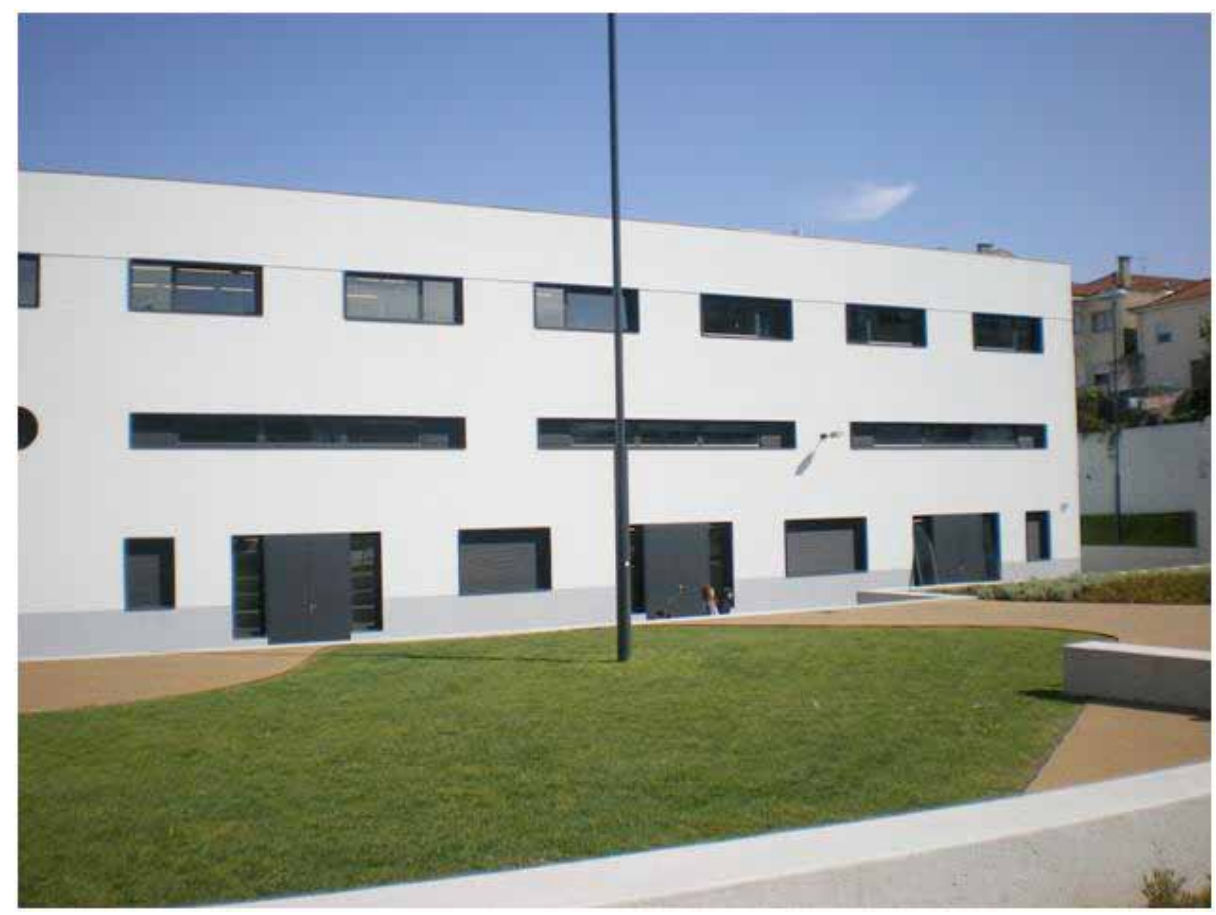

can be used by groups of students for informal learning. They also show how the library/multimedia centre can better connect to the social spaces. A further example of innovation, which shows the benefit of working with specialist consultants, was the research carried out on science laboratories (Figure 3.5). One model of laboratory was developed for different specialities such as physics, chemistry and biology by incorporating all the necessary installations (water, electricity, etc.) on the perimeter walls. This way, space is freed up, affording a variety of spatial arrangements, for example, for large- or medium-sized groups, or individual work. A central preparation room for two laboratories adds further flexibility, and the incorporation of a teaching/storage wall also constitutes innovation.

It is clear that a lot of valuable information has been collected and developed before and during the SMP. There would appear to be considerable scope for making this available more systematically, both to inform later phases of the SMP and to provide a resource for the medium and longer term.

\subsubsection{Regulation of construction in Portugal}

In Portugal, there are around 6I 000 construction firms that are regulated by the government through a public authority, the Construction and Real Estate Institute $(\operatorname{lnCl})$, which is responsible for issuing annual licenses to those carrying out construction and for supervising the firms. ${ }^{4}$

A firm requests a license that is appropriate for the category in which it wishes to work, and also appropriate for their speciality, experience and knowledge. The license has to be renewed annually.

Construction firms also have to show that they comply with a series of requirements concerning commercial fitness and economic, financial and technical capacity. This technical capacity is assessed by the presence on site of technical staff authorised to carry out this assessment.

In Portugal, construction may only be undertaken by Portuguese firms, or foreign firms if they have an office in Portugal and have a license issued by $\mathrm{InCl}$. Firms whose headquarters are in the EU may work in Portugal, as long as an equivalence is established by $\mathrm{InCl}$. 


\subsubsection{Construction}

Under the SMP, bids may be submitted by individual companies, if they are large enough, or by consortia. With relatively few contractors licensed to work on projects above EUR $16000000^{5}$, it was inevitable that many of the bids were submitted by consortia. For example, the construction costs alone on the groups of schools in Phase I were EUR 60330 000, EUR $52 \quad 500 \quad 000$, and just under EUR 52 million for groups I, 2 and 3 respectively. Only one construction company was large enough to carry out the work for one of the groups; for the other groups the consortia include four or more contractors.

For Phase 2, where the school groupings are smaller with two or three schools in each group, the costs in general range from approximately EUR 20 million to EUR 40 million. There are some contrac- tors large enough to carry out all the work for some groups, but many of the successful bids were from consortia of contractors.

The construction work for the government or public entities is carried out under contract and must be selected through a public procurement regime requested by the Code for Public Contracts. ${ }^{6}$

As in many other countries which have a similar code, the Code of Public Contracts provides a coherent framework in which the work can be carried out. On the one hand, it sets out clearly what each party has agreed to do, and on the other it provides mechanisms should there need to be changes or clarifications. It also specifies the procedure to follow should one or other of the parties not perform as they should.
The contractor tenders against a specification and a set of construction drawings; they are contractually bound to meet that figure although the contract does allow for variations should the design need to change or if there are errors or unexpected problems occur on site. The contract is administered by a supervisory body, which like the contractor is regulated. This body is engaged separately by Parque Escolar and also oversees the quality of construction. The Review Team understood that these arrangements are working well and that cost targets are being met. Parque Escolar also has its own project managers who monitor costs and expenditure and is responsible for authorising payments to the contractor.

A significant complicating factor in relation to projects such as those in the

Figure 3.I 2. New facilities (canteen, science laboratories and sports hall) constructed underneath the main building, Passos Manuel Secondary School, Lisbon

(C) Parque Escolar

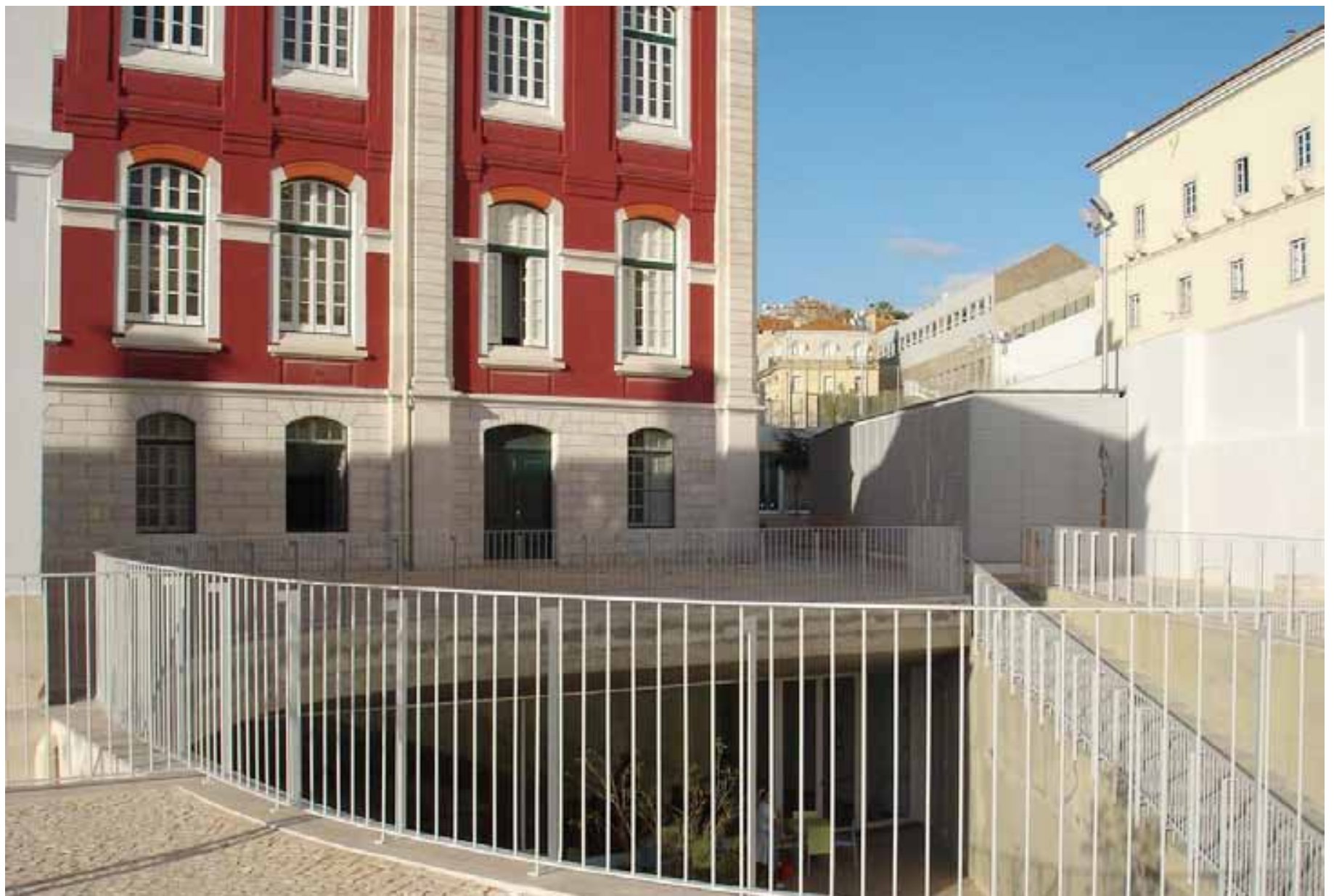


SMP is that, in general, construction takes place while the school is in operation. While as much work as possible is scheduled for when the school is not in use, this can be limited because of restrictions on working at night and at weekends, but also the only significant times available when schools are not being used are during vacations. This means that communication and co-ordination with the school is vital both to ensure that the work causes as little disruption as possible, but also to ensure that the areas of the building where work is planned can be co-ordinated with the school's timetable.

Inevitably, construction is disruptive - it is both noisy and dusty, and occasionally dangerous due to the type and extent of work being carried out on sites which are still carrying out their normal activities. However, the Review Team understood from its field visits that, overall, the schools had been able to function and that co-ordination with the schools was working well. Very few complaints were reported to the Review Team, and those that it did hear about were comments on isolated incidents. During its discussions, both teachers and students remarked how much they were willing to accept the disruption because the end result was worth waiting for. Several older students remarked that while they would not personally benefit, they believed that younger students would benefit in the longer term. In general, the time spent on site by the contractors was no more than a year. There is no practical alternative in as much as it would not be feasible to close a school completely during the construction period and move everyone to another location.

The Review Team did not assess the quality of construction, as this was not in its remit. However, as far as it could see, the supervisors and the Parque Escolar team were able to ensure that it met the standards they expected and that were set down in the specifications.

\subsection{Overall conclusions on organisation and design}

Parque Escolar should be commended for the way it has planned, organised and is implementing the SMP.

Teaching, administrative and management staff, parents, students and several unions all informed the Review Team that they were satisfied with the implementation of the SMP and with the results obtained where construction works have been finished.

Parque Escolar is working under difficult conditions as the schools being modernised, or in the process of entering into Phase 2, are all in use. It is stressful for the educational community to have to manage a school under

Figure 3. I 3. Renovated library facilities, Gabriel Pereira Secondary School, Évora

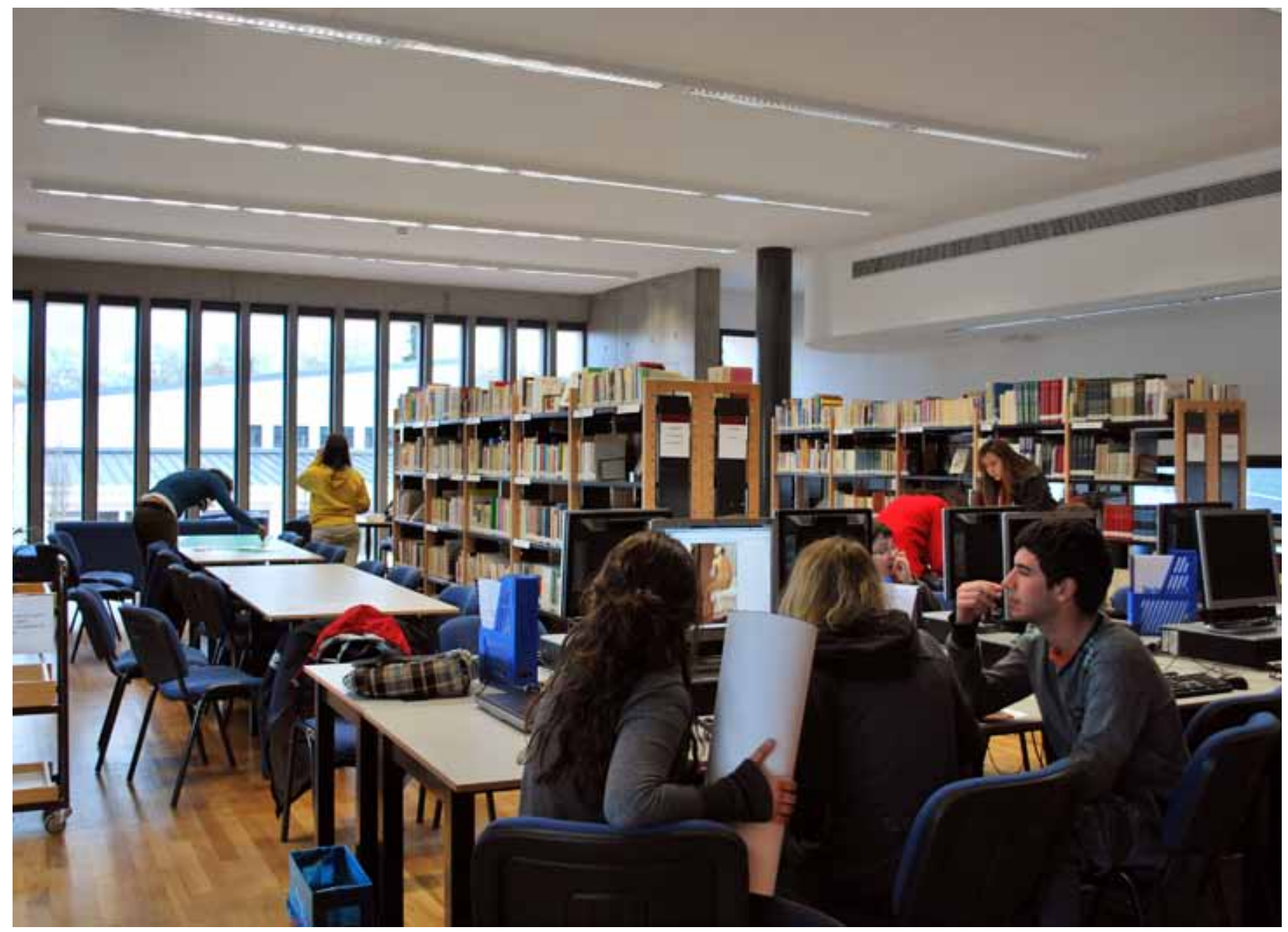


(re)construction, with the problems of noise, dust, disruption etc., as well as working in the building when it is being refurbished and in temporary prefabricated buildings (Figure 3.12). Architects and contractors also experience stress from the pressure to plan, design and construct the modernised schools in short timeframes and with tight budgets. Nonetheless, as noted in 4.3. I, the SMP appears to be meeting the deadlines with minimal delays.

This SMP is a unique opportunity for the government of Portugal, in conjunction with educators, architects and builders, to provide innovative facilities to their communities.

Parque Escolar is aware that a good architectural design improves the quality of education, and that architecture is itself an educational tool, expressed through form, space, volume and materials. Buildings are intended to consolidate and induce learning. This was clearly observed in the schools visited and by studying the document provided to the Review Team containing the preliminary design approach to some 108 schools.

Parque Escolar's efforts are also evident in the care it has taken to select designers and to maintain and promote its relations with numerous stakeholders involved.

When this complex programme has been completed, Parque Escolar will have gained invaluable experience in the planning, design, construction and maintenance of educational buildings. It can be expected that this experience will continue to serve Portugal's education system through programmes for different levels of education, all over the country. It will be able to provide information, training and advice to regional and local authorities, and, if necessary, implement other large educational/architectural modernisation programmes.
Figure 3.14. Linking interior spaces, Padre Alberto Neto Secondary Schools

(C) Joâo Morgado
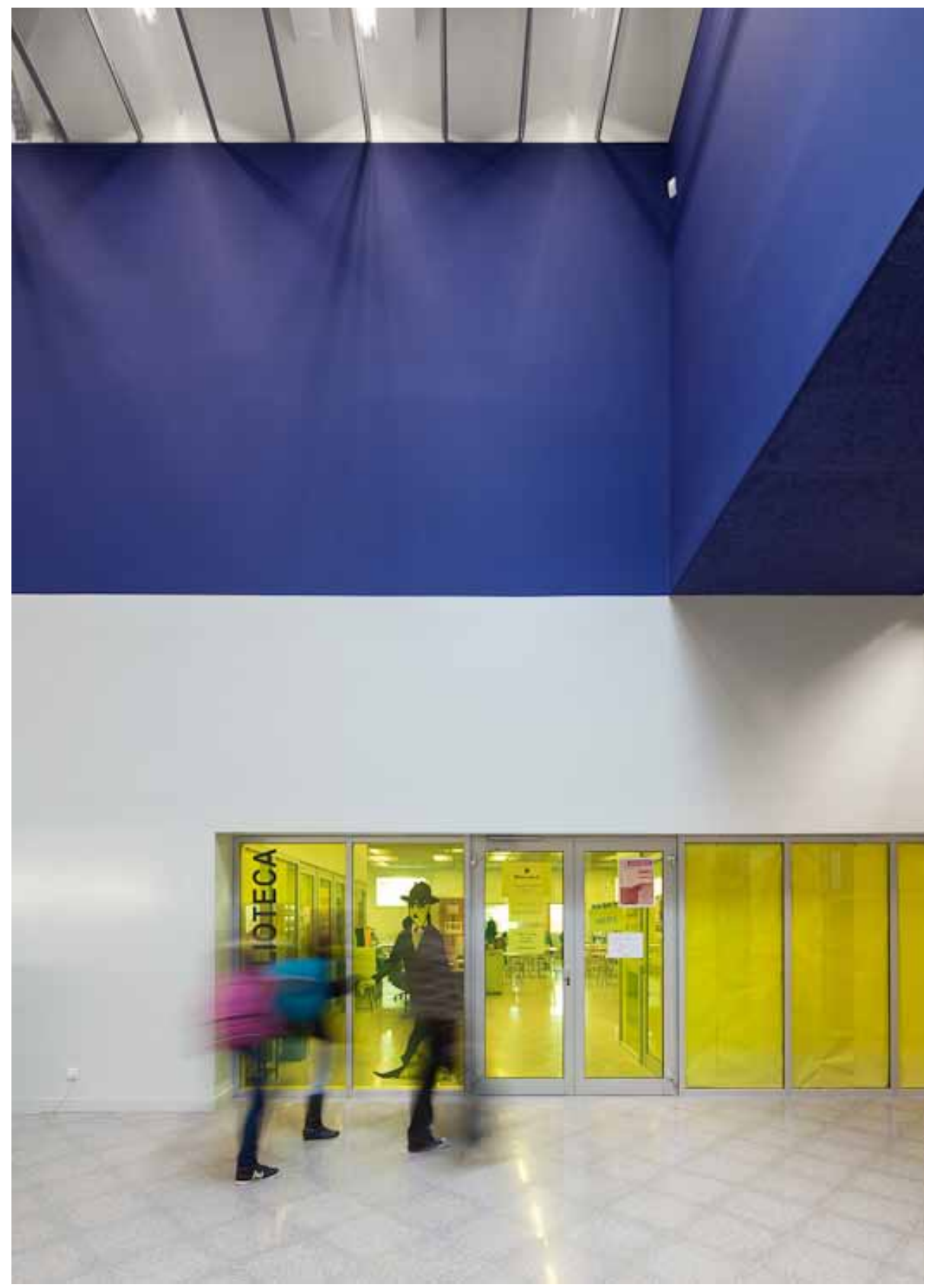


\section{Notes}

I. CELE Organising Framework on Evaluating Quality in Educational Spaces, www.oecd.org/edu/facilities/evaluatingquality.

2. For example, although the functional programme analysed in the Mouzinho da Silveira School indicates the number of spaces, it gives no indication of the floor area neither for individual spaces nor for the total school. However, the Review Team noted that this information is provided for some schools.

3. For example, the Movement 4 Innovation demonstration projects in the United Kingdom, where projects are cited as demonstration projects of innovative techniques. See: www.constructingexcellence.org.uk or the Council of Educational Facility Planners e-library CEFPIdea, www.cefpi.org.

4. The authorisations issued by $\mathrm{lnCl}$ are called Alvarás (contractors dealing) and are organised into 9 classes with 5 categories each and 54 subcategories of works: Ist Category: Buildings and built heritage; 2nd Category: Roads, Urbanisation works and other infrastructures; 3rd Category: Hydraulic works; 4th Category: Electric and Mechanical installations; 5th Category: Other works.

5. Of the 60900 firms, 24500 have an Alvará (licence) and the other 36400 have a Título de Registo (Title of registration) that only allows them to perform small works with a value of less than EUR 16600 . Of the firms with an Alvará, 84 can carry out projects with a value of more than EUR 16000000 - which is class 9 - and the rest are distributed between the remaining classes.Around 2I 200 firms (87\%) have licenses for classes I, 2 and 3 that only allow them to work on projects up to a value of EUR 660 000: frequently these firms will act as sub-contractors to larger firms.

6. Decree law no. 18/2009 of 29th July signed Directives No. 2004//7/CE and 2004//8/CE of 3 Ist of March into Law. 

In the light of the above analysis, this section sets out the conclusions and recommendations of the Review Team as regards the SMP and its future development. For convenience, these have been grouped in line with the main objectives of the Review:

- How effectively the programme addresses the physical quality of school buildings; the suitability of the facilities for current and future needs and whether there are sufficient spaces to meet the needs; and how stakeholders are engaged in the process.

- How the programme can better meet Portugal's strategic objectives for secondary education.

- Whether and how the overall programme should be rationalised.

- The governance structure of the programme and the relationship between Parque Escolar, national educational authorities, school institutions and other stakeholders.

- The funding mechanisms, levels of funding available, and the efficiency with which resources are used.

\section{I.The impact of the SMP on the} quality and suitability of school buildings

The SMP is strongly and effectively driven by Parque Escolar, which has sought to draw on international benchmarks and best practice in design and its processes. Parque Escolar is aware that good architectural design improves the quality of education, and that architecture is also an educational tool, expressed through form, space, volume and materials. It has set out to create buildings that consolidate and support effective learning. This was clearly observed in the schools visited, in the documentation provided to the Review Team, in Parque Escolar's attention to the selection of the designers and in its relationships with numerous local stakeholders involved.

The SMP is about to transform the physical quality of the vast majority of secondary schools in Portugal, and enure that they are suitable for a more practical, scientific and vocational curriculum and for changing educational needs. This is a challenging task however. It is made more difficult by the speed of implementation of the SMP, which has been determined for a variety of reasons related to the availability of finance, the state of the global economy and other factors exogenous to the needs of education services.
There are lessons to be learned from the UK experience, where $70 \%$ of the focus in the current Building Schools for the Future programme has reportedly been on timeliness, rather than on the quality and appropriateness of what is being built. The Review Team are clear that Parque Escolar should remain firmly focused on its mission to provide high quality school environments.

The processes entailed in the SMP that the Review Team has described above is generating considerable amounts of data that could be more systematically analysed and applied at every level - local, regional and national - to improve both the quality and cost effectiveness of subsequent phases of the SMP. However, several curriculum consultative groups and teachers reported that the design process was being rushed, that valuable opportunities for developing ideas were being overlooked or lost, and that the community was not given the opportunity to be fully involved in it.

To address these challenges and concerns within the constraints of the agreed timetable for the SMP the Review Team made the following recommendation:

RECOMMENDATION: A national consultative body should be set up to provide advice and feedback to Parque Escolar. Membership should be drawn from relevant parts of government, in particular the Ministry of Education,

Figure 4. I. New science laboratory, Gabriel Pereira Secondary School, Évora

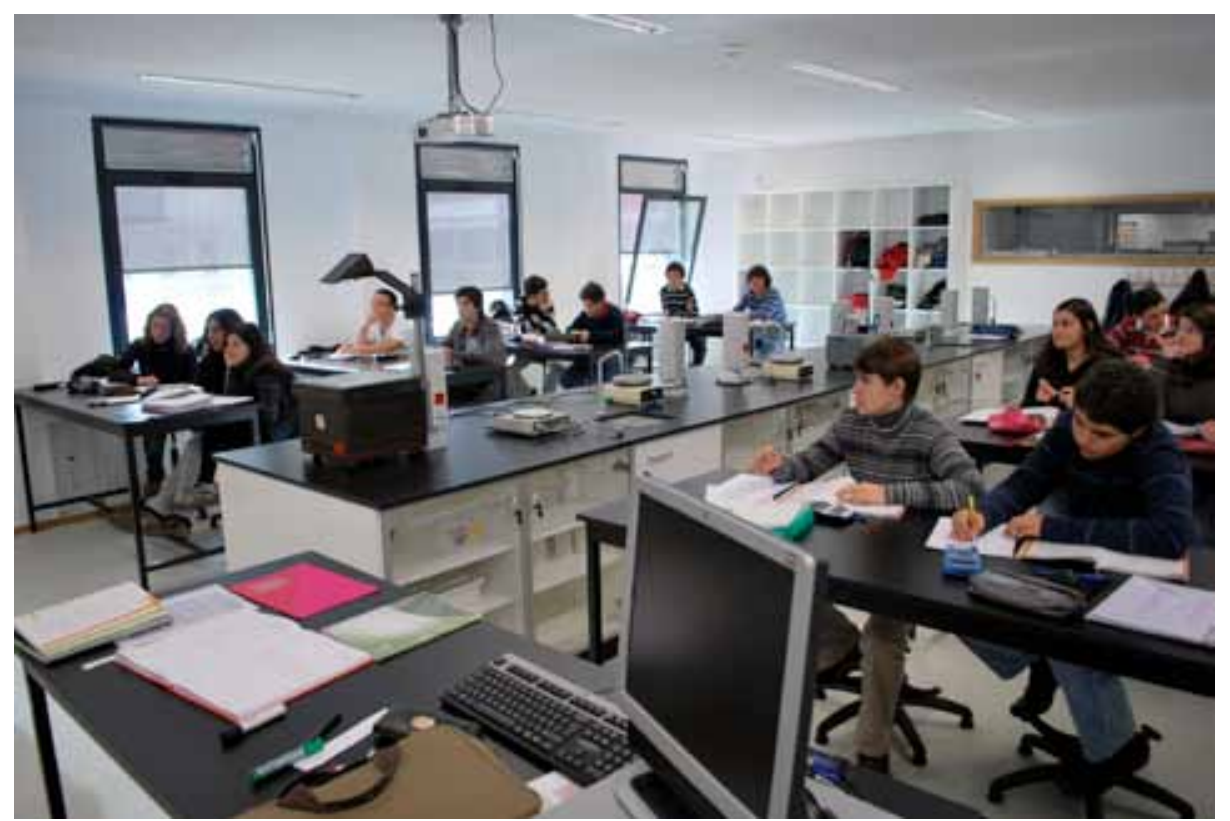

from the inspectorate and regional directors, and from key educational and economic stakeholders nationally.

This would create a platform for involving stakeholders and provide the opportunity to have regular communication about the programme and its progress. The consultative body should include those responsible for key education policies and developments nationally. Its remit should be to provide advice and information on relevant issues from their own field of expertise; and a forum for discussing the implications of policy changes on the facilities and how these might be tackled. In 3. I, the Review Team identified a particular issue in relation to possible regional specialist vocational facilities that would benefit from being discussed in such a forum. More generally, such a consultative body would provide a two-way channel of communication focused on the qualplore, along with the inspectorate and others, what the design of the buildings and the teaching spaces were intended to achieve, how they could support teaching and learning in the schools, and how this should impact on the work of the inspectorate (see 3.2.3).

Both to inform the deliberations of this advisory body and to provide direct support to Parque Escolar in its continuous improvement of the Programme, the Review Team made the following recommendations: ity of the physical learning environment. It would enable Parque Escolar to ex- 
RECOMMENDATION: A post-completion review should be carried out two or three months after completion of the construction of each school under the SMP, and again once the school has begun to use the new facilities and become familiar with them (see 3.4.6).Annex $A$ suggests how this might be done.

RECOMMENDATION: A series of research projects should be set up with universities or other research institutions to establish and record how the spaces in a structured sample of the schools are being used, as well as how well the physical environment supports those uses, and to study technical innovations and international best practice and their applicability across the SMP (see 3.4.7).

RECOMMENDATION: The best practice identified by the above processes should be reflected in a regularly updated web-based manual to guide future design proposals.

RECOMMENDATION: To support the school directors in managing their school buildings, Parque Escolar should act as facilitator by providing supporting guidance, technical documentation and advice and draw from the evaluations and research carried out into other schools within the SMP and wider (see 3.4.5).

RECOMMENDATION: Parque Escolar should create a specialised Technical documentation centre, with publications, documentation, photographs, etc, that can serve Parque Escolar staff, school principals and architects, as well as other stakeholders (see 3.4.8).

This type of technical documentation centre would bring together in one place material of benefit to school directors, architects as well as Parque Escolar staff. The centre could be set up electronically with a website on which this information is made available. For example, the UK website www.teachernet.gov.uk devotes one section to school building design and resources. The content of this may serve as a model for Parque Escolar to begin developing its own site. The key will be to develop a site that is simple to set up and straightforward to use.

A key part of the strategy under the SMP should be to promote the effective use of space and to help teachers and staff in schools to get the best out of their buildings (see 3.4.6). To this end, the Review Team made the following recommendations:

\section{RECOMMENDATION: Parque Escolar} should develop use and management guidelines for schools, which can be handed to the school once the building project has been completed. Further to that, there should be regular and ongoing training and familiarisation sessions for teachers and their support staff that cover both the use of the teaching spaces and the equipment, to provide them with opportunities for learning new techniques and benefitting from the expertise of specialist consultants.

RECOMMENDATION: A two to threeday training programme and operational workshops on educational buildings planning, design maintenance and use should be organised for key staff at Parque Escolar and for the school principal, senior staff and architect of each school covered by the SMP, preferably at the stage of preparing the functional programme and preliminary design.

\subsection{Meeting Portugal's strategic objectives for secondary education}

The SMP is intent on meeting the government's key objectives for secondary education. In particular:

- Demand forecasts used by Parque Escolar to determine the design of each school in the SMP, combined with space standards that have some room to manoeuvre in relation to international standards, seem to ensure - according to current trends - that the stock of schools is sufficient for the foreseeable future.

- At the local level, the consultative process within the SMP already aims to develop and construct well designedbuildings that meet the changing needs of teachers and students. It seems likely to produce a stock of schools that are "fit for purpose": the remodelled schools should support national curriculum policies such as the introduction of ICT on a large scale, and the development of new, more personalised and laboratory-based teaching methods for individual teachers.

- The SMP is intent on securing the provision of 2 lst century practical laboratory and workshop facilities in all secondary schools (Figure 28). There may, however, be issues as regards the capacity of the remodelled secondary schools to meet all the specialist

Figure 4.2. Sports pavillion, Rodrigues de Freitas Secondary School, Porto

(C) Francisco Piqueiro / FotoEngenho

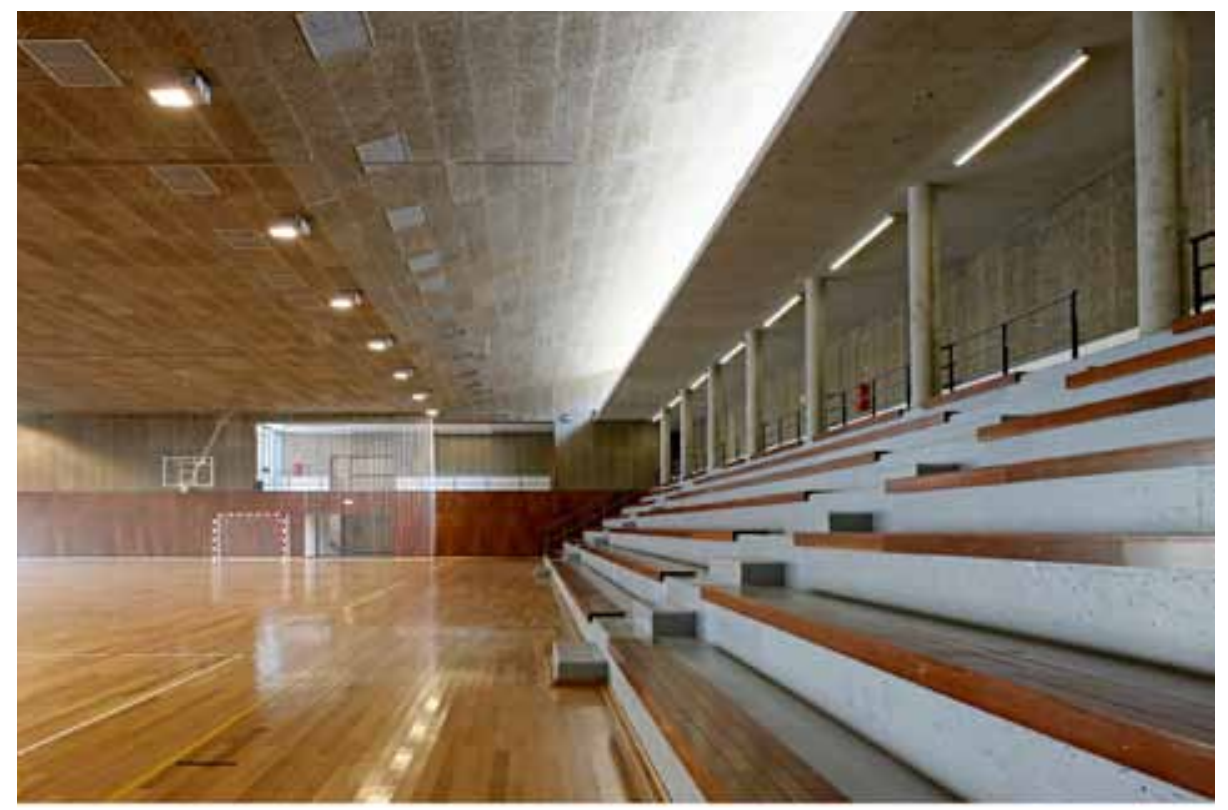


education and training needs of young people that elsewhere (e.g. in Australia, UK or many north European countries) would be met in larger scale and more employer-focused specialist facilities. The remodelled schools furthermore may not have the flexibility to cope with changes in specialist sectoral or subject demand over time.

The recommendations in 4.1 above should support not only improvements in quality but also the achievement of the government's wider objectives for secondary education. To complement these and strengthen the existing arrangements, the Review Team made the following recommendations:

RECOMMENDATION: The impact on demand and outcomes of the new vocational provision for 15-18 year olds in secondary schools should be monitored, taking account both of changing labour market requirements and the impact of the raising of the school leaving age; and, if there is evidence of gaps or failures to meet demand, options are considered for the development of more specialist vocational provision related to the emerging needs of economic sectors serving a local area or cluster of schools.

RECOMMENDATION: In particular, arrangements should be considered whereby in each region particular secondary schools are designated as the specialist vocational centres for particular subjects or industrial sectors, with strong links with relevant enterprises in the region.

\subsection{Options for rationalising the SMP}

The SMP has been managed as a separate, high profile initiative. Parque Escolar has had a major impact and, taking advantage of its independent status, achieved a considerable amount in a short time. It is unlikely that less focused arrangements could have had anything like the same success. As a specialist centre of expertise it has been proactive, innovative, agile and able to anticipate or respond quickly to situations, as appropriate. It benefits from consolidated expertise; it is highly focused and results driven, able to secure the financing needed and co-ordinate the work to ensure timely, safe and effective delivery and ensure the government's key objectives are met. However, the very strengths of such independence are also a potential weakness. As a result, as discussed in 5.1 and 5.2, there are issues in relation to links with other policies and programmes and engagement with other bodies and stakeholders. The Review Team has recommended measures to address these issues. Nevertheless, the SMP's scale and importance justifies and supports the separate infrastructure created to manage it, and so long as the active period of construction is underway, there does not seem to be any need to change the management arrangements rather the contrary. In future, there will be issues to address that will require research, financial analysis and political decisions.

Perhaps other ways should be considered for managing repairs and maintenance for the remodelled stock. It would seem sensible, in principle, to align such arrangements to those applying to secondary and other schools more generally. What options are open for consideration will depend in part on what progress has been made in the meantime towards greater delegation of budgetary and management responsibilities to schools, the financial situation and whether economies of scale can be achieved. Also, is there any benefit to us-

Figure 4.3. Conservatory/auditorium, Rodrigues de Freitas Secondary School, Porto (C) Francisco Piqueiro / FotoEngenho

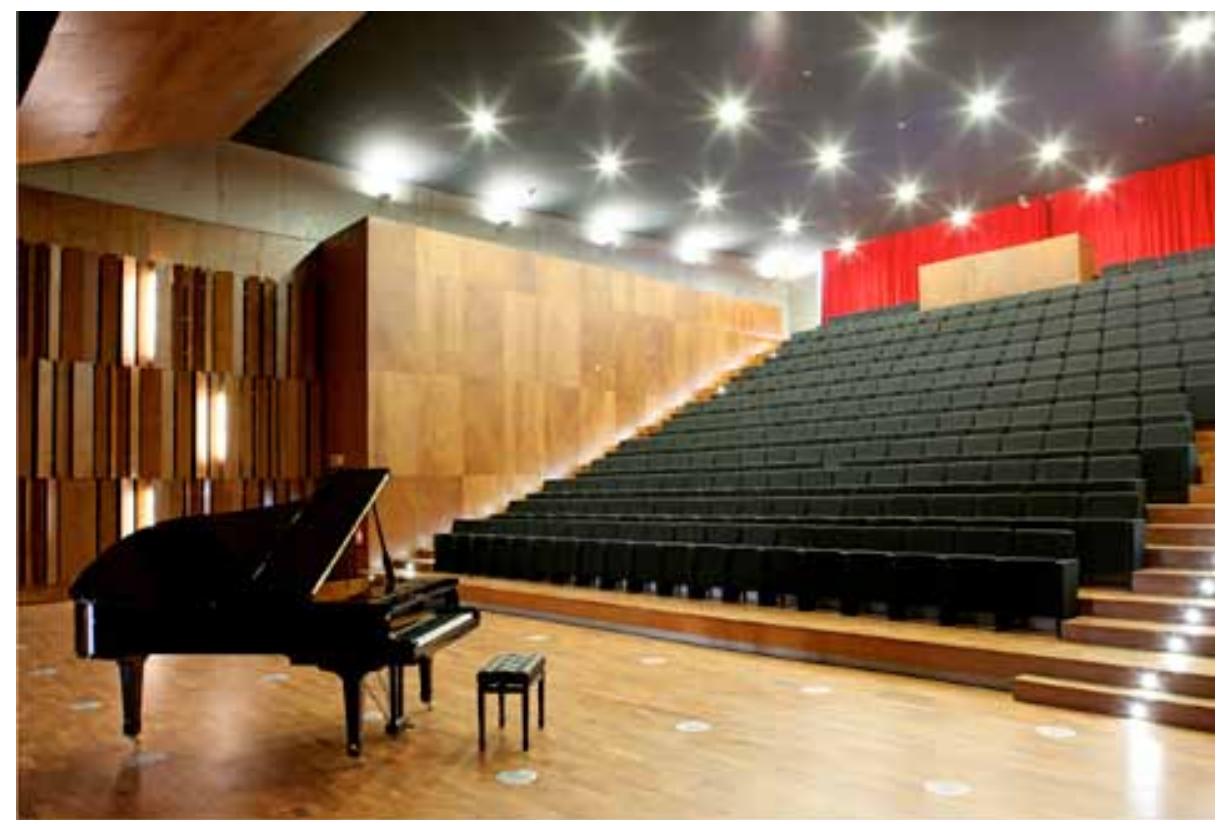

ing specialists who can collect data from individual schools and collate it across the system, and is the best use being made of school administrative staff. Consideration should also be given to the possibility that Parque Escolar might evolve from its current role as a body specialising in project planning, contract management and delivery to a specialist infrastructure management unit with responsibility for research, negotiating financial arrangements, contracting and co-ordination. The Review Team made the following recommendations:

RECOMMENDATION: The role of Parque Escolar in leading the SMP should be strengthened in the ways suggested in 4.1 and 4.2 above.

RECOMMENDATION: In the longer term, consideration should be given to how that role might best evolve, taking account of the expertise Parque Escolar has developed and the desirability in principle of aligning responsibility for repairs, maintenance and the future development of facilities with responsibility for the schools themselves. 


\subsection{Governance and relationships}

Parque Escolar was established as a special purpose state-owned company with specific responsibility for planning and delivery of the SMP. This has been a major, if not the crucial, factor in its success to date. The model developed has drawn on international practice in other countries where economic stimulus programmes and public-private-partnership (PPP) programmes are being run; but it has also drawn on Portugal's own traditions and its analysis of what combination of public and private sector best practice is most likely to work. The resulting body is well organised, and carefully managed by people with appropriate expertise in architecture, engineering, finance and project management. It has succeeded impressively to date. It may serve as a model for international application (see 3.2.1).

At the national level, however, communication and information between Parque Escolar and the Ministry of Education and other educational stakeholders as regards the design features and content of the SMP has been at best limited (see 3.2.3). Parque Escolar was established as an agency to implement an ambitious school building modernisation programme efficiently and in a short period. In many OECD member countries, government agencies have been established to bypass traditional ministries that struggle with all sorts of cumbersome regulations and bureaucratic procedures. Parque Escolar is no exception. And as elsewhere, Parque Escolar has sought expert advice from people outside the ministry of education: university professors, library experts, ICT experts, etc.

Yet, greater involvement of the ministry and the inspectorate is crucial for at least two reasons: there needs to be commitment from important policymakers to the programme and use can be made of their expertise and competencies in curriculum development, innovation strategies, initial teacher training, especially in an education and training system as centralised in Portugal. Their ideas on teaching and learning in the 21 st century may well provide a substantive input into school building programmes. Educational facilities should be intimately linked to educational policies.

At the local level, the picture is completely different. All local-level stakeholders praised the way and the intensity with which Parque Escolar interacted with them through information sessions and consultation meetings, before and during the building process. Meetings were held with parents, teachers, students, school boards and non-teaching staff during which architects, engineers and Parque Escolar staff presented plans and asked for input. Local stakeholders were pleased with the output of these meetings, and felt they had an impact on the plans and the process. The Review Team made the following recommendations:

RECOMMENDATION: No change should be made to the governance arrangements for Parque Escolar or the SMP.

RECOMMENDATION: Parque Escolar should, however, make full use of the national consultative body mentioned in 4.1 to involve national stakeholders more effectively via regular communication about the SMP, draw on advice from a wide body of informed opinion, and create a broader sense of ownership of the SMP.

RECOMMENDATION: Parque Escolar should hold regular meetings and implement the other measures recommended in 4.I to keep key stakeholders informed of its successes and obstacles and ask for their expert input.

Figure 4.4. Learning Street, Soares Dos Reis Arts School, Porto

(c) Francisco Piqueiro / FotoEngenho

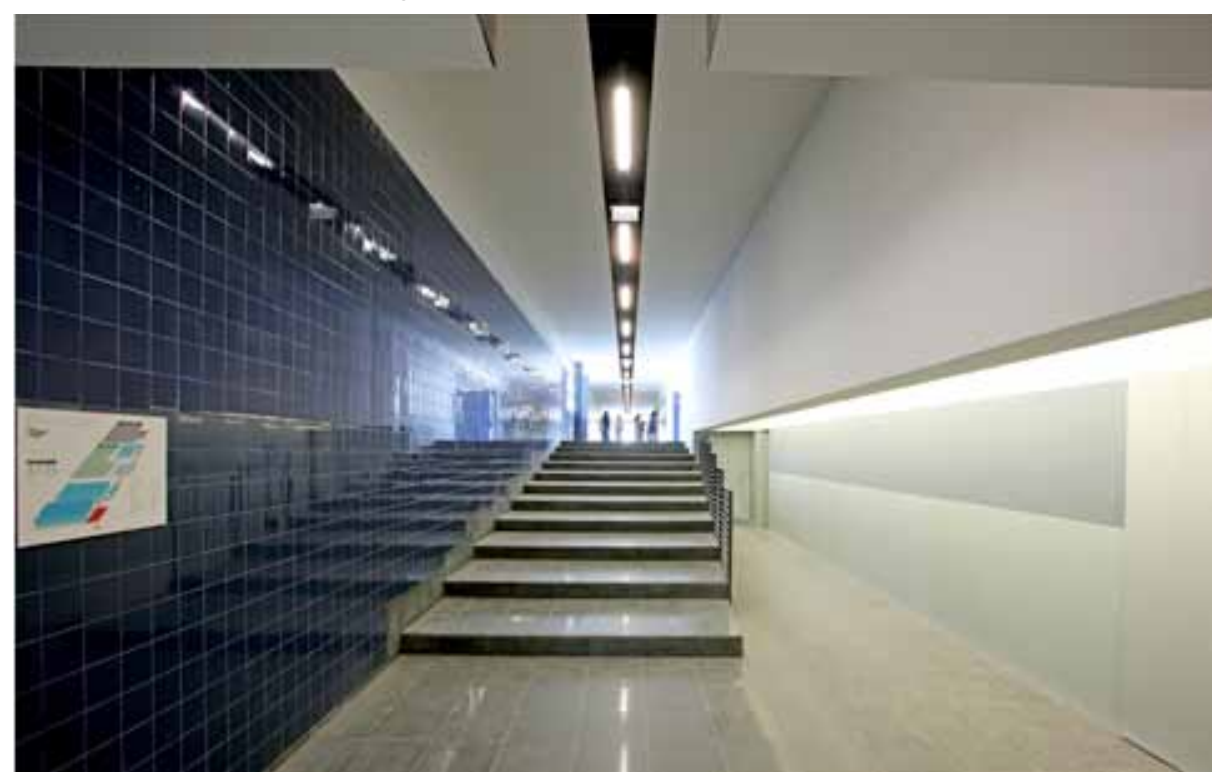


The inclusion within the SMP of sums to provide for the repair and maintenance of the 332 schools is an admirable - and possibly unique - feature of the SMP. It is a potential model for international application. It is not clear, however, that the sums set aside ( $7 \%$ of the total programme) will be sufficient for the purpose - certainly not if they are to include provision for updating and re-equipping the schools between now and 2037 in line with the requirements for the changing curriculum, pedagogy and learning styles (see 3.3.3). The Review Team made the following recommendations:

RECOMMENDATION: The Portuguese Government should draw on the experience of the SMP in determining the funding levels appropriate to the refurbishment of other elements of the stock of education buildings in Portugal.

RECOMMENDATION: The sums set aside for repairs, maintenance and the future updating of the secondary school stock are kept under review over the years ahead (see 3.3.3).

\subsubsection{Funding mechanisms}

Funding for the SMP has come from an innovative mixture of grants (EU Structural Funds and the Portuguese Exchequer) and loans (long-term loans from the European Investment Bank, Council of Europe Development Bank and Commercial Banks) (see 3.4.I). Their negotiation has required political commitment, professional expertise, and timely application (see 3.3.2). The SMP has been considered a political priority at a time when Portugal's circumstanecs in relation to the EU and the world recession have given the Portuguese Government a dual incentive to press forward with its intervention programme. Those concerned are to be congratulated on having secured so large an injection of funding into the secondary school system (see 3.3.3).

Another initiative is the development of the regime providing ongoing maintenance of schools after their remodelling. There are, however, questions as to the robustness of these arrangements over the long term (see 3.3.3). The Review Team made the following recommendation:
RECOMMENDATION: The contractual maintenance arrangements, and levels of finance set aside under them for continuing repairs and improvement, should be kept under review over the years ahead and adapted if it makes sense to align responsibilities in due course with new models of service delivery based on independent international and local research (see 3.3.3).

\subsubsection{Efficiency and effectiveness}

Parque Escolar is responsible for the whole SMP process. It operates at a system-wide level and in relation to each individual school; it oversees overall planning, including initial design, contracting and maintenance of the completed buildings. So far, it seems that the SMP is on course to achieve the planned impressive rate of delivery. Delays to individual projects have been no more than a few weeks (see 3.3.I). Despite some concerns expressed above as to the consultation process, the design and flexibility of the re-

Figure 4.5. Library after renovation, Passos Manuel Secondary School, Lisbon

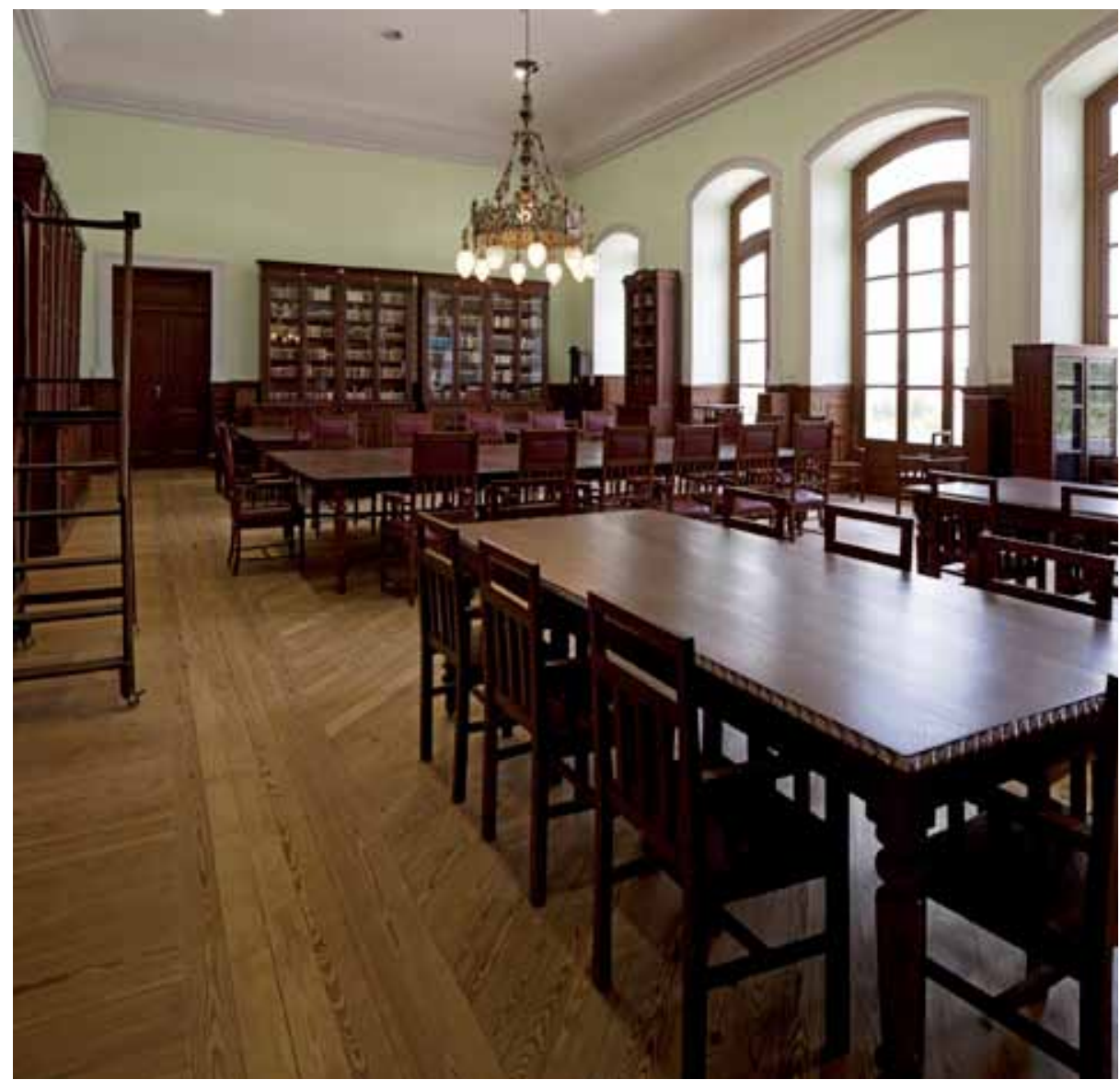


- The modernised schools will critically include appropriate spaces for the VET curriculum envisaged in each case locally, but the specialist spaces may not always prove to be fit for purpose in a few years' time as demand for different specialisations fluctuates.

- The space standards being applied give flexibility of delivery, but within finite resources may be at the cost of other objectives. The additional costs are not only short-term: schools could face unnecessarily high energy and cleaning bills for many years to come. Perhaps even more importantly the application of the sort of approach to determining space requirements and environmental standards illustrated in Annex A could yield not insignificant capital savings.
- At the system level, the use of the resources available for the 332 secondary schools that were given priority means that the remaining secondary schools may struggle to attract funding for their modernisation in future years. This is also the case for the much larger number of schools for younger pupils, and alternative forms of delivery of VET, which may be needed for young adults, who are now required to stay on in compulsory education up to the age of 18. The Review Team made the following recommendation:

RECOMMENDATION: Parque Escolar together with the Portuguese Government should look to use the monitoring, evaluative and consultative processes advocated in 4.I-4.4 above to inform swift adaptation and refinement of the SMP as it proceeds phase by phase, and more generally to ameliorate the effects of concentrating so large an investment programme into so short a space of time.

RECOMMENDATION: To support efforts to improve the cost effectiveness of the SMP, Parque Escolar should consider adopting a different approach to calculating the spaces required for the remodelled schools. An approach developed by UNESCO and applied effectively elsewhere is illustrated in Annex A.

Figure 4.6. Front entrance, Agrupamento de Escolas D. Filipa Lencastre, Lisbon

(c) Nuno Pires / Luis Calixto

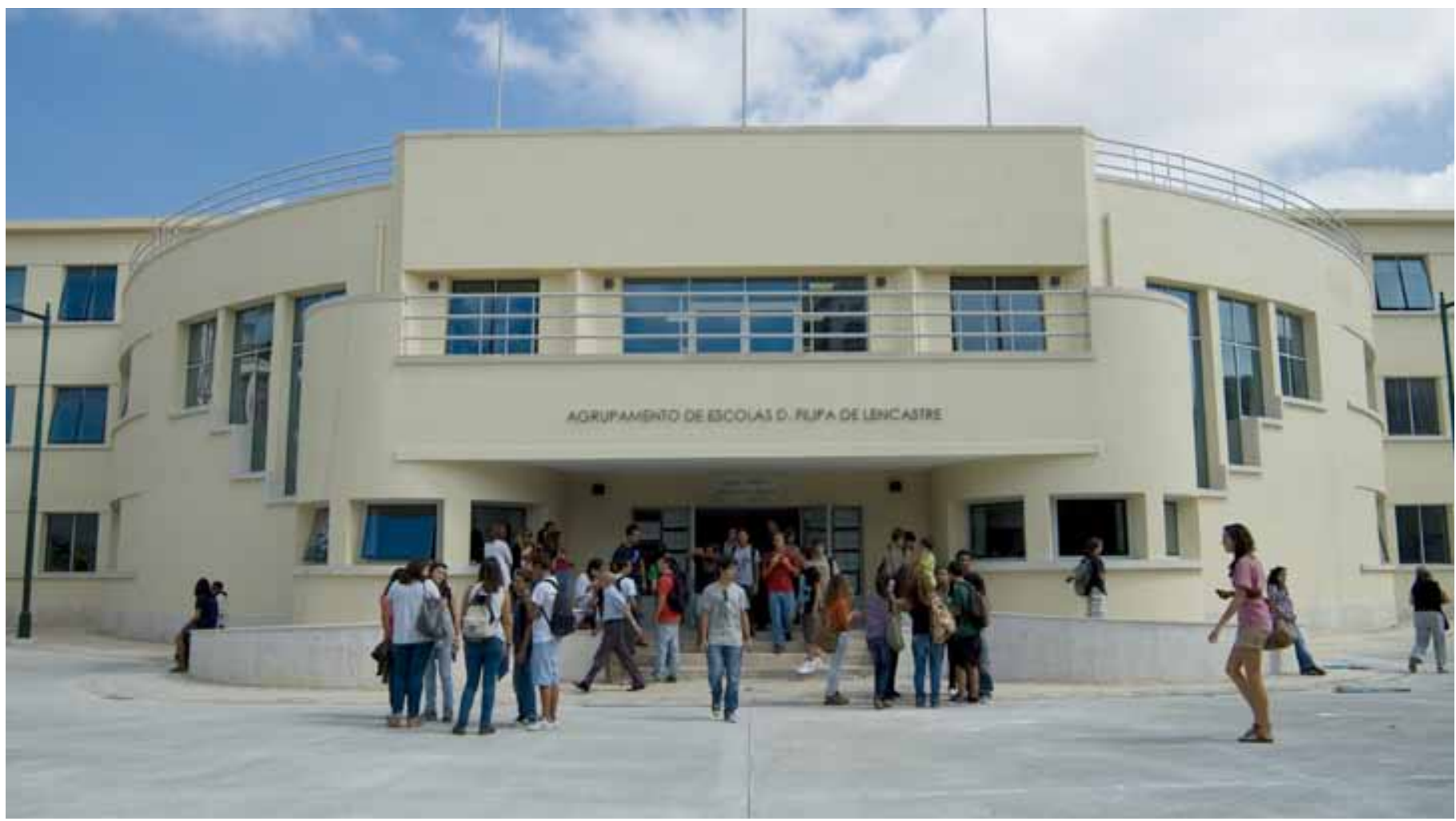



BER (Building Research Establishment) (1986), Estimating Daylight in Buildings, BRE Digests DG309 and 310.

CABE (Commission for Architecture and the Built Environment) (2007), Creating Excellent Secondary Schools: A Guide for Clients, CABE, London.

Capucha, L. (2009), Briefing Inciativa Novas Oportunidades - Eixo Adultos, ANQ, 30 June 2009; SIGO provisional data at 30 June 2009, Agência Nacional para a Qualificação.

Cherry, E. (1999), Programming for Design: From Theory to Practice, New York, Wiley.

Council of Ministers (2007), Resolution of the Council of Ministers No I/2007, Council of Ministers, Portugal.

Eurydice (2009), The Education System in Portugal, Eurydice.

Fisher, K. (2000), “Making Better Use of School Buildings: Schools as Social Capital”, in OECD (2000), The Appraisal of Investments in Educational Facilities, OECD, Paris.

Littlefair, P.J. (1988), Average Daylighting Factor:A Simple Basis for Daylight Design, BRE Information Paper IPI5/88.

Ministry of Education, Portugal (2007a), Estatísticas de Educação 2006-2007, Gabinete de Estatística e Planeamento da Educação, Ministério da Educação, Lisbon

Ministry of Education, Portugal (2007), Decree-Law No 4I/2007.

Ministry of Education, Portugal (2009), School Network: Redevelopment and Rehabilitation, Ministry of Education, Portugal.

OJEU (2004), Directive 2004/I8/EC of the European Parliament and of the Council, On the co-ordination of procedures for the award of public works contracts, public supply contracts and public service contracts, Official Journal of the European Union.

OECD (Organisation for Economic Co-operation and Development) (200I), Knowledge and Skills for Life: First Results from PISA 2000 , OECD, Paris.

OECD (2004), Learning from Tomorrow's World: First Results from PISA 2003, OECD, Paris.

OECD (2007), Science Competencies for Tomorrow's World, OECD, Paris.

OECD (2008), Public-Private Partnerships: In Pursuit of Risk-sharing and Value for Money, OECD, Paris.

Parque Escolar (2009), OECD Programme Review: Background Information Secondary Schools Modernisation in Portugal, Parque Escolar, May 2009,.

Preiser,W. (1995), “Post-occupancy Evaluation: How to Make Buildings Work Better”, Facilities, I3(I I), Pp. 19-28.

PriceWaterhouse (2008), Evaluation of Building Schools for the Future - 2nd Annual Report, DCSF, London. 
(1).
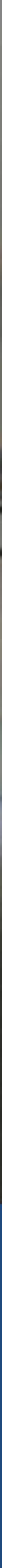


\section{Developing the functional programme}

It is at the stage of developing the functional programme that the "modernisation", in its educational/architectural meaning, really can take place.

Architectural programming of educational spaces, which is "the research and decision-making process that defines the problem to be solved by design" (Cherry, 1999), is crucial due to the different factors that affect the conception and the design of the schools included in the SMP. For example, it has to take account of new pedagogical requirements, educational innovation, more active participation by students and the impact of ICT. All of these factors affect how space is used in schools, often resulting in new types of space such as small group meeting spaces, as well as different relationships between spaces. One example is the new role of the multimedia centre (library/resource centre), which becomes the heart of the school. It needs to be located near the social/dining spaces so as to facilitate the learning street (informal learning, individual work, small group work) referred to in the design guidelines.

UNESCO's methodology is used to calculate the type, number and utilisation rate of spaces, and is an example of an approach that could be used at this stage.
Using this methodology, it is possible to analyse different approaches to providing educational spaces, to identify the most appropriate solution and the define the number, type of spaces to be provided, as well as the utilisation rate, in a joint dialogue between the school community and the designer.

It could also help to stimulate dialogue between educators and architects when defining pedagogical, social and local needs (strategic plan and functional programme) before starting the preliminary design. When UNESCO's methodology is used, the architect designing the school should be involved in developing the functional programme, together with Parque Escolar and the school.

\section{Application of UNESCO methodology for calculating space requirements}

To illustrate the practicality of the methodology developed by UNESCO's Architecture and Education Unit, here are some of the activities carried out at the seminar-workshop on Pedagogical-Architectural Programming, held in Tlaxcala, Mexico (2-5 October 2007).

At this workshop, CIPAE (Centro Internacional de Prospectiva y Altos Estudios) worked with 10 teams of educators (secondary school principals) and architects

Table A I. Classification of educational spaces in each team at the CIPAE workshop, October 2007

\begin{tabular}{|c|c|c|c|c|c|c|c|c|c|c|c|}
\hline 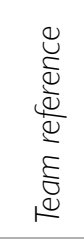 & 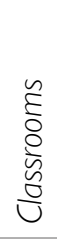 & 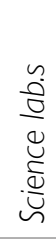 & $\begin{array}{l}\frac{0}{0} \\
\frac{0}{8} \\
0 \\
0 \\
0 \\
0 \\
0\end{array}$ & $\frac{\tilde{v}}{\underline{\theta}}$ & $\begin{array}{l}\frac{n}{\frac{n}{2}} \\
\frac{\frac{1}{\hat{v}}}{\frac{v}{d}} \\
3\end{array}$ & 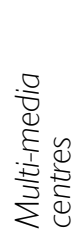 & 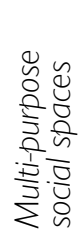 & 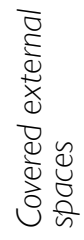 & 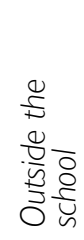 & 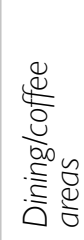 & $\frac{1}{8}$ \\
\hline$I-2$ & 16 & 4 & 4 & 4 & 5 & 2 & I & I & 2 & & 39 \\
\hline 6 & 6 & 6 & 3 & 3 & 3 & 9 & I & 3 & 3 & I & 38 \\
\hline $11-12$ & 14 & 5 & 2 & & 2 & 5 & & & 9 & & 37 \\
\hline 13 & 21 & 3 & I & 2 & 3 & 2 & I & 3 & 3 & & 39 \\
\hline 16 & 7 & 3 & 4 & 2 & 4 & 6 & 3 & 8 & 2 & & 39 \\
\hline 22 & 9 & 5 & 2 & I & 2 & II & 1 & 3 & 5 & I & 40 \\
\hline $22 b$ & 9 & 5 & 2 & 1 & 2 & 10 & 1 & 3 & 5 & I & 39 \\
\hline 4 & 18 & 4 & 3 & 3 & 3 & 3 & 2 & 2 & 2 & & 40 \\
\hline 23 & 9 & 4 & 4 & 3 & 4 & 4 & 5 & 3 & 4 & I & 41 \\
\hline 26 & 8 & 5 & 4 & 5 & 2 & 10 & 0 & I & 3 & I & 38 \\
\hline
\end{tabular}

to define the number and type of educational spaces (schedule of accommodation) for a new secondary school for I 200 students with the same weekly study plan. There was a general introduction to innovation in education and architecture in various countries of the world, followed by an explanation of the methodology. The 10 multi-disciplinary teams each worked with a computer to develop spreadsheet analyses.

The teams exchanged ideas on the educational project and its impact on the number and type of spaces. They worked for a whole day to find alternative solutions to meet their "aspirations", and at the end of the day, each team had its "solution". The teams then presented their solutions to the group, as well as supporting rationale.

Table Al shows that each team developed a different approach to their list of spaces. These ranged from 8 to 16 classrooms; 2 to II multimedia centres (obviously sizes and dimensions need to be further developed); and 2 to 9 "spaces" located outside the school, i.e. in the market, in the public library, in local industry, zoo, etc.

\section{Organising operational workshops}

To implement this approach, Parque Escolar could organise one or two-day operational workshops with a group of schools. The purpose of the workshop would be twofold: to explain the methodology, and to bring together the school principal and architect to work out the functional programme and the preliminary design. Each workshop could include several schools simultaneously, say 5-10 schools organised in 5-10 teams each consisting of a school principal and designer. It could take place just before the stage defined in the process map as "the concept design Ist draft presentation to Parque Escolar".

There would be a number of benefits in holding such operational workshops. They would show each school community the importance of the development of their strategic plan and its implication on the architectural design. They would also serve to familiarise in-situ school principals and designers with the objectives of the SMP.These workshops could be held at crucial stages of launching a group of schools.

Note: For the same educational programme and for the same number of students, the work, approach and discussions of each team (educator/architect) resulted in different types and numbers of educational spaces. 


\section{Box AI. Analysis of the functional programme for the Mouzinho da Silveira School}

This school has 30 groups ("turmas") and, based on the assumption that all spaces are educational and that this principle is applied, the following general analysis can be made from the functional programme and can help to review it, if necessary:

- 3 I classrooms (A.I)

- 4 spaces for ICT (A.2)

- I Informatics workshop (A.2)

- 5 science laboratories (A.3)

- 4 design, visual education spaces (A.4)

- I multimedia studio (A.4)

- I library

- I gym (G), which should also allow in its capacity for simultaneous use by 4 "turmas"

Total number of spaces: 44.These are used by the 30 groups ("turmas") or 47, if the Sports Gym is used simultaneously by 4 groups ("turmas").

This global analysis does not include the Social Spaces (C), which can also be utilised as learning spaces (individual, small groups, etc); I dining/multipurpose area; I cafeteria; and I covered area for students. The total number of spaces thus increases to 47 or 50 .

Speaking purely theoretically, the 30 groups ("turmas") would only require 30 spaces; but in practice, some flexibility is required to move from space to space; so if 10-15\% flexibility is provided, the total required spaces for 30 "turmas" would be 33 to 35 .

Probably, other schools do not have these additional spaces, so this analysis is meant to highlight the need for an in-depth study at this stage. Obviously, it does not cover all the schools included in the SMP. It is a sample to illustrate a methodology.

During these workshops, the various school teams can exchange ideas on approaches and find more innovative and individual education solutions for each school. They can also develop a deeper understanding of the relationship between educational needs and the architecture supporting them, and identify a more precise number of total spaces and maximise the rate of utilisation. Finally, they can include management concepts, including maintenance of the future building. The advantage of using such workshops as part of the SMP is illustrated through an analysis of the functional programme for the Mouzinho da Silveira Secondary School (Box AI).

The advantages of carrying out this analysis before starting the design are:

- A substantial amount of construction area and costs may be reduced; in this case some II spaces, say $50 \mathrm{~m}^{2}$ per space, i.e. about I $000 \mathrm{~m}^{2}$. A further analysis of the Ist concept design will be completed by Parque Escolar: circulation areas that are, obviously, not included in the functional programme can be analysed and will add a substantial amount of construction. Alternatively, "saved" construction costs could be allotted to another school to buy additional equipment, etc.
Figure Al. Suggestion for additional functional diagram

(C) Rodolfo Almeida

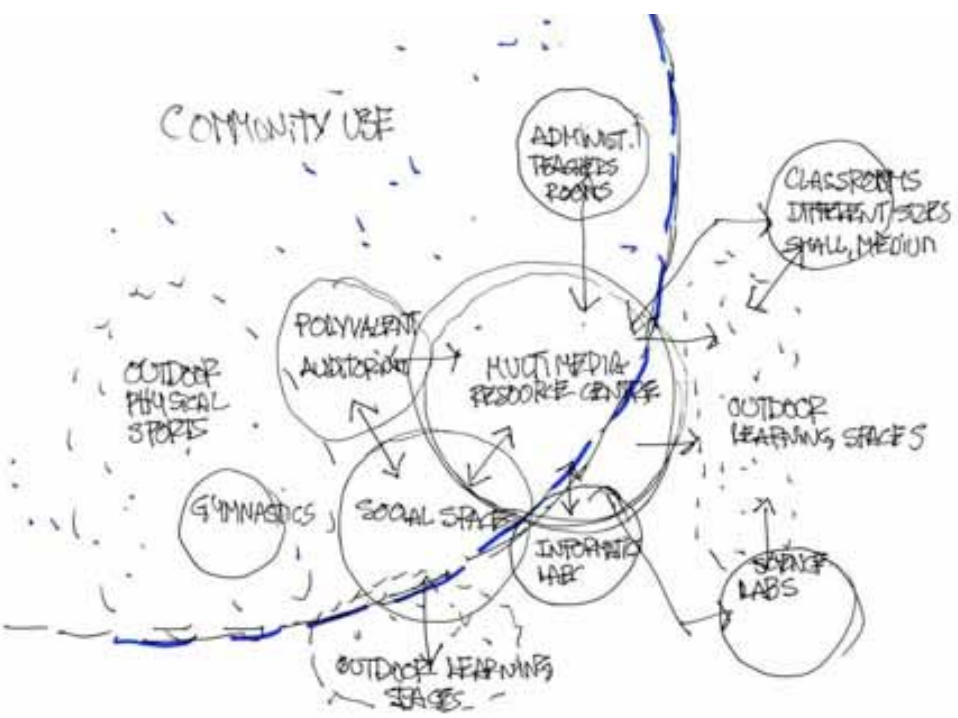


- It raises awareness among school directors about the efficient management of the school as a "whole", and not only by room.

- It highlights the need to revise the net area $\left(\mathrm{m}^{2}\right)$ allotted per student if the $\mathrm{m}^{2} / \mathrm{student}$ figure is too high. If so, either the school could have a greater design capacity or the cost of the school is too high for the number of students.

- The architect is immediately aware of the need to be fully and continually in contact with the school community throughout the whole design process.

\section{Developing the design manual}

Here are some suggestions for further developing the design manual to meet the challenges of the SMP:

\section{Provide examples of school design}

Provide international examples of school design that have addressed similar issues and opportunities as those facing Portugal. This will stimulate the educators and architects working on the SMP during the definition of the strategic plan and the functional programme, as well as the preliminary design (see below). These examples will also provide useful feedback on what Parque Escolar believes to be good international practice. This can be achieved by including sketches and photographs, and reference to examples of international practice and would also provide a more user-friendly presentation.

\section{Develop the concept of the school as a whole}

Incorporate and develop the concept of the school as a whole: a place where students, teachers and the learning community live, learn and co-exist in harmony. This objective is part of the SMP: to create attractive, flexible, multi-functional spaces "capable of providing varied use to the extended community".

\section{All spaces are educational spaces}

Incorporate the concept that all spaces are educational spaces: classrooms, science labs, computer rooms, etc, but also the library, gymnasium, circulation areas, outdoor spaces, social area, dining/cafeteria, etc. This concept will help to clarify the methodology for space calculation, as it will reduce the amount of floor area.
Also, the architects, principals and teachers will need to take this holistic conceptual approach into account to manage the building as a "whole", and not in terms of individual spaces.

\section{Innovative and contemporary diagrams}

Transform functional diagrams so that they become innovative and contemporary diagrams: by introducing various sketches that can inspire designers and the teaching community. One diagram could portray the library as the heart of the school, presenting it as a multimedia centre and linking it to social areas, cof- fee/dining area, outdoor learning areas, etc. This way, it reflects the use of ICT, team teaching, individual/small group learning, student-to-student learning, etc. (see Figure Al).

\section{Table to check net area}

A table profiled for designers could be included, against which they could check preliminary designs in terms of net area $\left(\mathrm{m}^{2}\right)$ per type of space: teaching, administration, circulation space, etc. They could obtain the percentage of floor area allocated to each type of space, the total net area and the net area $\left(\mathrm{m}^{2}\right)$ per student.

Table A2. Examples of space standards used in different countries

\begin{tabular}{|c|c|c|c|c|}
\hline Country & $\begin{array}{l}\text { Total area } \\
\left(\mathrm{m}^{2}\right)\end{array}$ & $\begin{array}{l}\text { No. of } \\
\text { students }\end{array}$ & $\begin{array}{c}\mathrm{m}^{2} / \\
\text { student }\end{array}$ & $\begin{array}{l}\text { School name/source and } \\
\text { level of education }\end{array}$ \\
\hline Argentina & 1800 & 300 & 6.0 & $\begin{array}{l}\text { Northlands-Nordetta } \\
\text { (secondary) }\end{array}$ \\
\hline Australia (NSW)' & 8604 & 1200 & 7.3 & $\begin{array}{l}\text { Generic design brief for a } \\
60 \text {-classroom school }\end{array}$ \\
\hline Australia (WA)' & 9874 & 1200 & 7.7 & $\begin{array}{l}\text { Generic design brief for a } \\
60 \text {-classroom school }\end{array}$ \\
\hline Belgium (Fr. Comm.) & 17962 & 1600 & 11.2 & $\begin{array}{l}\text { Centre Scolaire Saint Benoit } \\
\text { (upper secondary) }\end{array}$ \\
\hline Belgium (Fl. Comm.) ${ }^{2}$ & 9000 & 1000 & 9.0 & $\begin{array}{l}\text { AGIOn (Flemish Ministry of } \\
\text { Education), Section I.Article I5, } \\
\text { (general secondary school) }\end{array}$ \\
\hline \multirow[t]{4}{*}{ Ireland } & 6092 & 700 & 8.7 & $\begin{array}{l}\text { Balllyhaunis Community School } \\
\text { (post-primary) }\end{array}$ \\
\hline & 8404 & 1100 & 7.6 & $\begin{array}{l}\text { Coolmine CS } \\
\text { (post-primary) }\end{array}$ \\
\hline & 8418 & 1000 & 8.4 & $\begin{array}{l}\text { Balbriggan CC } \\
\text { (post-primary) }\end{array}$ \\
\hline & 6997 & 900 & 7.8 & $\begin{array}{l}\text { Summerhill C } \\
\text { (post-primary) }\end{array}$ \\
\hline Italy & 6500 & 650 & 10.0 & $\begin{array}{l}\text { Monzambano } \\
\text { (lower secondary) }\end{array}$ \\
\hline \multirow[t]{2}{*}{ New Zealand } & 3637 & 450 & 8.1 & $\begin{array}{l}\text { Te Matauranga } \\
\text { (primary/community) }\end{array}$ \\
\hline & 2050 & 200 & 10.3 & $\begin{array}{l}\text { Unlimited Paenga Tawhiti } \\
\text { (secondary) }\end{array}$ \\
\hline Switzerland & 3860 & 450 & 8.6 & Upper Gymnase de Bugnon \\
\hline \multirow[t]{3}{*}{ United Kingdom } & 8000 & 1300 & 6.2 & $\begin{array}{l}\text { City and Islington College } \\
\text { (6th form college building) }\end{array}$ \\
\hline & 21125 & 1758 & 12.0 & $\begin{array}{l}\text { Queen Anne } \\
\text { (secondary) }\end{array}$ \\
\hline & 14337 & 400 & 10.2 & $\begin{array}{l}\text { Blyth Community College } \\
\text { (upper secondary) }\end{array}$ \\
\hline
\end{tabular}

I. Dining areas are not provided in Australian schools.

2. General norm does not include sport halls or workshops in case of technical secondary. 
Figure A2. Tajimi Junior High School, Japan

Classrooms are flexible; there is a central multipurpose space and a link to a covered outdoor learning area.

Source: PEB Compendium of Exemplary Educational Facilities (OECD, 2006), drawing by Rodolfo Almeida

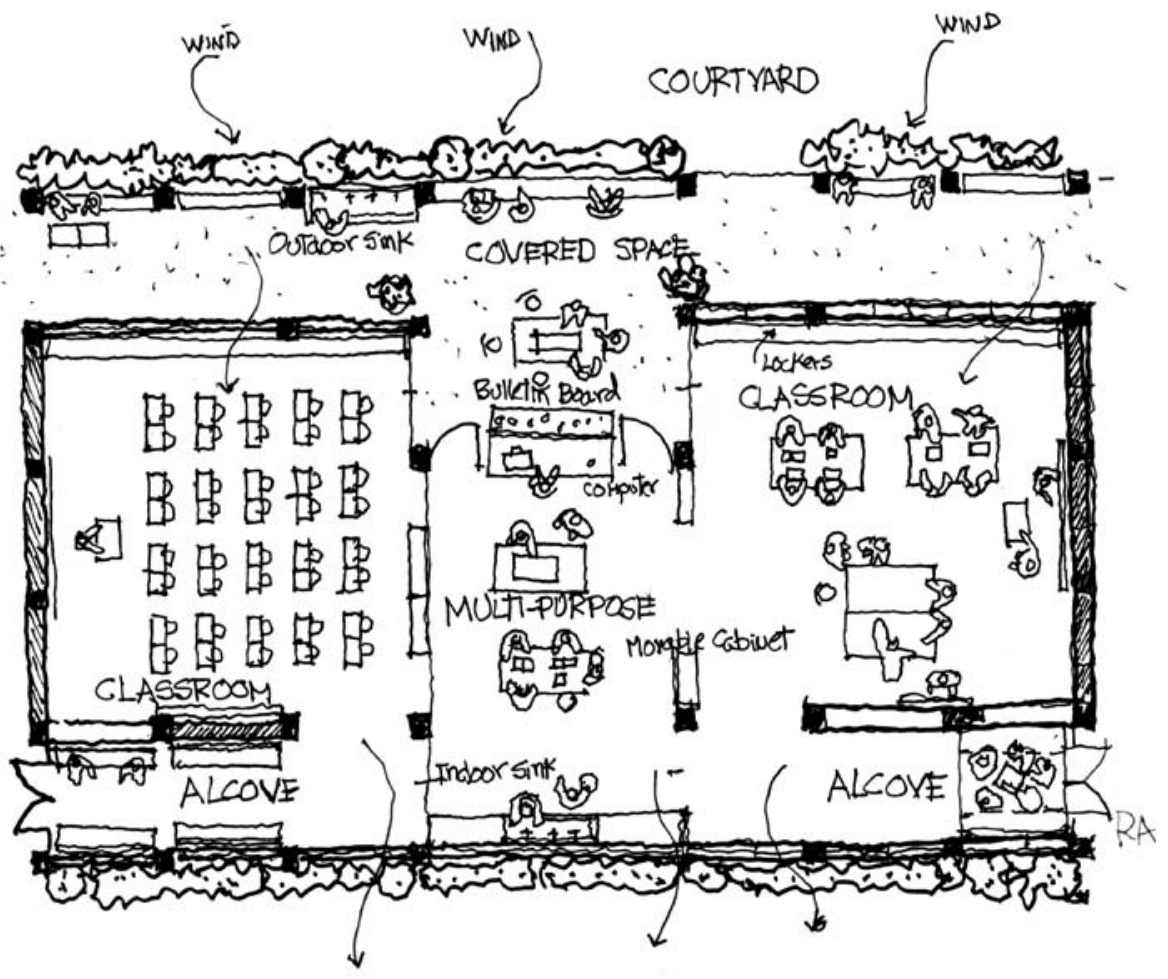

Analysis of space standards used in the different schools

A clear analysis of space standards used in the different schools and their modification (if necessary) will benefit the whole SMP by providing benchmarks. Table A2 shows examples of space standards in different countries. It is purely indicative, given that each country has its own education system, context, costs, etc. but it provides a useful overview of the standards being used elsewhere.

\section{Include two new types of functional diagram}

The design manual is intended for remodelling/refurbishing/extending existing schools. It would therefore help designers if it included two types of functional diagrams with additional sketches, one for "historical" schools and another for schools built after 1968, i.e. the majority of schools being refurbished, as follows:

- For historical schools, those constructed before 1968: The current version of the functional diagram cannot be easily applied because of the constraints imposed by the existing structure. But if an extension or new building is required, the designers/teaching staff will

Figure A3. Kiihtelysvaaran kunta school, Finland

The "learning street" (informal, small groups, individual work) linked to the classrooms and to the social space (cafeteria); note that classrooms also have small space for teamwork.

Source: Designs for Learning (OECD, 200I), drawing by Rodolfo Almeida

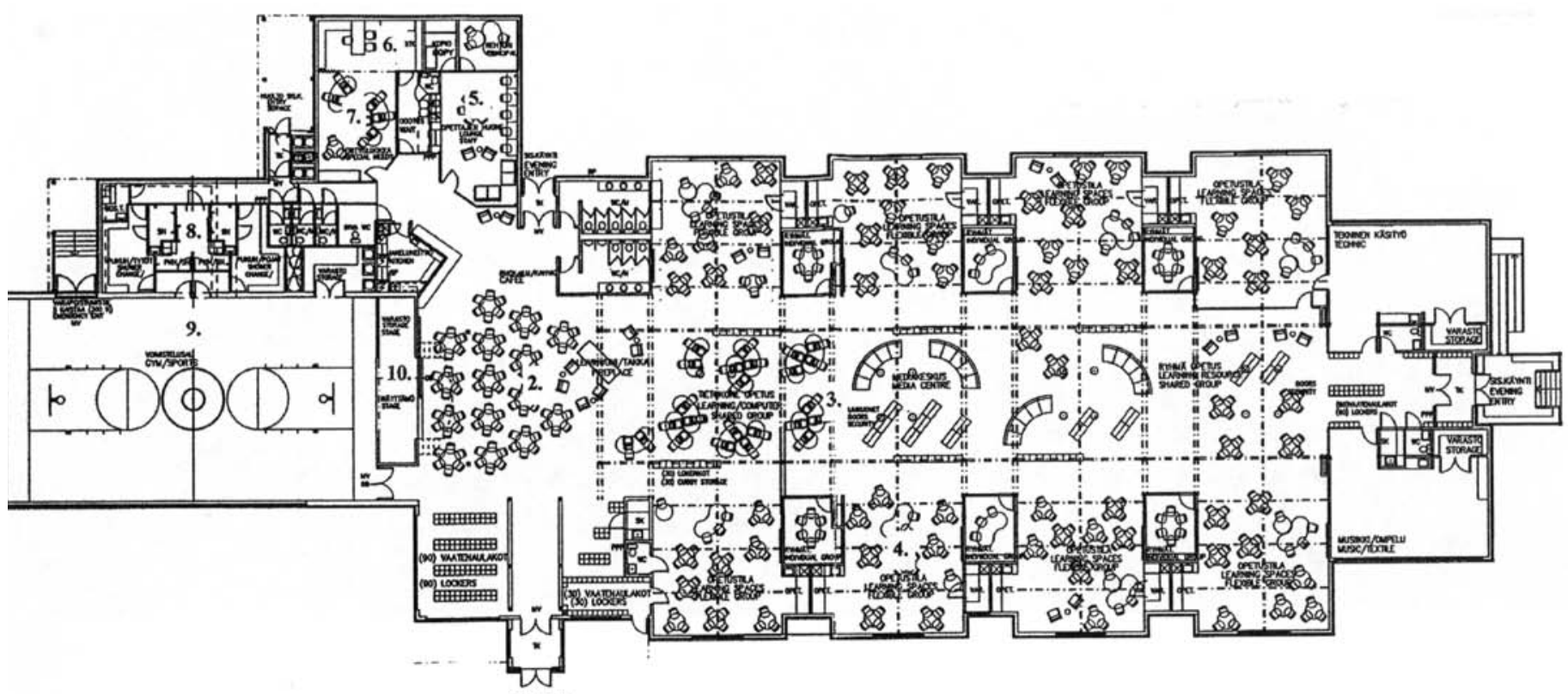


Figure A4. Oteha Valley School, New Zealand.

Learning Pod, with common space.

Source: PEB Compendium of Exemplary Educational Facilities (OECD, 2006), drawing by Rodolfo Almeida

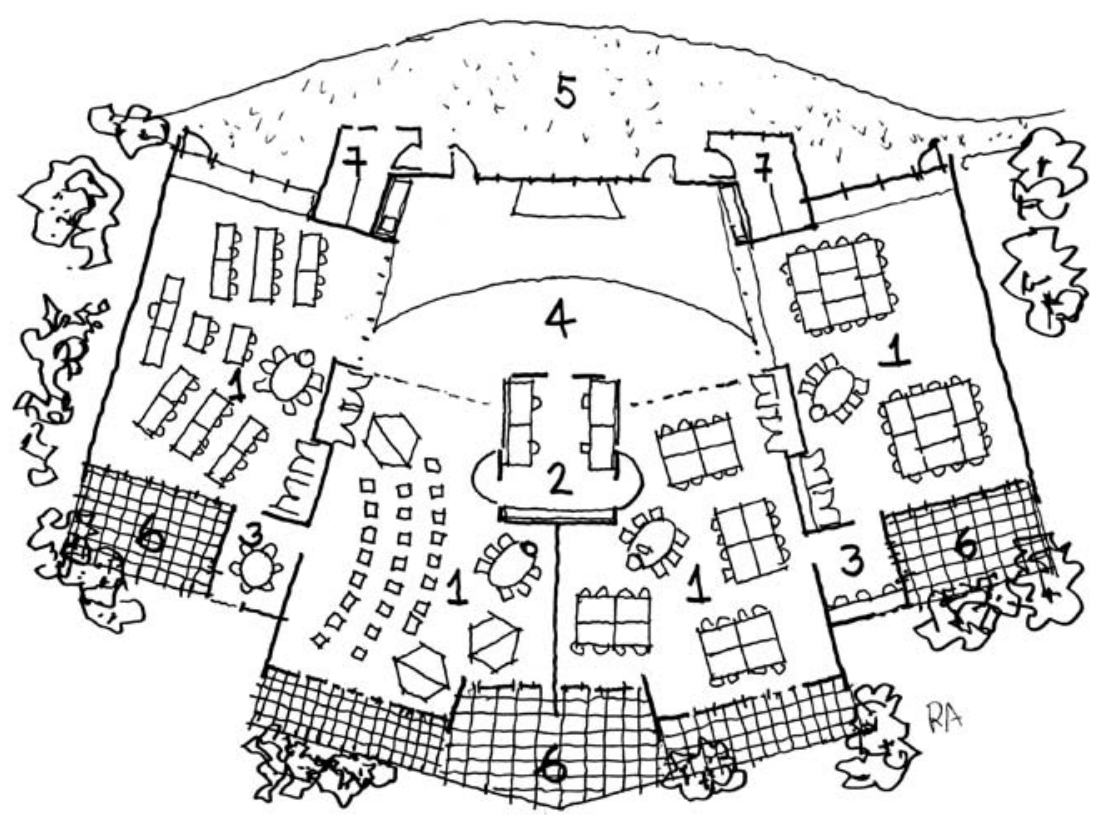

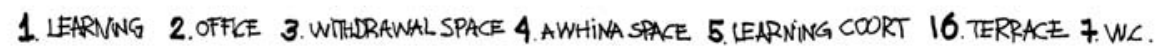

Figure A5. Nible Park, United States

Common activity area for classrooms (Circulation space integrated as a learning area). Source: Steve Crane, architect, drawing by Rodolfo Almeida

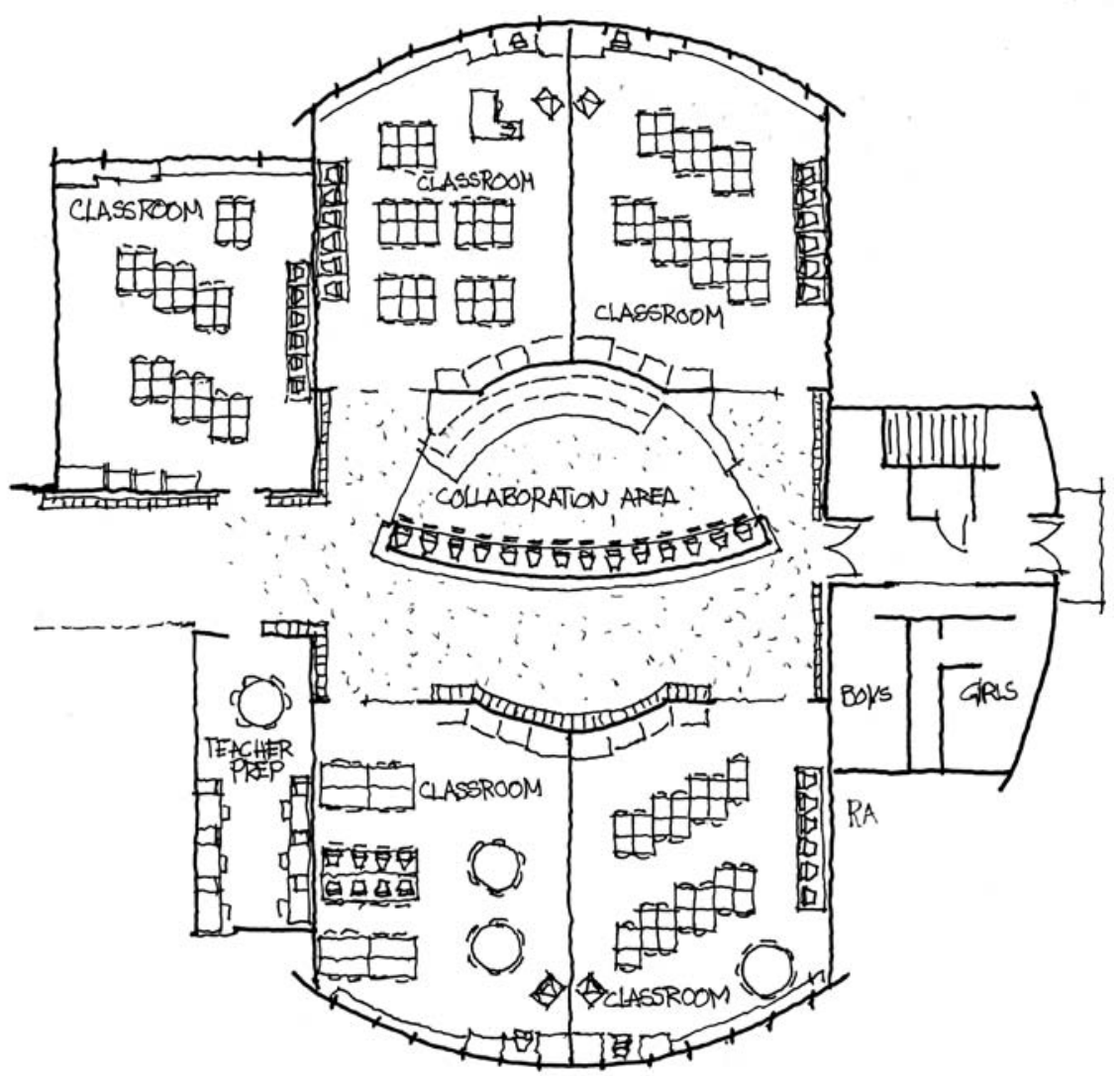

need innovative ideas on how to tackle this, in order to avoid duplication of the old historical building (which in many cases have extensive circulation space and single, self-contained classroom boxes).

- For schools built after 1968: One section could illustrate how to redesign the existing blocks by making them more flexible, and not only closed boxes. It could introduce ideas for flexible spaces: to easily divide or increase a classroom; to have smaller/medium size spaces; to link the blocks to outdoor learning spaces, etc. A second section could illustrate how to link the blocks with a creative concept that wouldmodernise the school overall. Such guidance will need to stress the main features of the building stock, including its constraints and opportunities.

\section{Guidelines for physical comfort}

Particular attention should be given to the formulation of clear guidelines for physical comfort. Currently in the design manual, lighting is not adequately defined. For example, page 23 of the design guidelines Manual de Projeto Arquitectura recommends 500 lux in classrooms for "normal light"; while on page 2I for ICT Rooms, it recommends natural light from the left, which is an old-fashioned concept. There is no clear distinction between daylight and "night lighting". The Review Team observed that several schools visited during the daytime had electric lighting switched on, not only in corridors but also in classrooms and laboratories which have big windows. This is an expensive operational item and can also influence maintenance costs.

There are many methods for calculating daylight. The international method used in several countries is based on the amount of light coming from a fully overcast sky. In Portugal, statistical information can be obtained from national/regional observatories, and this data could provide a percentage daylight factor. Light should be homogenously spread in the space, whether it comes from one side of the space, both sides, from the roof, etc. Some very practical methods, illustrated by drawings and developed by the Building Research Station in the UK, are available. They can be used at the design stage to define the size of vertical, horizontal as well as roof windows and their locations (BRE, 1986; Littlefair, 1988). 
Figure A6. Park City, United States

Common activity area for classrooms (Circulation space integrated as a learning area). Source: Steve Crane, architect, drawings by Rodolfo Almeida
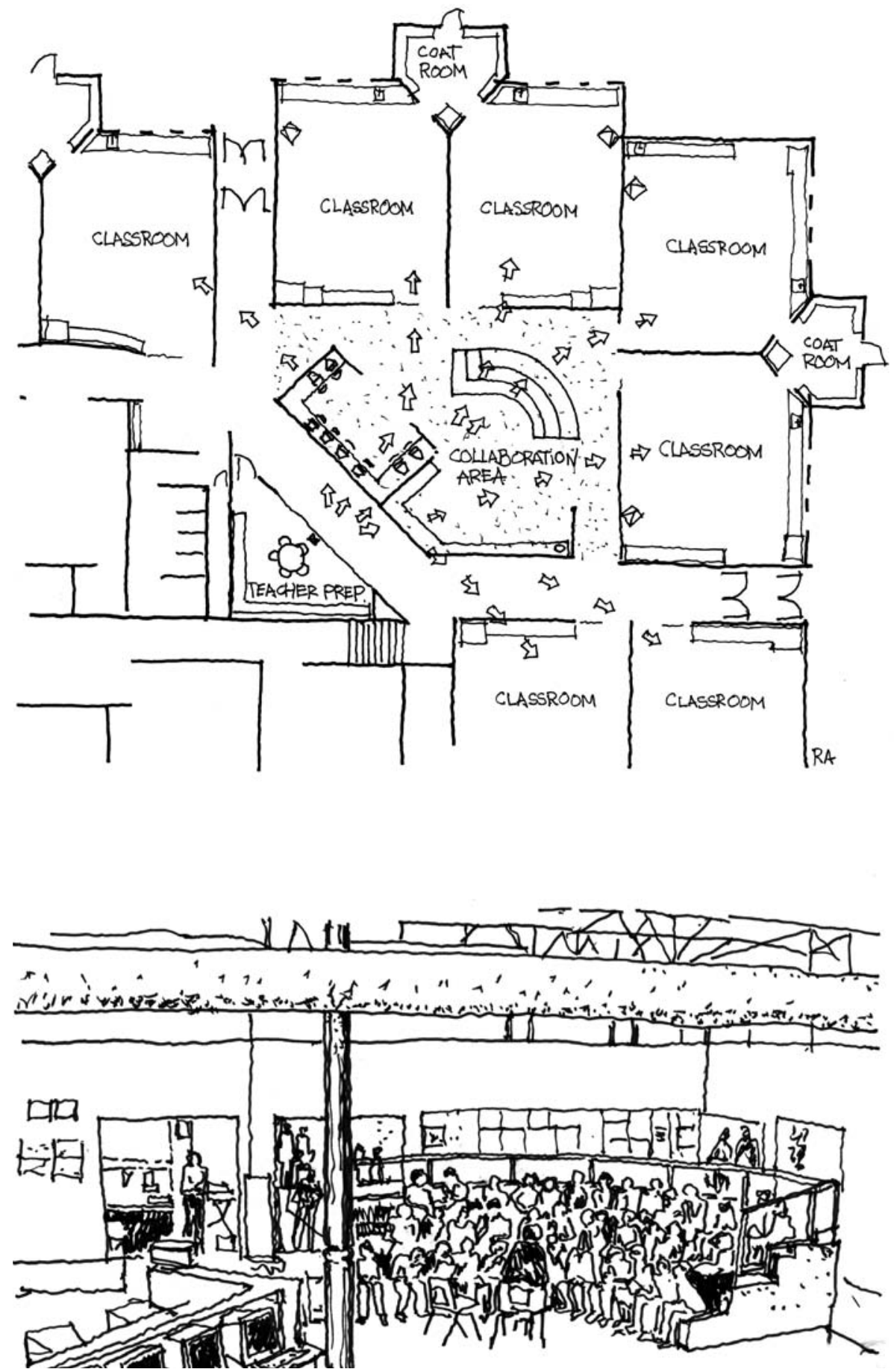

Illustrations that can be added to the design guidelines manual.

Figures A2-A 12 illustrate how school design from different countries can motivate and stimulate educators and architects at various stage: the definition of the strategic plan and the functional programme and preliminary design.

\section{Process for a post-completion review}

In order to provide quick and useful feedback from completed projects that can be used to inform other projects, a postcompletion review could be carried out two or three months after the completion of construction and once the school has begun to use the new facilities and become familiar with them.

Such a review would identify some aspects that need refinement or training for the users. The important issue is to provide just enough information that is useful and manageable without it being a burden for those who collect and analyse it. Such an evaluation should be carried out relatively quickly, using simple techniques, and provide data that can be analysed relatively easily. It would therefore be an initial assessment as opposed to a more thorough post-occupancy evaluation which might be carried out after 12 months.

A significant point to keep in mind is that the review may involve many stakeholders. To keep them engaged they must be sure that something will result from the time they spend taking part. If they perceive that nothing useful comes from having invested their time, it may be harder to get them involved in the future. This is easier to manage with a small review.

This will inevitably mean focusing closely on the critical questions to be answered in the evaluation, as well as looking for robust techniques for getting the information. It will also be important to identify the best time within a school's life cycle for this to take place.

Having said this, evaluation should go hand-in-hand with a policy for acting on findings. The danger of carrying out evaluations which involve other stakeholders is that if there is no discernable action as a result, or clearly articulated reasoning as to why there will not be, then it is likely to disengage stakeholders and in particular, teachers and other staff in 
Figure A7. Sunset Ridge, United States

Common activity area for classrooms. (Circulation space integrated as a learning area). Source: Steve Crane, architect, drawings by Rodolfo Almeida
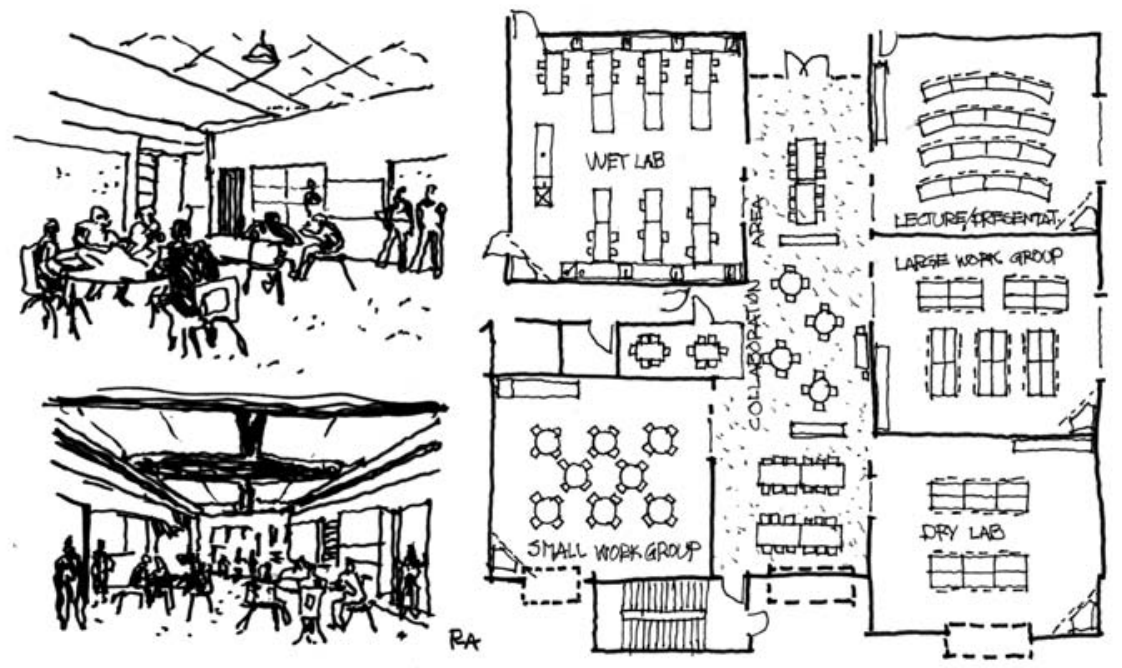

Figure A8. Het Spectrum Primary School, Netherlands

\section{Use of internal circulation spaces for a variety of activities.}

Source: Ministry of Education, Culture and Sciences. School Building Prize 1998,Amsterdam. drawing by Rodolfo Almeida

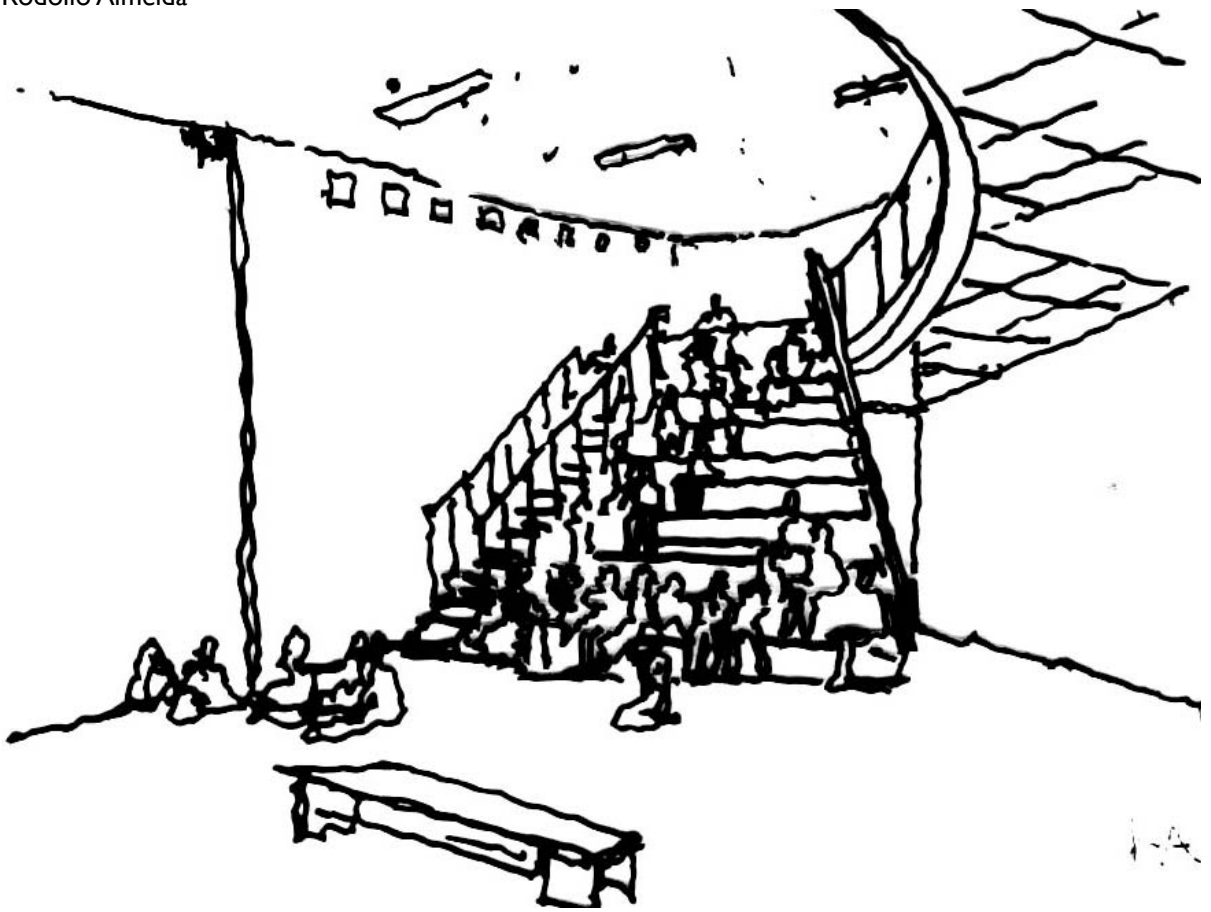

the schools. The policy for acting on the findings would need to be linked to some allowance for adapting the environment.

\section{Scope of the review}

The scope of the evaluation at this stage is to identify:

- Has the building met the brief, i.e. does the building reflect what was asked for in the brief?

- Can the systems be used easily? Is there basic training in appropriate use of the systems?

- Are there particular problems a) that the users have; b) with systems not working; c) technical performance of the building, e.g. material wear and tear.

- Do the technical systems work?

The aim of these questions is to find out whether there is a particular technical performance issue which needs to be addressed in the specification for new buildings. They also set out to identify whether the solutions appear to present any immediate problems for the users and how they might be rectified. The techniques that can be used include: interviewing the architect, builder and other professionals involved in the planning and design to understand the constraints under which they were working, interviewing individual teachers and staff; drawing up short questionnaires; holding meetings or focus groups with staff to discuss problems; and conducting walk through observations. 
Figure A9. Hosmarinpuisto Educational Building, Helsinki, Finland

Linking an open auditorium with social space and a cafeteria: informal learning, individual work and team work.

(c) Rodolfo Almeida

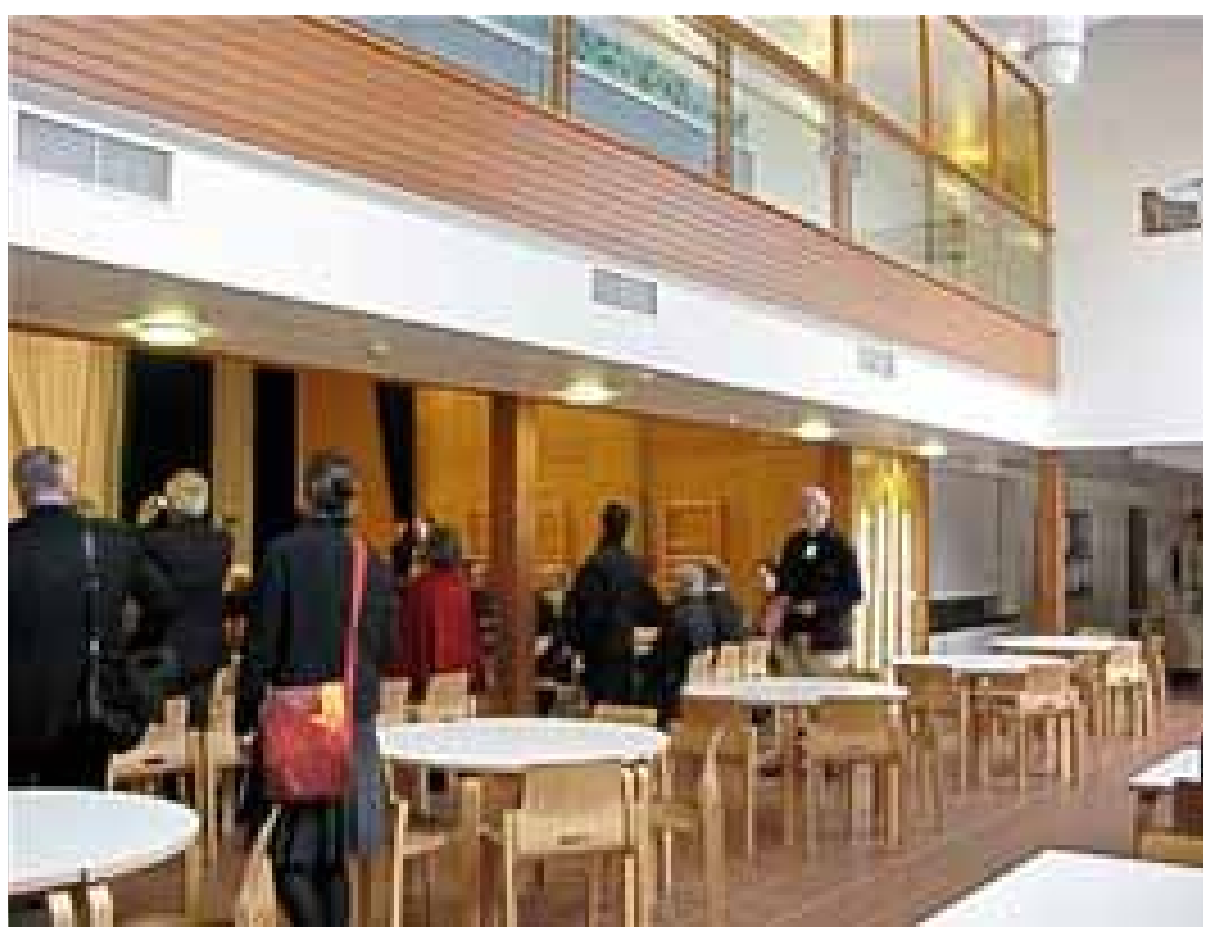

Figure A 10. Ruusutorpaa Educational Building, Helsinki, Finland

Linking an open auditorium with a social space and cafeteria: informal learning, individual work and team work.

(c) Rodolfo Almeida

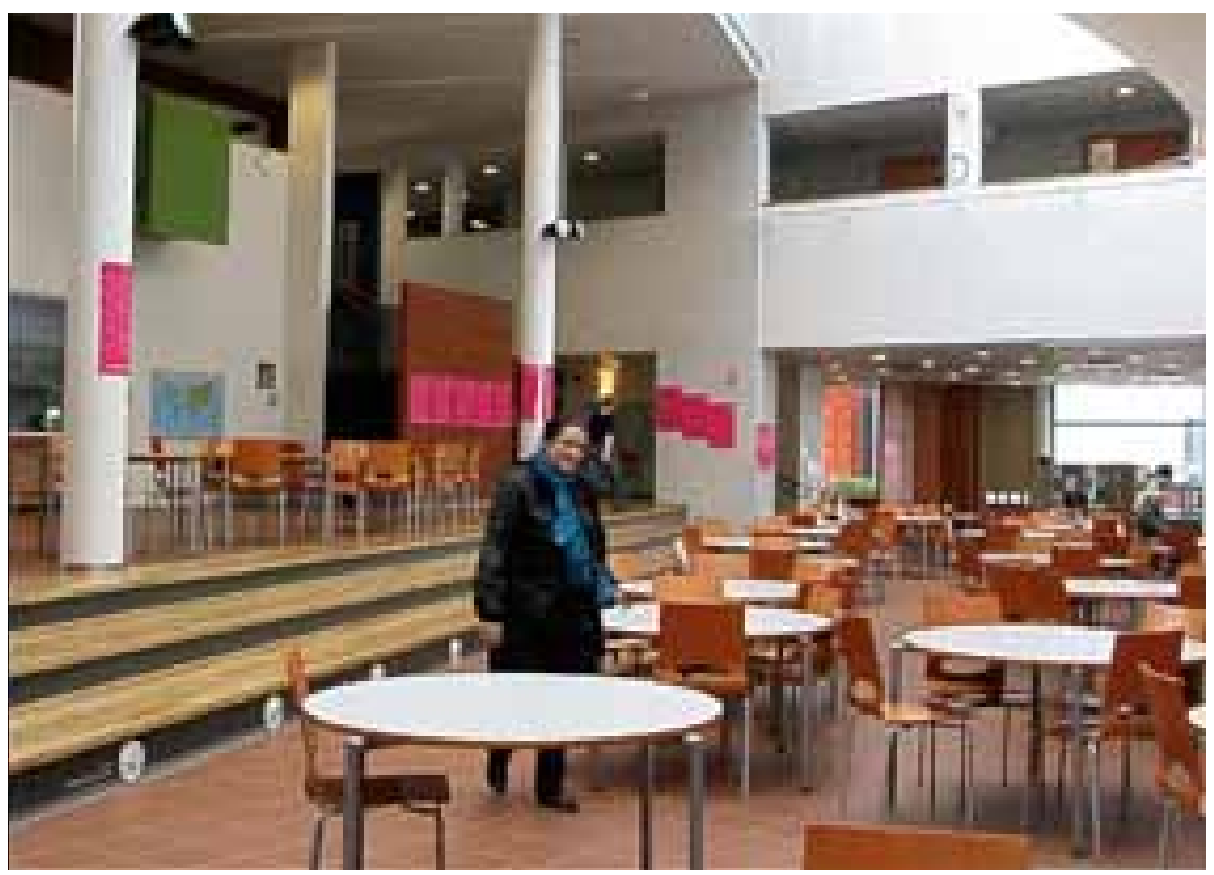


Figure A I I. Arabian Peruskoulu Educational Building, Helsinki, Finland

Use of circulation space as a learning area.

(C) Rodolfo Almeida

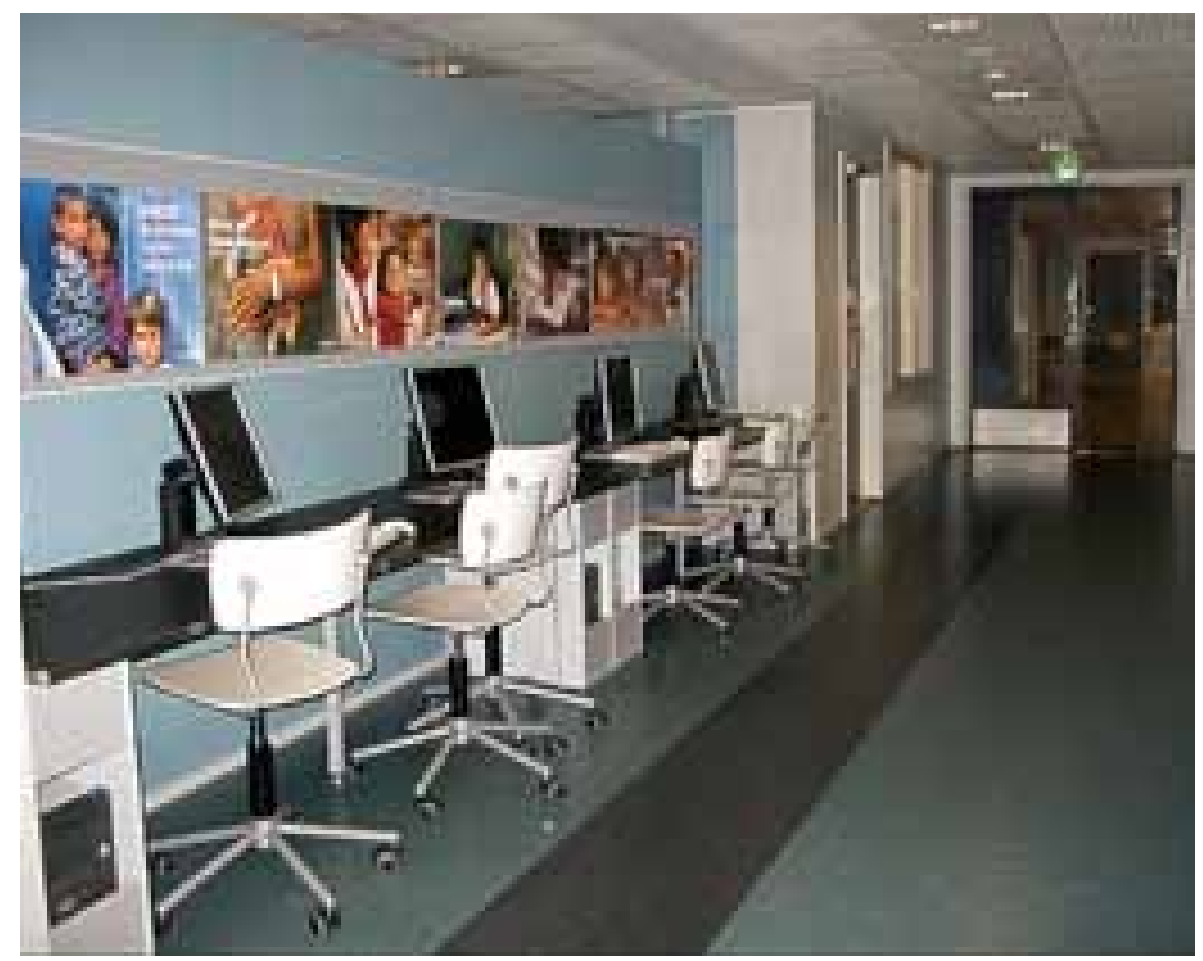

Figure A I 2. Metsola Educational Building, Helsinki, Finland

Use of circulation space as a learning area.

(c) Rodolfo Almeida

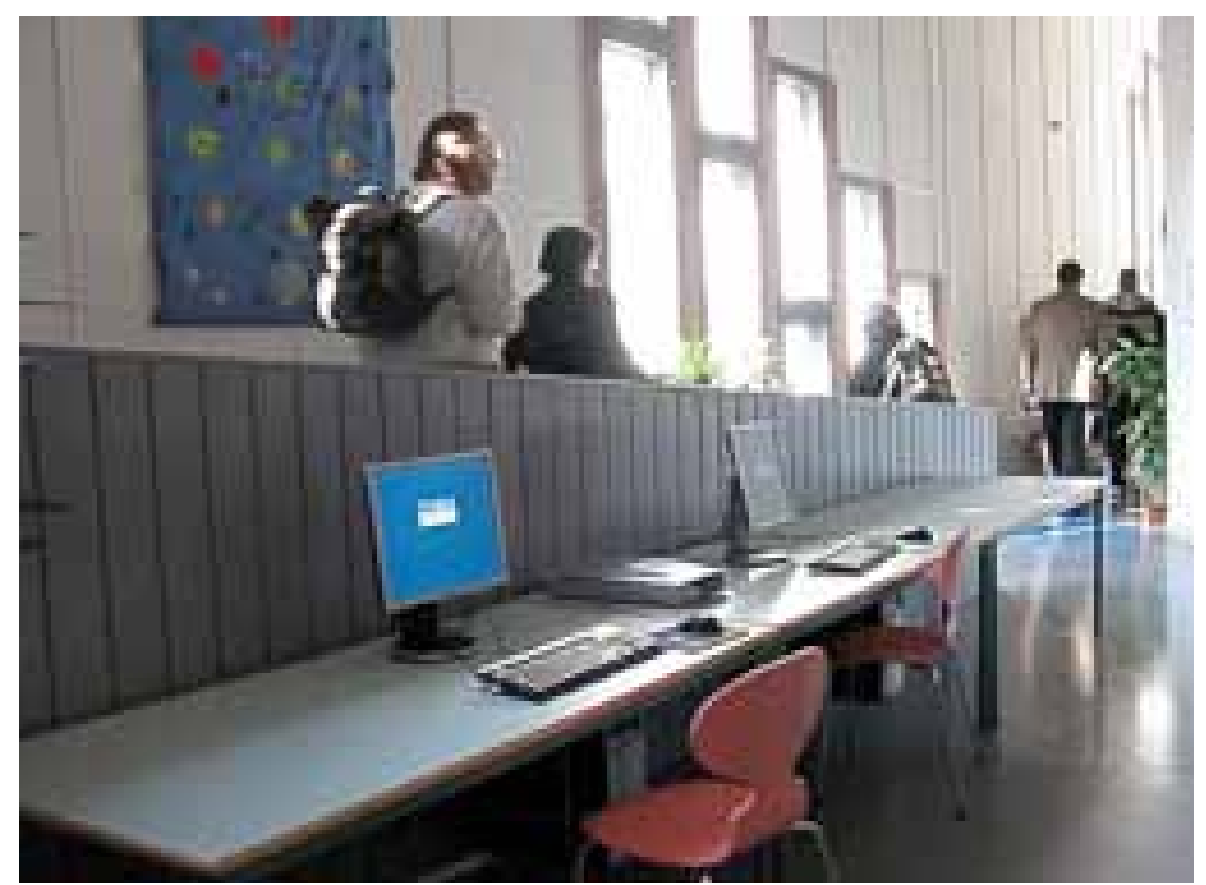

(c) OECD 2012 Modernising Secondary School Buildings in Portugal 

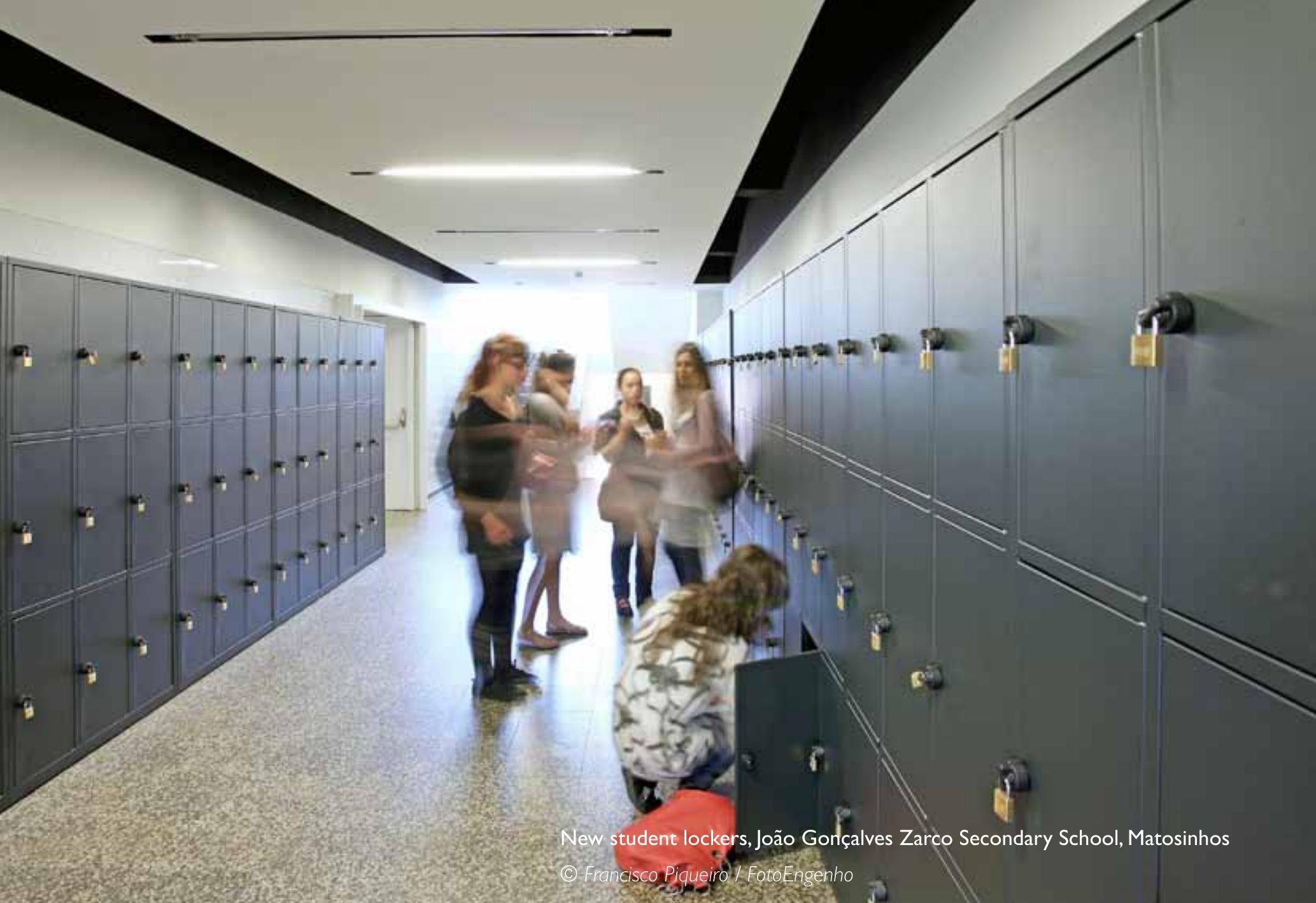

\section{ANNEX B}

ADDITIONAL INFORMATION 


\section{ANNEX BI. OECD/CELE REVIEW TEAM}

Rodolfo Almeida is an architect and director of the Division of Architecture at the International Centre for Prospective and Higher Studies (CIPAE), Puebla, Mexico. He is also an international consultant on architecture for education for UNESCO and works with other governments including Bhutan, Saudi Arabia, Haiti, Mozambique, Guatemala, Iran, Cyprus and Mexico.

From 197I-97, he worked at UNESCO in Paris in the Architecture for Education Unit, and became Director of the Unit from 1982-83. While at UNESCO he worked in the field in more than 90 countries in all aspects of research, planning, design and construction of educational buildings. Rodolfo was DirectorGeneral of the Regional School Building Centre for Latin America and the Caribbean (CONESCAL), Mexico.

Alastair Blyth is a policy analyst at the OECD Centre for Effective Learning Environments. Since joining the OECD in August 2007, he has worked on activities related to higher education facilities, and sustainable and innovative learning environments.

Alastair is an architect and has worked on a range of school building projects. As a consultant, he developed briefs with clients and stakeholders, and the design team for two pathfinder sustainable schools projects, and a project to review the briefing process for a large county au- thority in the UK, with a particular focus on education buildings.

David Forrester is a senior international consultant specialising in the development, reform and evaluation of education systems. He has over 20 years experience as a senior civil servant in a range of UK Government Departments: Education and Employment, Trade and Industry and H.M. Treasury. $\mathrm{He}$ is responsible for the development and implementation of policy in England on school, college, public sector higher education and lifelong learning recurrent and capital funding systems; the creation of the self-governing school, college and university sectors; school and college standards, qualifications and quality agendas, including introduction of the national curriculum testing and associated accountability regime, built around Ofsted inspections and intervention in failing schools and colleges; and the Connexions strategy for 13-19 year old young people, including all school, college and training provision, and associated pastoral and financial support.

From 1995-200I David was Director for Further Education and Youth Training (Under Secretary) in the UK Department for Education and Employment. From 1988-1994 he was Under Secretary in the UK Department of Education and Science (DES), responsible for school funding, governance, qualifications and quality nationally.

Ann Gorey is a registered teacher and a former deputy principal. Currently she is a senior policy advisor in the "Building
Management, Strategic Services" division of the Department for Transport, Energy and Infrastructure at the Government of South Australia. Previously she worked for the Department of Children's Services as project officer on educational facilities and acting Superintendent, Educational Facilities. She worked for the Commonwealth Government of Australia in Education, Aged Care and Disability Services and for the South Australian Parliament as Secretary to the Parliamentary Public Works Committee. In 2007, she was seconded to the OECD Programme on Educational Building to conduct research on procurement of educational buildings and education for sustainable development. Ann has experience of education policy development, and the implementation of educational building programmes.

Gaby Hostens was director-general for international education and training policies in the Flemish community until May 2008. He started his career as a teacher and in 1987 became the principal of a secondary general and vocational school. He later became an advisor for secondary education to the Flemish minister of education and later the chief of staff, and then director-general of secondary education in the Flemish community where he had overall responsibility for policies and funding of secondary education, vocational and technical education.

A member of the OECD Education Committee (now the Education Policy Committee) since 1994, he was the Chairman of the Committee from 1997 until 2000.

Figure B I. Teachers' room, Dom Dinis Secondary School, Lisbon

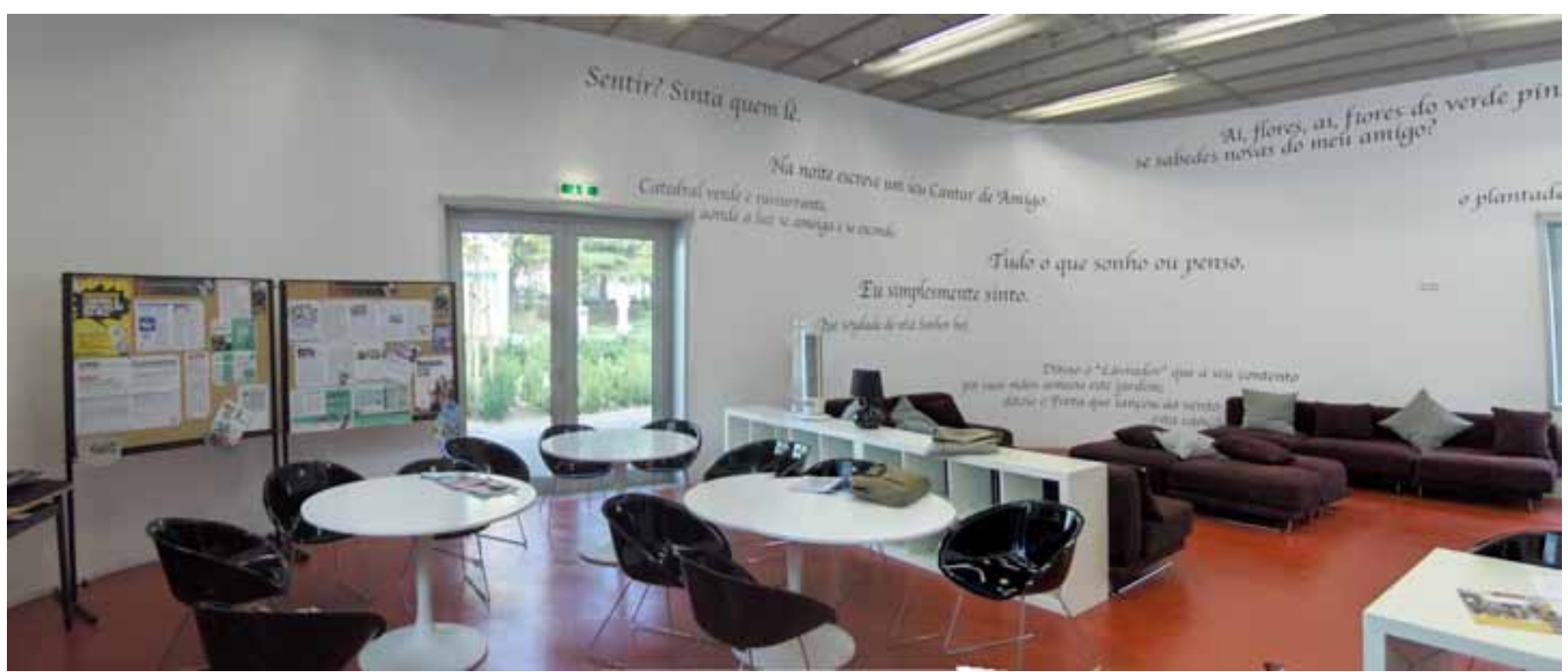




\section{ANNEX B2. \\ PROGRAMME OF THE \\ REVIEW VISIT AND PEOPLE INTERVIEWED}

During the review visit, the Review Team met the following groups and individuals:

\section{Ministry of Education}

- Valter Lemos, Secretary of State for Education

Central services from the Ministry of Education:

- Office for Education Statistics and Planning (GEPE - Gabinete de Estatística e Planeamento da Educação), Dr João Mata; Isabel Almeida

- General Directorate for Innovation and Curriculum Development (DGIDC - Direcção-Geral de Inovação e de Desenvolvimento Curricular), Dr Joana Brocardo

- ANQ (ME Continuing Education and Adults Certification Directory), Dr. Luis Capucha

- General Inspectorate of Education (IGE - Inspecção-Geral da Educação), Dr José Maia Azevedo

Regional Education Directorates of:

- Lisbon and Tagus Valley (DRELVT)

- Centre (DREC)

- North (DREN)

- Alentejo (DREALT), Dr José Verdasca

School field visits

These visits included a general visit to the school and separate meetings where possible with the school boards, teachers, staff, parents, architects and Parque Escolar regional representatives.

- Escola Secundária Dom Dinis, Lisbon Pilot project (Figures I.I, 3.4, 3.5, 3.10 and $\mathrm{BI}$ ).

- Escola Secundária Gabriel Pereira, Evora (Figures 3.8, 3.13, 4.1 and p. 43).

- Escola Secundária Mouzinho da Silveira, Portalegre.

- Dom João de Castro, Lisbon - Pilot Project.

- Rodrigues de Freitas, Porto - Pilot Project (Figures 2.2, 4.2, 4.3 and B2).

- Soares dos Reis, Porto - Pilot Project (Figures 0.2, 2.4, 3.I, 3.7, 3.II, 4.4 and p. 53).

- Avelar Brotero, Coimbra.
Parque Escolar

- Board of Directors

\section{Parque Escolar departments}

- Conception, monitoring and evaluation

- Procurement

- Infrastructures

- ICT

- Energy efficiency

- Financing

\section{Parque Escolar consultants}

- Building Environmental Condition Consultant Vaco Freitas (FEUP - University of Porto)

- Workshops consultant, Henrique Gante

- Science Laboratories consultant, Vitor Teodoro

- Building Construction and Seismic condition consultants, Jorge Proença and Jorge Brito

- School Libraries consultant, Teresa Calçada

President of the National

Education Council, Júlio Pedrosa

National Association of parents, Dr Albino Almeida

\section{National Schools Board Council, Dr Alvaro Santos}

\section{Teacher Unions met individually:}

- National Federation of Teachers (FENPROF - Federação Nacional dos Professores)

- National Federation of Education Unions (FNE - Federação Nacional dos Sindicatos da Educação)

Group of teacher unions

- ASPL

- National Association of Teachers (ANP - Associação Nacional de Professores)

- SPLIU - Sindicato dos Professores Licenciados pelos Politécnicos e pelas Universidades (Graduate Teachers from Polytechnics and Universities Trade Union)

- SIPPEB - Sindicato dos Professores do Pré-escolar e do Ensino Básico (Preprimary and Compulsory Education Teachers Trade Union)

- Pró-Ordem - Associação Sindical Pró-
Ordem dos Professores (Pro-Teachers Association Trade Union)

Groups of teacher unions

- FENEI

- FEPECI

- SINPOS pós-graduados

- SIPE - Sindicato Independente de Professores e Educadores (Teachers and Educational Childcare Staff Independent Trade Union)

- SNPL - Sindicato dos Professores Licenciados (Graduate Teachers Trade Union)

- SEPLEU - Sindicato dos Educadores e Professores Licenciados pelas Escolas Superiores de Educação e pelas Universidades (Educational Childcare Staff and Graduate Teachers from Higher Colleges of Education and Universities Trade Union)

Meetings held on OECD/CELE's preliminary visit, I0-I I March 2009

The preliminary visit was undertaken by a member of the OECD Secretariat and one expert.

- Parque Escolar executive board

- Parque Escolar staff responsible for aspects of the programme

- GEPE

- Regional Education Authority (DREAI)

- Teachers' representatives at Escola Secundária Gabriel Pereira, Evora

The following schools were visited:

- Escola Secundária Gabriel Pereira, Evora (Figures 3.8, 3.13, 4.I and p. 43).

- Dom João de Castro, Lisbon - Pilot Project.

- Passos Manuel, Lisbon (Figures 3.5, 3.12 and 4.5).

- Escola Secundária Dom Dinis, Lisbon Pilot project (Figures I.I, 3.4, 3.5, 3.10 and $\mathrm{BI})$. 


\section{ANNEX B3. PARQUE ESCOLAR: OBLIGATIONS, ORGANISATIÓN AND EMPLOYEES}

\section{Main obligations of Parque Escolar}

As set out in the document "Modernising Portugal's Public Secondary Schools" (April 2009), the main obligations of Parque Escolar are the following (Table BI):

- Maintenance and conservation of all school facilities covered by the Programme in order to ensure its operating conditions, under the terms set out in the partnership agreements to be entered with both Regional Education Authorities and the Executive Board of schools as defined in a Public Services Agreement (PSA 2007-2009).

- Maintenance and conservation of all school equipment (furniture, fixtures, kitchen, labs, sports etc).

- Maintenance and conservation of all technical equipment installed and supplied during the rehabilitation works, including, notably:

- All electrical installations, including the distribution system within school facilities and all those related with the production of energy from renewable sources (photovoltaic).

- Communications and information network equipment.

- Water supply and treatment equipment.

- Safety and surveillance equipment.

- Gas equipment.

- Elevators.

- Renewal of all school and technical equipment at the end of their useful life. Under the rules set out in the PSA 20072009, Parque Escolar is under obligation to enter into partnership agreements with both the Regional Education Authorities and the local schools' executive board to define:

- The scope of works and their specific technicalities.

- The schedule of any work, which should ensure any work fits with the calendar for the school year (to minimise the inconvenience of works during term time, in principle, works shall be scheduled to start by the end of a school year and to finish approximately one year later, before the beginning of the next school year).

- Alternative spaces to ensure the normal operation of the schools.

- Maintenance services.

- Procedures and principles to govern the relation between Parque Escolar, the local school and the entity selected to perform the maintenance activity.

- Upon award of each maintenance contract, Parque Escolar is obliged to deliver to each school a maintenance manual, setting out the terms and conditions of the maintenance service to be provided and the quality standards of the service to be delivered.

- An adequate insurance plan for all school infrastructures.

Such partnership agreements are subject to the approval of the Minister of Education.

\section{Organisation and key}

responsibilities of the

departments in Parque Escolar

\section{Design, Monitoring and Evaluation}

- Produce an inventory of school buildings, detail the ones in need of modernisation and rehabilitation operations and elaborate their respective programs of intervention, within the policies established by the Parque Escolar Board of Directors, in co-operation with other organs of the company's structure.

- Ensure the preparation of studies on the modernisation of buildings, according to curricular requirements, standards and use, promote and develop design guidelines of facilities and equipment.

- Establish principles of intervention on the different school buildings, in function of their historical context, morphological features and constructive and functional abnormalities.

- Harmonise the activities of the teams involved on the design of the buildings in accordance with the strategy defined by the Parque Escolar Board of Directors.

- Establish mechanisms for monitoring the optimisation of maintenance procedures of facilities and equipment of schools.

- Develop and manage the file system of the technical documentation of each intervention.

- Responsible for studying ways to incorporate more energy-efficient so- lutions in schools and guarantee that the modernisation interventions are environmentally sustainable in terms of materials, construction techniques and equipment.

\section{Procurement Department}

- Be responsible for preparing and harmonising procedures in matters relating to procurement techniques, as well as the development, co-ordination and implementation of all activities leading to the procurement of all public investment within the SMP.

\section{Planning, Monitoring and Control}

- Ensure the existence of the General Planning Project (PGP) and the Schedule Physical-Financial (CFFP), applying them in conjunction with other organs of Parque Escolar and other entities.

- Ensure the physical and financial control of each school in the SMP and ensure its updated information is available to the other organs of Parque Escolar.

Infrastructure General Department

- Develop, coordinate and implement all activities leading to the new physical infrastructures of each school covered by the SMP.

- Based on the intervention plan set by the Administration, co-ordinate the Budget and the Estimates of Physical Planning and Financial provisional elaborated by each Regional Departments of Infrastructure. When approved, these documents are incorporated by the Planning, Monitoring and Control Department into Parque Escolar's Plan of Activities and Project Budget.

- Prepare information to support the planning, monitoring and control Department in the development of the Quarterly Report of the Implementation Plan of Activities and Budget of the Project Investment adopted, regarding designs, buildings and equipment in terms of their physical and financial situation, with critical evaluation of the several phases.

- When necessary, submit for approval appropriately justified changes to the Plans and Budget for Investment Activities of the Infrastructure General Department.

- Control the physical development of interventions and their costs.

- Prepare periodic reports regarding 
the performance of the Infrastructure General Department, integrating information provided by each relevant department.

- Prepare documents regarding the supply of goods, services and implementation of works, in conjunction with the Legal and Procurement Department, to be approved by the Parque Escolar Board of Directors.

- Implementation of the various processes of competition with the Procurement Department and support of the Legal Department.

- Technical and financial management of contracts for goods, services and works, including those concerning maintenance and conservation, through the different Regional Departments of Infrastructure and the Technical Support Department.

\section{Regional Departments of} Infrastructure

- Divided into four sub-departments: North, Centre, South and Lisbon Metropolitan to ensure proximity.

- Deliver the Infrastructure General Department's mission in their corresponding geographic area, particularly regarding the monitoring of functional programmes, studies and implemen- tation of projects that underpin each intervention.

- Submit for approval the concept and draft designs for the various interventions developed in accordance with the brief previously validated by the Parque Escolar Board of Directors.

- Physical and financial management of several contracts in the areas of studies, projects and works.

- Support the Technical Support Department in the planning, preparation and management of contracts for equipment in the areas of furniture, kitchens and laboratories.

- Develop technical procedures required

Table B I. Number and academic background of employees in Parque Escolar, by department (June 2009)

No. of employees
Department in Parque Escolar

Infrastructure General Department

\begin{tabular}{|l|l|}
\hline 2 & Infrastructure General Department \\
\hline 3 & Technical Support Department \\
\hline 8 & Special Facilities Department \\
\hline I5 & Department of Infrastructure Lisbon \\
\hline 15 & Department of Infrastructure North \\
\hline 7 & Department of Infrastructure South \\
\hline 3 & Design, Monitoring and Evaluation \\
\hline 1 & Planning, Monitoring and Control \\
\hline 4 & Department of Innovation and Development \\
\hline 3 & Information Systems \\
\hline 4 & Department of Special Projects \\
\hline 1 & Legal Department \\
\hline
\end{tabular}

Secondary Education; Civil Engineering

Architecture; 2 Design/Arts; Secondary Education

Electrical Engineering;Mechanical Engineering; Chemical Engineering

4 Civil Engineering; 2 Architecture; I Electrical Engineering; Secondary Education

I Electrical Engineering; 7 Architecture; 5 Civil Engineering; I Secondary Education; I Social and Behavioral Sciences.

6 Civil Engineering; 4 Architecture; 2 Secondary Education; I Electrical Engineering

I Electrical Engineering; 4 Architecture; 8 Civil Engineering; 2 Secondary Education

5 Civil Engineering; 2 Literature

3 Architecture

Organisational Psychology

Mechanical Engineering; Social and Behavioural Sciences; Civil Engineering

Information Sciences; Secondary Education

2 Civil Engineering; 2 Architecture

5 Legal/Advocacy

Communication/Media

General Administrative Financial Department

\begin{tabular}{|l|l|}
\hline 3 & Logistics Services \\
\hline 2 & Human Resources \\
\hline 3 & Accounting and Financial Management \\
\hline 3 & Financing \\
\hline 2 & Reporting and Control Management \\
\hline I & TOTAL \\
\hline
\end{tabular}

Engineering for Planning Territory; Secondary Education; Organisational Psychology

Organisational Psychology/Management; Human Resources Management

3 Management/Financial

2 Economy; Social and Behavioural Sciences

2 Management/Financial 
to tender for the supply of goods, services and works, for their respective regional needs, with the support of the Procurement Department and the Technical Support Department.

- Provide physical and financial control of projects and works in accordance with the respective delegated established powers.

- Report monthly to the Infrastructure General Department on the development of the school's intervention in their jurisdiction, compiling data on the physical and financial projects, work and cost deviations.

- Development of all activities and responsibilities in conjunction with the schools, engineering, inspections, contractors and other external actors and, of course, with other organs of Parque Escolar.
Communication and Image

- Promotes and manages Parque Escolar's institutional image. It is responsible for Parque Escolar's events organisation and helps the Board to plan and implement institutional information campaigns.

\section{Legal Department}

- Provides legal support to all Parque Escolar's activities, at all stages (e.g. procurement and contracts).

\section{Financial and Human Resources}

Department

- Responsible for the economic and financial management, implementing standard internal procedures and optimises the financial sources. This division is responsible for the preparation of annual budgets, activities plan, eco- nomical and financial studies, providing the Board with the required information to take strategic and managerial decisions. Additionally, is also responsible for managing human resources.

\section{Department of Special Projects}

- Responsible for assisting the Board in the diversification of revenues (e.g. schools' infrastructure rental, schools' canteens and staples shops, among others) and also to implement the technological plan for each school (e.g. computer labs, electronic blackboards with touch screens, Internet connection).

Figure B2. Cross-sections, Rodrigues de Freitas Secondary School, Porto
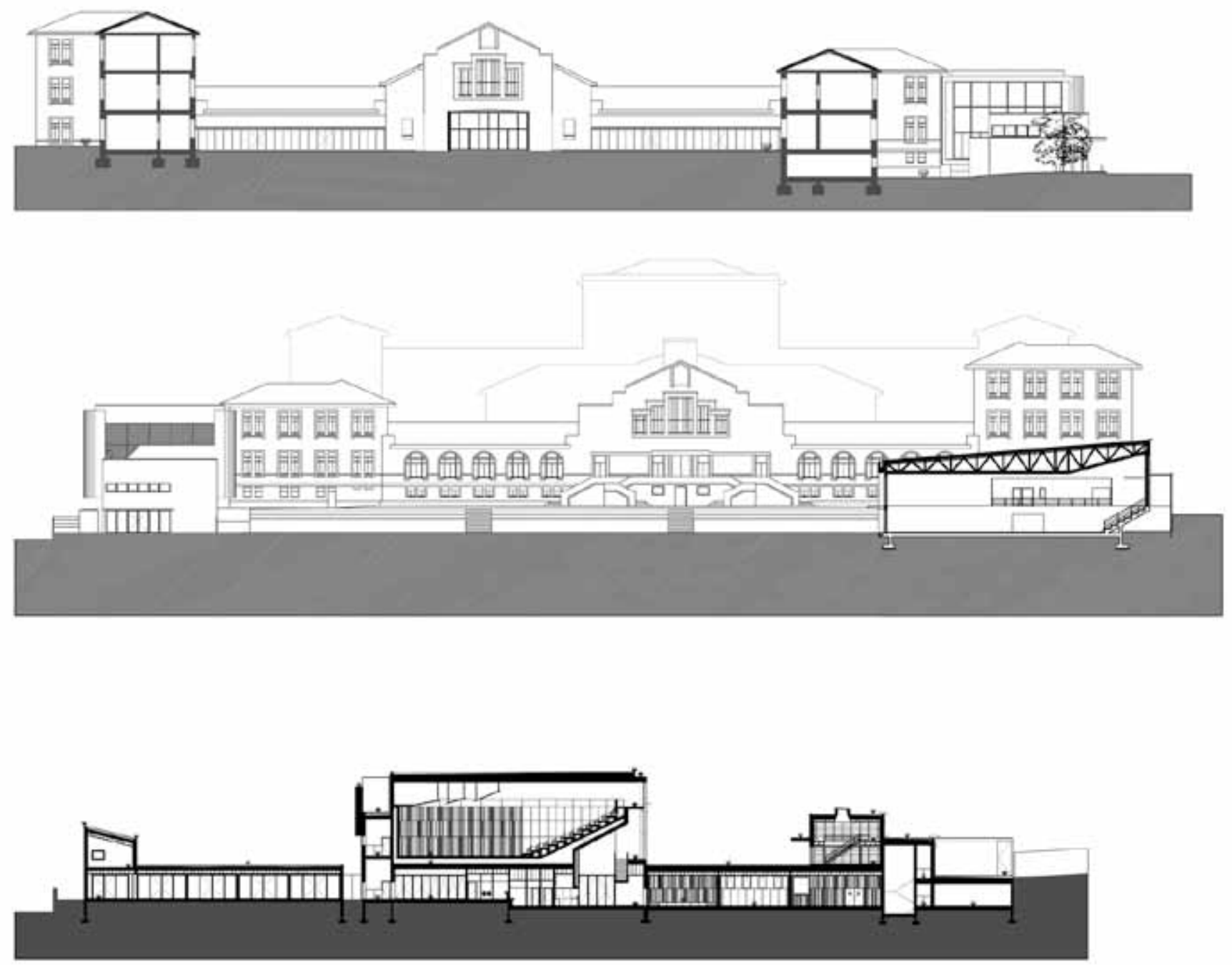


\section{ANNEX B4. THE PROCESS FOR MODERNISING EACH SCHOOL}

\author{
Pre-design phase
}

\section{Developing a strategic plan}

Initially the school is asked develop a strategic plan by evaluating its current and future educational needs, and the impact on its facilities. The educational "needs" are defined in the Educational Project which sets out the educational orientation of the school and the principles, values, goals and strategies that the school (or school cluster) hopes to achieve.The Educational Project is revised every three years and is one of the instruments for school autonomy, along with internal rules of procedure and the annual activities plan which defines objectives, organisation and programming of activities, and estimates of the necessary resources required. Parque Escolar provides guidelines for carrying out this assessment and for articulating the findings in an electronic document completed by the school online. This provides a range of information including enrolment, geographic and demographic information, and a description of existing facilities including the size of the spaces and their needs for the future.

The school submits the strategic plan online: "The structure of this on-line document is [intended] to help the school to be explicit and precise as to the relations between facilities, organisational conditions and needs for the success of the school project as well" (Parque Escolar, 2009).

\section{Physical condition and anomalies survey}

An in-depth technical survey of the condition of the structure and fabric, including a seismic analysis, of each school is carried out. These are done through contracts with faculties of engineering in the different regions, where schools are located. A detailed report is produced identifying the physical condition and anomalies of each school, as well as a seismic analysis for those located in seismic areas.

The report sets out the physical problems of the buildings, technical recommendations for each building component (structure, floors, walls, windows, roofing, paintings, electrical and hydraulic installations, etc.). It includes detailed architectural drawings for all of the existing buildings, a topographical survey of the site, and is illustrated with numerous photographs to signal the main problems of the buildings.

This reports are stored electronically in a database at Parque Escolar and at the respective regional offices in order to facilitate the architectural design, preparation of the tender documents, contractor's work on site, technical inspection, and feedback.

\section{Design phase}

The design phase consists of five stages through which the design is gradually developed: the functional programme; concept design; schematic design; building phase design; and licensing project. The stages reflect practice in other countries and allow for progressive decision-making with the milestones acting as gateways.

\section{Developing the functional programme}

Parque Escolar develops a functional programme for the school which is based on regional demographics and an analysis of the existing offer of educational areas. The information from the strategic plan is also used to develop a functional programme.

Past enrolments in the first cycle at school geographic administrative units called Agrupamentos Escolares (school clusters) are analysed and information is compared with the evolution of childbirths for the region. This allows school enrolments to be estimation for the next five years. The existing offer on sciencehumanities, technological and artistic education is considered as well as the needs expressed by local authorities and school itself, in order to find the main educational areas to be considered in the remodeling of the school. A calculation is made on the number of classes and the number and type of educational spaces needed for the school, based on the weekly study plans.

Meetings are then held by Parque Escolar with the school to validate this programme with the architects present so that they can begin to develop an understanding of the needs of the school for which they will be developing the design.

\section{Concept design}

During this stage, the architect produces an initial design that locates in plan form the functional areas and provides sufficient information for Parque Escolar and the school to evaluate whether the design approach meets the spatial needs defined by the functional programme. The design is reviewed by Parque Escolar and, if validated, is reviewed by the school.

\section{Schematic design}

At this stage, a more detailed design is drawn up and other technical specialists such as engineers become involved. The schematic design is subject to the same process as before: it is reviewed by Parque Escolar and, if validated, reviewed by the school. The latter involves more people (teachers, staff, parents, members of the student association) and some may involve the community.

\section{Building phase design}

During the this stage, the scheme design is developed in greater detail with construction drawings and specifications. The aim of this stage is to create a set of information from which the construction work can take place. In order to optimise the construction process, the project is reviewed by an external reviewer / supervisor before submitting the drawings and specifications for tender. Once the first four phases are completed a "licensing project" is submitted in accordance with the local authority's requirements.

\section{Construction phase}

During the construction phase the building contractor carries out the work supervised by a separate company. This supervisor makes sure that the contractor follows the contract, co-ordinates with the school, in particular over the phasing of the construction so that the school is able to vacate some areas and occupy others in sequence with the contractor in order to allow full functioning in safety and without major disruptions. The supervisor also oversees any input from the design team that is needed during construction, for example, to solve problems where hidden parts of the structure could not be assessed during the earlier surveys. The supervisor also oversees onsite safety procedures. 



\section{ORGANISATION FOR ECONOMIC CO-OPERATION AND DEVELOPMENT}

The OECD is a unique forum where governments work together to address the economic, social and environmental challenges of globalisation. The OECD is also at the forefront of efforts to understand and to help governments respond to new developments and concerns, such as corporate governance, the information economy and the challenges of an ageing population. The Organisation provides a setting where governments can compare policy experiences, seek answers to common problems, identify good practice and work to co-ordinate domestic and international policies.

The OECD member countries are: Australia, Austria, Belgium, Canada, Chile, the Czech Republic, Denmark, Estonia, Finland, France, Germany, Greece, Hungary, Iceland, Ireland, Israel, Italy, Japan, Korea, Luxembourg, Mexico, the Netherlands, New Zealand, Norway, Poland, Portugal, the Slovak Republic, Slovenia, Spain, Sweden, Switzerland, Turkey, the United Kingdom and the United States. The European Union takes part in the work of the OECD.

OECD Publishing disseminates widely the results of the Organisation's statistics gathering and research on economic, social and environmental issues, as well as the conventions, guidelines and standards agreed by its members. 


\section{Modernising Secondary School Buildings in Portugal}

This is the report of a policy review of Portugal's Secondary School Building Modernisation Programme, which was conducted in 2009 by the OECD Centre for Effective Learning Environments (CELE). In 2007, the Portuguese government launched a major programme to rehabilitate its secondary schools.

The review team's recommendations offer lessons to all governments investing in educational infrastructure to improve the quality of education.

\section{Contents}

\section{Introduction}

1.1. The Secondary School Building Modernisation Programme (SMP)

1.2. Objectives of the review

1.3. Structure of the report

1.4. The review visit

2. Context and features of the SMP

2.1. Secondary education in Portugal

2.2. The SMP

2.3. Administration and delivery

2.4. Funding the SMP

2.5. The process of implementation

3. Strengths and challenges of the SMP

3.1. Meeting the strategic objectives for education in Portugal

3.2. Governance

3.3. Funding

3.4. Quality, suitability and sufficiency of the modernised schools

4. Conclusions and recommendations

4.1. The impact of the SMP on the quality and suitability of school buildings

4.2. Meeting Portugal's strategic objectives for secondary education

4.3. Options for rationalising the SMP

4.4. Governance and relationships

4.5. Funding

Please cite this publication as:

OECD (2012), Modernising Secondary School Buildings in Portugal, OECD Publishing.

http://dx.doi.org/10.1787/9789264128774-en

This work is published on the OECD iLibrary, which gathers all OECD books, periodicals and statistical databases. Visit www.oecd-ilibrary.org, and do not hesitate to contact us for more information. 